\title{
West Virginia waterscapes: Surface and mineral owners' perspectives on groundwater contamination due to natural gas extraction
}

\author{
Bethani Turley \\ West Virginia University, bt0023@mix.wvu.edu
}

Follow this and additional works at: https://researchrepository.wvu.edu/etd

Part of the Appalachian Studies Commons, and the Human Geography Commons

\section{Recommended Citation}

Turley, Bethani, "West Virginia waterscapes: Surface and mineral owners' perspectives on groundwater contamination due to natural gas extraction" (2019). Graduate Theses, Dissertations, and Problem Reports. 4079.

https://researchrepository.wvu.edu/etd/4079

This Thesis is protected by copyright and/or related rights. It has been brought to you by the The Research Repository @ WVU with permission from the rights-holder(s). You are free to use this Thesis in any way that is permitted by the copyright and related rights legislation that applies to your use. For other uses you must obtain permission from the rights-holder(s) directly, unless additional rights are indicated by a Creative Commons license in the record and/ or on the work itself. This Thesis has been accepted for inclusion in WVU Graduate Theses, Dissertations, and Problem Reports collection by an authorized administrator of The Research Repository @ WVU. For more information, please contact researchrepository@mail.wvu.edu. 


\section{West Virginia waterscapes:}

Surface and mineral owners' perspectives on groundwater contamination due to natural gas extraction

\section{Bethani Turley}

Thesis Submitted to the Eberly College of Arts and Sciences at West Virginia University in partial fulfilment of the requirements for the degree of Master of Arts in the Department of Geology and Geography

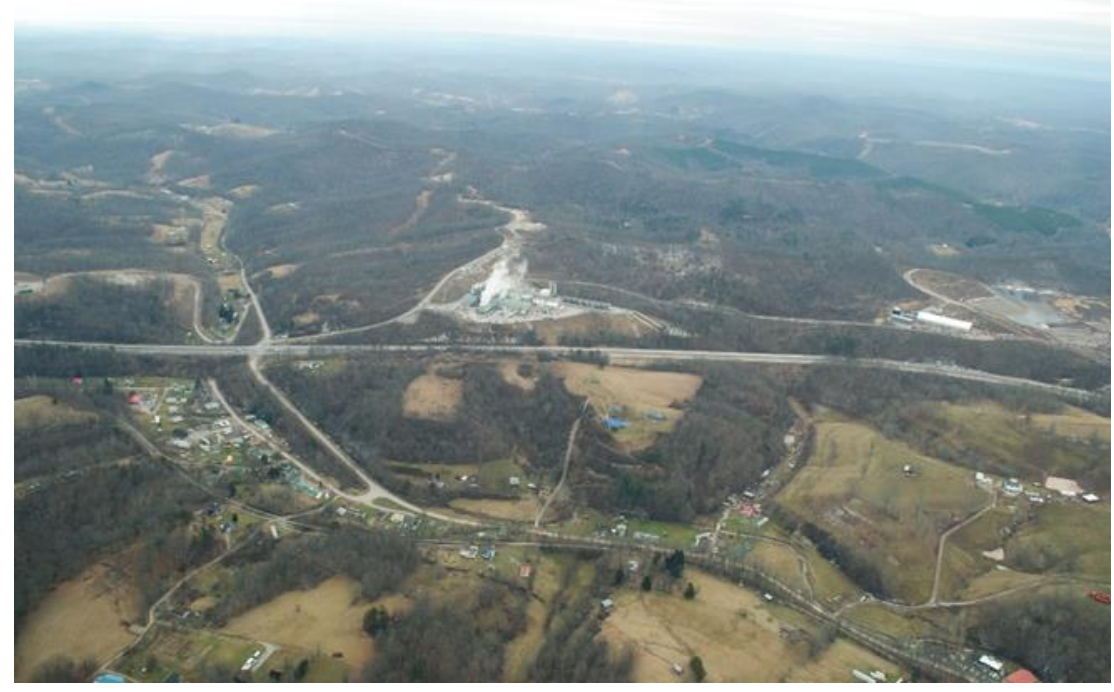

Martina Angela Caretta, Ph.D., Chair

Karen Culcasi, Ph.D.

Cynthia Gorman, Ph.D.

Department of Geology and Geography

Morgantown, West Virginia

2019

Key Words: groundwater, natural gas extraction, water testing, waterscapes, feminist geography,

West Virginia

Copyright 2019 Bethani Turley 


\begin{abstract}
West Virginia waterscapes:

Surface and mineral owners' perspectives on groundwater contamination due to natural gas extraction in West Virginia

Bethani Turley
\end{abstract}

In the past decade, northwest West Virginia has experienced increasing natural gas extraction from the Marcellus shale. Because water usage for natural gas extraction is high and increasing, there has been a proliferation of concerns about gas extraction's impacts on surface and groundwaters, especially how hydraulic fracturing and drilling impacts residents' access to safe household well water. This issue is particularly salient in rural West Virginia, where many residents rely on groundwater wells for household uses. This thesis, based on 30 in-depth interviews with surface and mineral owners, explores resident perspectives and lived experience of natural gas extraction's impacts on household groundwater wells. Residents with groundwater drinking wells rely on baseline water testing when oil and gas development occurs near their homes to be able to detect changes in water quality. Water testing is typically conducted by contractors hired by oil and gas companies, but it is mired by delayed test results and incorrect testing procedures, producing residents' negative feelings and lack of trust toward oil and gas companies. Using the framework of waterscape, this thesis attends to the social and political contexts produced around water in West Virginia. This analysis also contributes to the framework of waterscapes by drawing on concepts from feminist geography of embodiment and epistemic authority. Together this conceptual framework is used to analyze West Virginia residents' lived experiences of well water contamination and the production of waterscapes around natural gas extraction. This thesis contributes to debates about how gas extraction is changing waterscapes while centering the complex social relations apparent in natural gas extraction in West Virginia. 


\section{Table of Contents}

Abstract $\quad$ ii

List of Figures $\quad$ iv

Acknowledgments $\quad \mathrm{V}$

Chapter One: Introduction to the research

1.1 Introduction 1

1.2 Research questions $\quad 3$

1.3 Note on terminology $\quad 5$

Chapter Two: Conceptual framework

$\begin{array}{ll}2.1 \text { Political ecology } & 7\end{array}$

2.2 Waterscapes and hydro-social cycle $\quad 8$

2.3 Embodiment and water $\quad 11$

$\begin{array}{ll}2.4 \text { Epistemic authority } & 20\end{array}$

Chapter Three: Unconventional oil and gas extraction in the United States and West Virginia

3.1 Unconventional development in the United States 23

3.2 The social dimensions of unconventional oil and gas development 27

3.2.1 Social science literature on unconventional oil and gas 27

3.2.2 Water and unconventional extraction $\quad 29$

Chapter Four: Methodology

4. 1 Epistemology 33

4.2 Positionality 34

$\begin{array}{ll}4.3 \text { Methods } & 39\end{array}$

4.3.1 Case Study: West Virginia

4.3.2 Interviews $\quad 45$

4.3.3 Member-checking and dissemination 48

4.3.4 Data Analysis $\quad 50$

Chapter Five: Household groundwater impacts due to natural gas extraction

5.1 Impacts of water contamination $\quad 52$

5.2 Baseline water testing and trust $\quad 62$

Chapter Six: Discussion

6.1 Embodiment, emotion and uncertainty $\quad 68$

$\begin{array}{ll}6.2 \text { Epistemic authority } & 72\end{array}$

$\begin{array}{ll}6.3 \text { Intersections of embodiment and epistemic authority } & 78\end{array}$

Chapter Seven: Conclusion $\quad 85$

$\begin{array}{lr}\text { References } & 88\end{array}$

Appendix A: Interview guide for local stakeholders 101 


\section{List of Figures}

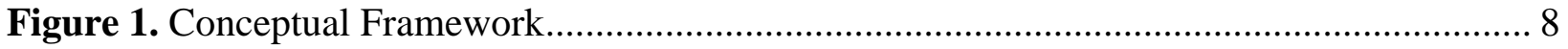

Figure 2. Shale development areas across the USA....................................................... 23

Figure 3. Comparison of conventional and unconventional well pads in West Virginia ........... 25

Figure 4. Subsurface depths of groundwater and horizontally drilled wells ............................. 26

Figure 5. Map of West Virginia depicting locations of active horizontal wells, nearby cities, and

interview locations within the Marcellus and Utica shale. .................................................. 41

Figure 6. Well pad proximity to houses in northwestern West Virginia. ................................. 43

Figure 7. Map depicting distribution and categories of stakeholders interviewed. ................... 46

Figure 8. Breakdown of stakeholders interviewed by county, organization and gender. ........... 47

Figure 9. Public dissemination and member checking of preliminary results ......................... 48 


\section{Acknowledgments}

I would first like to thank everyone who participated in this research for welcoming me into your homes and sharing your stories with me. Additionally, I want to thank everyone who supported me during graduate school. Chris, thank you for your support, encouragement, and love the last seven years. Thanks also to my parents and family for their support and love, always. Thank you to my adviser and committee chair Martina Angela Caretta. I appreciate your deep commitment to mentoring and I feel lucky to have had my first graduate experience as your student. I am also grateful to my committee members Karen Culcasi and Cynthia Gorman who have provided constant insights and willingness to push my thinking along. Thank you to my colleagues who are first and foremost my friends. Alanna Higgins, I appreciate your friendship, constant encouragement, and support. Thanks also to Elizabeth Dever for reading this thesis and for accompanying me during fieldwork. Jess Holler, you have also been a constant source of inspiration, knowledge, and support over the years and I hope someday to thank you for that. Lastly, I want to thank the West Virginia Energy Institute for funding this research. 


\section{Chapter One: Introduction to the research}

\section{$\underline{1.1 \text { Introduction }}$}

Natural gas extraction is booming in Appalachia. Unconventional development of the Marcellus Shale in West Virginia has brought in out of state workers, created local jobs, and generated gas royalties to mineral owners (Wilson 2017). Industry representatives and proponents routinely argue that unconventional oil and gas (UOG) extraction is safe for the environment, and that it is a lower carbon alternative to coal, used for transition to renewable energy and with the goal of national energy security (Neville et al. 2017; Scanlan 2017; Schafft, Borlu, and Glenna 2013). However, there is much public and academic debate about the tradeoffs to health and environmental quality due to drilling and hydraulic fracturing, often focusing specifically on how natural gas extraction impacts water.

Across the US, these debates have ensued between residents who see the environmental externalities of extraction and scientists who study environmental impacts, specifically centering around the risks to household drinking water and the sensationalization of natural gas' extraction impact on the environment. On the one hand, the 2010 documentary Gasland by Josh Fox demonstrated hydraulic fracturing's hazards with Pennsylvania residents lighting their tap water on fire (Vasi et al., 2015). And on the other hand, groundwater contamination has not been shown by environmental scientists to be a predictable externality of UOG development, but rather occurring as disparate or clusters of incidents through spills and accidents (Harkness et al. 2017; U.S EPA 2016).

United States (US) citizens have mobilized against natural gas extraction due to concerns over water impacts and contamination from hydraulic fracturing (Willow and Wylie, 2014; Vasi et al., 2015). However not all communities in proximity to gas wells have mobilized, as some communities demonstrate reluctance to mobilize in addition to prevailing support for extraction (Gullion 2015; Jerolmack and Walker 2018). Within social science research on water contamination, specific attention to groundwater has been less explored despite the immediate impacts well water quality and quantity changes have on residents' everyday life (except for Alawattegama et al., 2015; Kern, 2015).

Marcellus Shale development has been contentious and social acceptance and regulation has varied across states (Baka et al. 2019; Sangaramoorthy 2019). Located within the Marcellus Shale, the bulk of unconventional development in West Virginia has occurred since 2010 (Shaw 
and Mishkin 2019). West Virginia (and similarly Western Pennsylvania) continue to interest researchers who want to understand public reception of natural gas extraction within the context and history of coal mining and manufacturing as compared to urban and suburban areas where natural gas extraction is the first type of ongoing mineral extraction (Jacquet et al. 2018; Poole and Hudgins 2014). The context of legacy environmental and water contaminants from coal mining and manufacturing in West Virginia complicates simple elucidations of natural gas extraction's impacts on water. Additionally, many rural West Virginians rely on groundwater drinking wells for their homes, making the question of groundwater impacts particularly salient and urgent for this geographic area.

As a state with a long history of coal mining and legacy contamination, West Virginia is an interesting case study of the spatial arrangements made by natural gas extraction in which economic growth and environmental decline are produced in the same locations. As such, Appalachia and more specifically West Virginia have long been defined as an environmental sacrifice zone for the US while at the same time producing tremendous profits for extractive companies (Fox, 1999; Zwick, 2018). Some have called this scenario the "resource curse" in which areas with natural resources do not end up with the economic benefits of those resources (Partridge, Betz, and Lobao 2013). Accordingly, theories have emerged to describe the so-called resource curse of West Virginia as the workings of an internal colony to the US (Lewis, Johnson, and Askin 1978). Most recently, the decline in coal and manufacturing jobs in the region has revived discussions about the importance of natural resource extraction to West Virginia (McGreal 2017) which has also revived a rhetoric of jobs and economic development as the primary concerns in the state over environmental concerns (Cruger and Finewood 2014).

Against this backdrop, geographers have noted UOG extraction's production of space, revealing how natural gas relies on private property and underground enclosure (Hesse, Baka, and Calvert 2016; Ryder and Hall 2016) and the production of benefits at multiple scales (Sica 2015). West Virginia has a long history of supporting national energy needs, while also being marginalized from the benefits of its natural resource extraction and development (Fox 1999). Because of the dominant narrative that UOG is developed for the public good and national energy security, it is important to consider how individuals in closest proximity to UOG development are impacted by development. Within communities impacted by UOG development there are uncertainties about the outcomes, benefits and risks. 
The aim of this thesis is twofold. First is to explore how West Virginians in the northwestern counties are affected by groundwater contamination, especially residents who live near UOG infrastructure and rely on household groundwater wells. Second, considering that water contamination can be difficult to determine, and that many West Virginia residents do not have documented or confirmed contaminated water wells, is to explore residents' perceptions of groundwater impacts due to natural gas extraction. The term perception is critiqued for being a concept that implies different perspectives on an underlying truth (Clapp et al. 2016). This research is focused on West Virginians' perceptions to understand how West Virginia residents who have well water view natural gas extraction and the risks it presents to their water and homes, not because their views are somehow false or biased. Put another way, this research tries to complicate the polarized narratives between scientists and activists that has dominated conversations on groundwater impacts. There is a contested domain of knowledge around groundwater, and as such, well water presents a unique entry point for this case study because of its materiality and spatial location. Water is fundamental to everyday life and the home and hence well water is an important facet of life in rural West Virginia.

\subsection{Research questions}

The overall objective of this thesis is to explore how oil and gas development shapes West Virginia rural waterscapes. To be able to fulfill this objective, I will investigate two research questions:

1. What are residents' perspectives on household well water contamination due to UOG development in WV?

2. How does household well water contamination (verified, and perceived risks) impact residents?

\section{Conceptual overview}

This thesis draws on feminist geography and political ecology scholarship. First, this thesis is methodologically situated within feminist geography to examine the practices of knowledge production, both by myself as researcher and the prior and continual extractive knowledge production that West Virginia communities have experienced about water. Second, the framework of waterscapes from political ecology is used to elucidate how water is not simply 
a neutral material resource, but that it is shaped by political, technological, social and discursive factors. By using waterscapes as a framework, concepts from feminist geography of embodiment and epistemic authority are used to analyze West Virginian's lived experiences of well water contamination and the production of waterscapes around natural gas extraction.

\section{Overview of chapters}

This thesis is organized into six chapters, including this introductory chapter. In chapter two, the conceptual framework is presented using a literature review of the political ecology waterscapes framework and the concepts of embodiment and epistemic authority. A literature review of each of the concepts individually is provided, as they are all developed independently of political ecology and waterscapes. With this literature review, the concepts of embodiment, and epistemic authority are interlinked, and demonstrated as contributing to a discussion of waterscapes. Specifically, this thesis is an example of literature on subterranean or groundwater waterscapes. Chapter three provides background information about natural gas extraction in the US. This section describes the scope, technology, and practices associated with natural gas extraction. Also included is a literature review of the main themes that social scientists have analyzed about unconventional development's social impacts. Chapter three starts broadly by describing common scholarly themes that have emerged about unconventional natural gas extraction across the US, and then narrows by focusing on research specifically about water, and West Virginia. Next, chapter four details the research design and qualitative methodology by describing the tenants of feminist methodology and positionality within this research. This section also delves into the background information on the case study and give explanation about the use of semi-structured interviews, member-checking, and data analysis. Chapter five presents the research findings on West Virginia surface and mineral owners' perspectives on household groundwater contamination. Chapter five uses excerpts from interviews about water contamination's embodied impacts on health, as well as economic impacts to home value, and the everyday burdens of securing usable water. Additionally, this section presents findings about how drinking water wells are tested in the context of natural gas extraction, as well as residents' experiences of water testing undertaken by oil and gas companies. Chapter six provides a discussion of the research results and its contributions to the conceptual framework. Lastly, chapter seven includes concluding thoughts on this research. 


\subsection{Note on terminology}

Throughout this thesis, I use the terms unconventional oil and gas (UOG) development, natural gas or shale extraction, drilling and hydraulic fracturing. I use UOG development and natural gas extraction nearly interchangeably, to describe the natural gas extraction process and development generally. I use the terms drilling and hydraulic fracturing when I want to describe the specific steps of drilling and fracturing a gas well. Intentionally, I do not use the term fracking. Fracking has become the most common and colloquial term used to refer to UOG extraction by both the industry and public. Industry representatives may use fracking to refer specifically to the process of hydraulic fracturing, one step in the process of UOG development. However, public usage of fracking can refer to various other steps, or to all of the steps, in the process of oil and gas development, from lease negotiations with landmen to drilling and fracturing to well pad development and upkeep (Willow 2016b). Instead of using fracking, I use unconventional oil and gas development to refer to the entire or combined aspects of the extractive process. I specify drilling or hydraulic fracturing when I specifically am referring to those actions and their particular outcomes.

Even though it is commonly used, I choose to not use the term fracking because it is vague and often ideologically charged (Evensen 2016; Stoutenborough, Robinson, and Vedlitz 2016b, 2016a). The political divisiveness of the term fracking is debated. Some argue that the term fracking produces negative feelings towards natural gas extraction (Evensen 2016), while other posit that pre-existing attitudes towards natural gas extraction determine whether the term fracking is perceived as negative or not (Stoutenborough et al. 2016b, 2016a).

Some suggest that fracking is a popular term for activists who can then use the term as a substitute for another word, such as slogans that say "No fracking way" (Cusick 2014). In this same story, it is purported that the first use of the term fracking was in 1953 by the oil and gas industry. One explanation for the proliferation of this word by industry representatives is so that the industry can be part of the same conversation as activists, using the same words. However, pro-gas extraction activists avoid the term fracking and use the terms energy, jobs and shale (Cusick 2014). I attempt to work around this fraught terminology usage by not using the term fracking.

Another term used throughout this thesis that needs to be clarified is development. I use the term development to describe the whole process of natural gas extraction, from leasing to well 
pad and infrastructure implementation. I use the term unconventional development as synonymous with natural gas extraction, to specifically focus the type of extraction that requires horizontal drilling and hydraulic fracturing. In many contexts the term development has a positive connotation as a means for positive economic growth (Feltault 2006). However, to critical geographers the term development is full of ambivalence as they have consistently critiqued the mechanisms of development as top-down, insensitive to gender, and often unjust (Cookson 2018; Ferguson 1994). In this thesis, UOG development is not synonymous with development efforts in the Global South aimed at poverty alleviation and social inclusion (Cookson 2018). Here I use development to describe the material and physical infrastructural change to the landscape that must be in place to extract gas, and to describe UOG development as profit driven economic growth for mineral owners and oil and gas companies. 


\section{Chapter Two: Conceptual framework}

This thesis draws on theories and concepts from feminist geography and political ecology to situate this study within the broader geographic literature. First, this literature review will cover political ecology and the development of the framework waterscape, and the concept of hydro-social cycle. Then, it will connect literature on waterscape to concepts in feminist geography of embodiment and epistemic authority. This thesis is grounded in political ecology scholarship on waterscapes, which is attentive to how changes in water also produce changes in social relations. To explore these changes to water and social relations due to natural gas extraction in West Virginia, this work also draws on the concepts of embodiment and epistemic authority which consider both the corporeal experiences of water and the competing knowledges around water and extractive industry.

\section{$\underline{\text { 2.1 Political ecology }}$}

Political ecology emerged as an interdisciplinary field in the 1970's and 1980's to study the intersections of environmental questions through the lens of Marxist political economy (Watts, 2015). Political ecology is defined as research that "combines the concerns of ecology and a broadly defined political economy" (Blaikie and Brookfield 1987:17). This definition is broad enough to resonate widely while providing a theoretical basis to "do" political ecology. The field of cultural ecology and hazards research are seen as predecessors to political ecology but were critiqued by political ecologists as disciplines lacking theory (Watts, 2015, 1983). Coming out of University of Chicago in the 1980's, hazards research largely focused on the idea of rational individuals responding to natural disasters (Macdonald et al. 2012). Michael Watts has critiqued hazards theory for using a basic "ecosystemic approach" which renders human life to "atomised individuals" and employs the idea of "individual purposeful rationality" (Watts 1983:234, 240). As a critique of hazards research, the basis of political ecology is built on shifting blame and attention away from individual rationality towards examining how larger structures constrain, control, or empower particular groups of people.

Although political ecology is notoriously difficult to succinctly define, Perreault, Bridge, and McCarthy (2015) delineate five characteristics of political ecology work: engagement with Marxism, critique that is allied with those less powerful, engagement with feminist theory and politics, commitment to qualitative and interpretive methods, and attention to historical and 
social contexts. The field of political ecology is expansive and does not prescribe a specific method or analysis but is defined by the commitment to contextual analysis of environmental questions through qualitative methods with an explicit politics allied with marginalized populations. This definition is not comprehensive but is a broad outline of commitments that characterize political ecology.

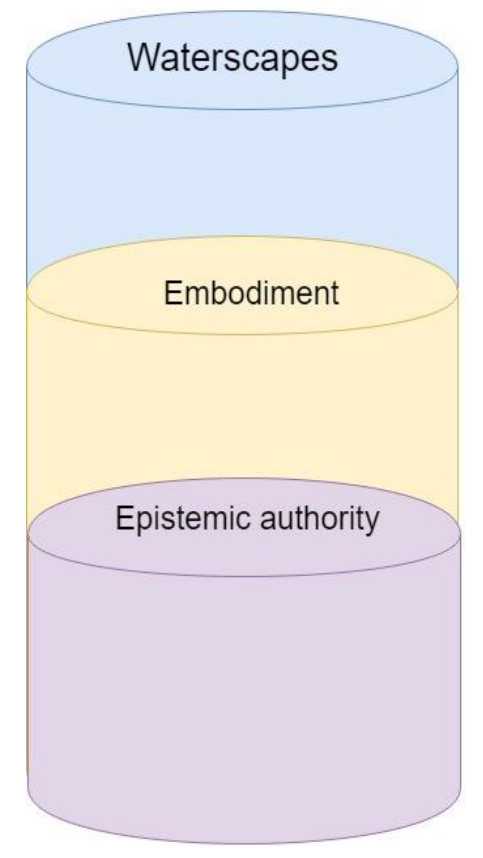

Figure 1. Conceptual Framework

This image of the conceptual framework (Figure 1) demonstrates how waterscapes is an overarching framework (Karpouzoglou and Vij 2017). In this thesis, waterscapes is used to explore the social and material production of water. Concepts from feminist geography, embodiment and epistemic authority, are also used to examine experiential, material, and discursive aspects of waterscapes. The goals is to bring the concepts of embodiment and epistemic authority in conversation with waterscapes to elucidate an analysis of subterranean or groundwater waterscapes in West Virginia.

\subsection{Waterscapes and hydro-social cycle}

As "different matters matter differently" (Gregson and Crang 2010:1027), the political ecology of water developed as a subfield that examines the social, cultural and economic dimensions of water. Political ecology of water has developed from a Marxist and urban lens, as 
discussed below. Dating back to 1957, Wittfogel defined water as an articulation of power, following Marx's dialectical interpretation of the labor process (Linton and Budds 2014).

Swyngedouw (1999) uses the concept of waterscapes to theorize how water and social relations are produced relationally. Political ecologists' development of an approach that considers how water is socially and naturally produced stems from the need to understand social challenges related to water quality and quantity (Karpouzoglou and Vij 2017; Swyngedouw 1999). Swyngedouw (1999) in fact argues that nearly all water flow is subjected to human intervention and that all forms of social change need simultaneous understanding of changes in the hydrological process.

Drawing on Smith's (1984) theorization of "the production of nature" that insists that the production of society and nature is a geographical process, and Latour's (1993) "quasi-objects" that are both natural and social, Swyngedouw (1999) defines water as both natural and social, a hybrid, not two separate entities (nature and culture) dialectically shaping one another. The production of "socionature" is not limited to the production of material conditions, but also refers to the production of discourses and representation of nature (Swyngedouw 1999).

The political ecology of water has roots in Marxism using analyses of capital accumulation (Linton and Budds 2014; Perreault 2013). Marx’s primitive accumulation, and Harvey's accumulation by dispossession are lenses that political ecologists use to analyze how water is controlled, often focusing on privatization and distribution of water in urban contexts (Bakker 2003; Loftus 2009). Loftus (2009) politicizes the distribution of water by arguing that controlling water distribution is an accumulation strategy to separate people from "free access to potable drinking water" (p. 964). Water evades ownership and enclosure and as such water is often thought of as public good or as a common pool resource, or equally available to all (Hudgins 2014), or rather uncooperative (Bakker 2004).

Within this framework political ecologists are concerned with who controls water, and conversely who accrues social power from water. Swyngedouw (1999) focuses on excavating the historical processes that created and continue to create the Spanish waterscape. His analysis includes how modernization projects in Spain controlled and distributed water. These modernization projects were framed through society's progress and betterment, but Swyngedouw (1999) asks who controls water, who acts, and who has the power to produce what kind of water. 
Although political ecology of water grows out of a Marxist tradition, Swyngedouw is against Marxist historical materialism which defines nature and culture as two separate, discrete a priori entities in which human culture encounters nature (Swyngedouw 1999). Instead, he argues that nature and society are related internally, such that both entities are inseparable, and historically geographically produced (Swyngedouw 1999). Linton and Budds (2014) demonstrate the idea of internal relations through their example of a public drinking fountain versus bottled water. The public drinking fountain produces water as a public good and produces a public to drink it. Conversely, bottled water produces water as a commodity and in turn produces consumers. They go on to argue however that dialectical vs internal relations are not necessarily contradictory. Accordingly, water is internally linked to society, historically produced, and cannot be rendered solely through technoscientific hydrology.

The main concept used within the framework of waterscapes is the hydro-social cycle. The hydro-social cycle is used in different ways, but with the goal of showing how water flows through natural and social realms (as opposed to the hydrological cycle which removes all social influence from water's flow). The creation of the hydrological cycle worked to create a field of expert hydrologists who have "technical authority over water" (Linton and Budds 2014:171). The hydrological cycle presents water as moving through physical realms, unmediated by society (Linton 2008). Conversely, the hydro-social cycle seeks to figure society and power back into water's cyclical flows, and work against the idea a modernist depiction of the hydrological cycle depicting "water resources" (Schmidt 2014).

At the heart of the hydro-social cycle concept is a critique of a hydrologic perspective that separates water from society, and the epistemic authority that the hydrologic perspective and hydrologic cycle carry (Linton 2008). The hydro-social cycle acknowledges how the hydrological cycle is changed and produced at multiple scales and how at the same time social and political power are also transformed (Linton and Budds 2014). Water and society are inextricably linked, and likewise, "hydro-social transformations are imbedded in and infused by class, gender, ethnic, or other power struggles" (Finewood and Stroup 2012:73).

The hydro-social cycle concept specifically provides an intervention into dominant conceptions of water via the hydrological cycle in the field of hydrology. The hydro-social cycle is useful for thinking about the epistemology and ontology of water as an entity known through objective technoscience of the hydrological cycle (Karpouzoglou and Vij 2017; Linton and 
Budds 2014). Conversely, there are other ways of knowing water such as the hydro-social cycle's considering how water is produced by capital, uneven development, and social power (Linton and Budds 2014).

Although political ecologists focus on social power, and discursive, symbolic and representational aspects of water, they never eschew water's materiality. Resource geography asserts the idea that water has biophysical resistances, and that we can also consider the "biophysical processes dialectically without invoking an external nature" (Bakker and Bridge 2006:9). Linton and Budds (2014) contend that groundwater necessitates a different analysis than surface water, because "groundwater flows and volumes are invisible to the observer, which makes them more complex to access and measure, either by hydrologists or other users" (p.177).

A subsect of scholarship on waterscapes has emerged in geography and anthropology that focuses in particular on groundwater or subterranean waterscapes. This literature has analyzed how "the underground's inaccessibility and hiddenness has ultimately meant that subterranean 'scientific' knowledge ... is relatively limited and hidden as well." (Melo Zurita and Munro 2019:40). Subterranean waterscapes are characterized by competing knowledges of what exists and occurs beneath the surface. (Willow 2016a).

\section{$\underline{2.3 \text { Embodiment and water }}$}

To further explore the West Virginia waterscapes around natural gas, and particularly the competing subterranean knowledges around groundwater and natural gas, this thesis is further grounded within the concepts of embodiment and epistemic authority. In general in anthropology, sociology or public health, embodiment as a concept might be used to describe how social factors and injustices impact on the body and cause physical tolls and sufferings onto individuals (Healy, Stephens, and Malin 2019). This thesis draws on this definition of embodiment while but adds to it by using conceptualizations of embodiment from feminist geography to explore impacts to the home and body, embodied emotional experiences, embodiment as scale, and how natural gas extraction and people embody social relations and injustices. Together, this conceptual framework centers lived experience and embodied knowledges. 
However, this thesis also departs from embodiment in particular ways. Traditionally, an exploration of embodiment may lead to the analysis that embodied experiences of health become oppositional or in conflict with scientific narratives or reveal something that science cannot reveal (for example McHenry, 2017). Scholarship on industrial pollution often focuses on the physical and emotional experience of exposure to pollution and contaminants (Davies 2018; Judge et al. 2016). As this thesis will later argue, embodiment does not fully capture the experiences of water contamination around natural gas. The following sections outline the multiple ways that embodiment manifests in feminist geography and in this thesis.

\subsubsection{Home, body, and emotions}

This thesis utilizes the concept of embodiment originated from feminist geography scholarship. Feminist geography is concerned with how gender, identity and intersectionality are shaped by and shape place and space, often focusing on issues deemed private or personal, asserting that personal and political matters constitute each other (Mcdowell, 1997; England, 1994; Rose, 1993). Feminist geography initially grew out of feminist critiques occurring outside of the academy in the 1970's, and developed as a response to the exclusion of women in the discipline of geography (Nelson and Seager 2005; Rose 1993). Feminist geography scholarship grew to include an analysis of women in/and development, with a focus on moving development studies from the model of "adding-in" women, to development models that incorporate a more complicated understanding of women's experiences of injustice (Chant and Gutmann 2002).

With the rise of third wave feminism, feminist geographers alongside feminist thinkers in a variety of disciplines began to critique the centrality of the white Western women in feminist thought and scholarship, noting the power relations that exist between women and the harm of homogenizing the category of woman (Mohanty 1984; Mollett and Faria 2013). Feminist theory profoundly impacted feminist geography by developing post-structural theories of gender performativity, bringing new understandings to the production of gender (Butler 2013).

Feminist geography draws upon feminist epistemology which is grounded on the critique of objectivity. Objectivity is the cornerstone of Western science, implying that one can be fully detached and disembodied from their research topic and participants. Feminist geographers have argued that Western objectivity can only be claimed by the white, male body, which is seen as unencumbered by its physicality, unlike women and people of color who are marked as different 
(Longhurst, 1995). Objectivity is built upon Cartesian dualism that assumes rationality as separate from and better than emotions (Knoblauch, 2012; Moss, 2005; Thien, 2005; Longhurst, 1995; Haraway, 1988). As opposed to this, feminist geographers' focus on bodies intends to disrupt a long history of research and knowledge produced as objective, with feminist geographers arguing that objectivity is disembodied (Haraway 1988). The turn towards emotions and embodiment in geography is both the rejection of a masculinist, rationalist mind/body dualism, and also grows out of a sense that modernity has not produced the knowable, predictable world as promised (Alaimo 2010; Clement 2017).

The concept of embodiment has become a part of feminist methodology and analysis, used as a way to explore emotions in research (Lund 2012). The emotional turn in geography has sought to incorporate individuals' embodied experience of emotions in the research process (Lund 2012; Thien 2005). In particular, feminist geographers were interested in the emotions of researchers themselves throughout the research process (Robyn, Elsie, and Lynda 2008). Emotional geography is not about studying emotions as discrete objects (Pile 2010; Sharp 2009), but instead focusing on how people and places construct and articulate emotion (Perreault 2017; Sultana 2011), and affect individual and community action (Ahmed 2004). Emotions are constructed through "speech acts, expressions, and physical actions" (Sultana 2011:169).

Emotional geography is often discussed in tandem with affective geography and phenomenology (Pile, 2010; Tolia-Kelly, 2006; Thien, 2005). Emotion and affect are considered relational, however emotion is considered as an embodied "way of knowing" (Pile 2010) and affect is the study of universalist and inexpressible feelings (Pile 2010; Sharp 2009). Human geography and phenomenology has sought to describe emotional and sensory experiences of place, but feminist geographers have critiqued scholarship for not problematizing the notion of a “coherent, bounded, self-aware" human subjectivity (Pile 2010:7). Emotions are not “individualized human subjectivities" but instead are embodied, relational, contextual experiences, that they are intersubjective and coproduced (Sultana, 2011, pp. 164).

Epistemologically, the concept of embodiment critiques disembodied objectivity, and seeks to theorize knowledge from lived experience (Moss and Dyck, 2003). Methodologically and analytically, a focus on embodiment is a deliberate political act to research aspects of life that are private, or intimate, specifically focusing on the body, the home, and subjective experiences (Dyck 2005). Often invoked is the feminist imperative that the "personal is political" 
(Nelson and Seager 2005:2). Feminist geographers deliberately subvert ingrained notions of what is politically important in geography by linking the body and home, deemed private and small scale, to the issues of the nation and geopolitics (Elmhirst 2011; Harris 2015; Oberhauser 1995; Smith 2012).

\subsubsection{Emotional geographies of water}

As part of a political ecological approach to water, water access, quality, and security have often been central concerns. Feminist political ecology approaches gender subjectivity and water by critiquing water governance's assumption of a "rational resource user" while forcing women to choose between pure or contaminated water (Sultana 2009, 427). Jepson (2014) in her exploration of household water security, defines water security in terms of water access, water quality and water affect. Water affect acknowledges aspects of wellbeing and distress due to water insecurity and includes the "emotional, cultural and subjective experiences of water" (Jepson 2014:109). Attention to water affect is attention to experience. Experience-based approaches such as water affect are less common in political ecology scholarship, because perceptions are problematized from a regulatory stance, however water affect and embodied experiences remain important as they shape "household practices" (Jepson, 2014). Focusing on the household and embodied dimensions seeks to "try to do justice to the experience" (Jepson, 2014) and brings "meaning and value" (Harris 2015:173) to studies of resource access and contamination. Sultana (2011) argues that political ecologists have not sufficiently explored emotions produced by environmental degradation and resources crises.

Bringing emotional geography to political ecology, Sultana (2011) examined the way that resources conflicts over arsenic contaminated water in Bangladesh are experienced as everyday emotional struggles, and how narratives of gendered emotional suffering are leveraged for increased water access. Water contamination figures into research on unequal gendered consequences on water governance and provisioning (Harris 2015; Sultana 2011). In both Sultana and Harris' works, water contamination produces subjectivity and forms of struggle when women have to use contaminated water, contributing to emotional worries about health and physical long-term health impacts. In these cases, water contamination is known, and embodied by the women in terms of power, suffering, and physical manifestations. 
Although the work on suffering has become influential in describing the visceral, emotional and physical impacts that water quality and quantity injustices can have on individuals (Perreault 2017; Sultana 2011), suffering is not the only salient emotion produced by water insecurity. In other studies that use ethnographic observations and surveys, researchers note how fear, worry, anger and bother are experienced because of water distribution inequalities and lack of water. Stevenson et al. (2012) specifically analyze fear, worry, and bother as continuous emotional distress. These studies have focused on the Global South and the lack of distributed water (Stevenson et al. 2012; Wutich and Ragsdale 2008) much like Sultana (2011) and Perreault $(2013 ; 2017)$ focused on water pollution in the Global South. This thesis extends these analytical themes to a case study in the Global North focusing on the emotional distress (concern, worry, fear, anger, bother) around energy shale development and the resulting impacts on household groundwater in West Virginia.

Adding another layer to research on the emotional dimension of water insecurity, scholarship on environmental toxicity explicitly links toxic uncertainty with emotional experiences of concern, fear, worry (Davies 2018; Mah and Wang 2018). Toxicity manifests uncertainty in a few ways. One, is the different temporalities between pollution events and the slow violence of incremental contamination (Davies 2018; Nixon 2011). Davies (2018) describes how incremental contamination produces emotions, focusing on feelings of entrapment from industrial infrastructure development. The concept of slow violence is often used to describe incremental contaminations. Nixon (2011) describes slow violence as gradual, or "a violence of delayed destruction that is dispersed across time and space, an attritional violence that is typically not viewed as violence at all" (p. 2). Industrial toxicity is theorized as postponement of destructive consequences into the future (Davies, 2018). Slow violence of industrial pollution is not characterized by individual acts but by "labyrinth of forces at work" (Davies 2018).

This labyrinth of forces, or social relations producing toxic uncertainties and pollution have been analyzed as producing displacement, dispossession, and emotional experiences. Perreault (2017) focuses on embodiment in his study of mining and water contamination in Bolivia, based on the idea that pollution lives a "double life" in both bodies and in geographic memories, arguing that pollution creates embodied and emotional suffering. Similarly, changing landscapes have been characterized as producing "solastalgia", or homesickness when surroundings change (Albrecht et al. 2007). Davies (2019) discusses the "stationary 
displacement" that occurs when communities are stuck in a place yet that place has been "stripped" of its inhabitability (p. 8). Embodiment connects material and symbolic dimensions of water contamination by connecting material landscapes to emotions and feelings of home and place.

Perrault's (2013) analysis of toxic accumulation provides an example of the role of embodiment in political ecologies of water through contamination and dispossession. Drawing on Harvey's theories of accumulation by dispossession, Perreault (2013) analyzes how the accumulation of pollution and sediment in water because of extraction causes land and water dispossession. Perreault (2013) does not use the concept of dispossession to describe how land is opened up for capital investment, but instead he argues that the accumulation of pollution in water pushes individuals away from previously usable land toward urban centers and "proletarianization". Willow (2016a) describes a similar case study of water pollution due to UOG development in Ohio, arguing that water contamination changes positive connection to place into feelings of alienation from place.

Multiple temporalities and outcomes of water contamination around natural gas extraction produce uncertainty about current or future consequences. Especially in this thesis, which presents a case study located in the Global North, anxieties and worries are produced around health and future outcomes, as well as a sense of worry because this environmental reality fails to conform to cultural expectations (Jepson, 2014).

Both literatures on water security and toxicity have pointed out how emotions function and arise around scarce and degraded water, particularly in the home. Whereas water security scholarship seeks to fully explain the many facets and impacts of water insecurity by including emotions and experience; toxicity explores how uncertainty produces emotional experiences, paired with a critical lens toward the industrial practices that produce pollution.

The household is the focus of this thesis because that is where water services are encountered (Jepson, 2014). Focusing on the household is not a reification of the importance of individual behavior, but rather how the household is an important space where water and social relations are encountered. Attention to the corporeal and emotional engagement with water around gas extraction resembles previous literatures in political ecology about the embodied political ecology of oil flow (Davies, 2018). Accordingly, embodiment is emerging as a concept in social science literatures of energy to explore the cumulative and wide ranging effects of 
energy production, especially focused on sites of production which may be distant from sites of consumptions (Healy et al. 2019). Although in some ways this emerging social science literature loses some of the nuance that feminist geography has contributed to the concept of embodiment, it also signals how important an embodied analysis of energy development remains to be as energy production and consumption continues to rise. In addition to contributing to this emerging work on energy development, this thesis also responds to the call in human geography for “increased focus on the everyday experience of pollution" (Davies 2018:1543).

The rest of this conceptual framework seeks to compliment the literature review of toxicity but further exploring embodiment as a political scale in geographic environmental research, and then lastly, exploring epistemic authority which has become a salient subject within geographic literatures on pollution and industry.

\section{Embodiment and scale}

Scale is fundamental in geography because scales are produced hierarchically and this hierarchical "process of scaling" makes the concept of scale analytically different from place or locality (Brenner 2001). Geographers define scale as a central concept in the discipline, but debate what scale is, how and why it is produced, and whether it is better to eliminate the concept of scale altogether (Marston et al., 2007). Geographers have critiqued uncritical uses of scales as pre-defined "containers" of space -- local, regional, state, nation, international -- by explaining that scales are socially produced as large and small relational scales (Gal 2016). Scale is used rhetorically to frame political problems as referring to particular geographic regions or scales (Kurtz 2003; Sica 2015). Geographers have referred to this practice as "scaling up" or “scaling down" an issue (Harrison 2006; Kurtz 2003). When problems are attributed to particular scales, their scale delimits which institutions can address the problem or not (Kurtz, 2003; Harrison, 2006; Budds \& Hinojosa, 2012). Scale is included in this conceptual framework as part of the concept of embodiment, specifically its rhetorical and discursive function, as well as to bring attention to the discursive framings of water impacts around natural gas. In this section I overview how scale has been conceptualized in feminist geography while weaving in some of the ways that scale has been used to analyze natural gas extraction.

Feminist geographers critiqued political geography's strict focus and privileging of national and international scales (Massaro and Williams 2013). Drawing on feminist geography's 
historical interest in private spaces and "small" scale, the subfield of feminist geopolitics seeks to link large- and small-scale political issues and hence destabilize scalar categories (Brickell \& Cuomo, 2019; Smith, 2012). By focusing on the home and body, which have been constructed as small scale, feminist geographers have shown that personal and private are political. Some examples include analyses that demonstrates that hegemonic and masculinist forces of security and violence operate similarly across personal, national and international scales (Brickell and Cuomo 2019; Pain 2015) and how construction of the nation relies on constructions of gender, race and class (Sinha 2013).

Scale is a relevant concept for UOG development, which has created a set of "stacked" scales in which benefits are claimed to accrue at every scale (Sica 2015). The idea of "weighing tradeoffs" is common in the literature on hydraulic fracturing (Finewood and Stroup 2012; Sica 2015). Multiple scholars have sought to examine and explain how these tradeoffs are framed by industry representatives and the public (Hudgins 2014; Matz and Renfrew 2015). One argument is that pro-industry discourse has constructed environmentalists as the reason for the decline in blue-collar jobs in the Rust Belt and Appalachia (Cruger \& Finewood 2014). Another argument is that pubic consensus on fracking in Pennsylvania has been won through "stacked" scale frames in which the benefits at local, regional and national scales are framed as benefits that serve multiple and overlapping scales (Sica 2015). The benefits include cheaper gas for consumers and less air pollution when burned, or the creation of jobs, tax revenue and cleaner air (Sica, 2015). Comparatively, the costs of natural gas extraction have not been framed consistently nor as extending beyond the local (Sica, 2015). Despite this argument more recent literatures on embodied energy injustices seeks to remedy this gap by articulating a framework that attends to the full spectrum of energy costs or injustices, effectively "scaling" the costs of natural gas (Healy et al. 2019).

Geographers have noticed the rhetorical functions of scale, arguing that scales are not containers positioned in a "nested, vertical hierarchy" (Andrews \& McCarthy, 2014, p. 10) but instead are relational "categories produced by human efforts to interpret and order" and social processes (Budds \& Hinojosa, 2012, p. 122). Although these scales are referred to as describing a fixed notion of space, scales are utilized to discursively frame arguments (Huber and Emel 2009). It is specifically the relational aspect of scales that reveal the politics of scale (Brenner 2001; Massaro and Williams 2013). In this sense feminist geographers have tried to undo the 
implicit hierarchical qualities of relational binaries of large/small scale to undo the implicit privileging of the former (Mohanty, 1984; Grosz, 2005). In the case of natural gas extraction, analyzing the assumed fixity of the scales to which benefits accrue also destabilizes the normalization of those benefits. Costs that are only consistently framed as accruing to the individual scale are not prioritized. One reason for this is that claims to individual scales do not hold the same weight as the aforementioned "stacked" scalar framing of benefits. Another is the privileging of national and state scales over ones deemed individual or local. The scale of individual, which may seem self-evident and natural, has particular consequences for industrial externalities. When industrial externalities are framed as problems at individual scales, and are considered as "accidental", this framing also produces the response to the problem and may naturalize a lack of a response (Harrison 2006).

Considering that production of scale produces government and regulatory responses, there has been a call within political ecology to engage further with legal geography as laws and regulations shape "social and legal spaces in which extractive industries operate" (Andrews and McCarthy 2014:7). Legal geography scholarship has shown how legal cases can cause individual political issues to "jump scale" generating implications at the national and international level (Gorman 2018). Andrews and McCarthy (2014) suggest that attention to legal frameworks is an extension of, not in conflict with, political ecology's interest in informal and extra-legal arrangements. Legal geographies note how power operates through the law, where and by whom, and how law is a "crucial site of contestation over human-environment relations" (Andrews and McCarthy 2014:9).

The way that legal geographies shape space, place, and the home needs further consideration around energy development (Andrews and McCarthy 2014). Split estates, the legal separation surface rights and subsurface mineral rights, create the possibility and context for drilling by producing separate spaces (Ryder and Hall 2016). In this sense, law produces surface and subsurface and distinct spaces which can then be owned by different individuals and acted upon differently (Ryder and Hall 2016). Legal frameworks are often framed as objective legal forms of justice, however feminist legal geographic perspectives have argued that legal frameworks are not objectivist and also have an interested "view from somewhere" (Haraway 1988; Valencia and Carrillo Martinet 2017). 


\section{$\underline{\text { 2.4 Epistemic authority }}$}

As argued in this thesis, embodiment does not fully capture the experiences of waterscapes and hydro-social changes around natural gas extraction in West Virginia. This thesis explores how scientific and technological management of water become interwoven into embodiment, hence this conceptual framework draws on both embodiment and also epistemic authority to explore how certain knowledges are created and privileged over others. Whereas in the section about embodiment, there has been analyses about emotions due to uncertainty about water contamination and toxicity, there also exists emerging literatures about resulting epistemic injustices and authority related to industrial pollution (Baka et al. 2019; Mah and Wang 2018).

In this thesis the concept epistemic authority is used to explore the interactions between residents and oil and gas companies, and to ask what knowledge is created about well water contamination, and whose knowledge is considered valid. Epistemic authority is the credibility granted to scientific and academic research and to experts (Janack, 1997). Within this thesis, there is an already existing context of contested and competing knowledges of subterranean waterscapes (Melo Zurita and Munro 2019; Willow 2016a), which is intertwined with the knowledge cartographies of natural gas extraction which explicitly favors governmental and industry knowledges (Baka et al., 2019).

Within feminist theory, epistemic authority is theorized as part of epistemic privilege, in which oppressed social positions and marginality are linked to the epistemic privilege of knowing oppression, and thus have epistemic authority to speak of their own experiences (Collins, 2013; Janack, 1997). Following this, epistemic privilege includes the oppressed group's ability to know both the dominant ideology and the lives and experience of the oppressed (Janack 1997). Within this debate about epistemic privilege, embodiment and perspectives are intrinsically linked. By arguing for oppressed groups' epistemic privilege, the argument is made that their embodiment of oppression and social relations leads to a particular privilege perspective to speak on behalf of that oppression (Hartmann 1979). This argument for epistemic privilege is critiqued, as not every oppressed person will take on a politicized perspective (Collins 2013).

In one sense, epistemic authority is a concept to suggest that oppressed groups have the authority to speak on behalf of their oppression. In other sense, and in this thesis, epistemic authority as a concept to describe the how some knowledge claims gain credibility over others. 
Epistemic authority is enacted by social contexts and practices, in which one's objectivity is judged by others through interactions and practices (Janack 1997). Epistemic authority is generated through researcher's claims to expertise and objectivity, as well as legislative rulemaking. Feminist geographers have long criticized the notion of researcher's disembodied objective knowledge and subsequent claims to epistemic authority, and have reflexively questioned their own positionality, privilege, and epistemic authority as researchers. In response, feminist geographers have focused research on individuals' lived experiences of everyday oppression and power (Haraway 1988; Harding 1986; Janack 1997; Rose 1997).

\section{Intersections of embodiment and epistemic authority}

Environmental controversies have been a specific area in which geographers have explored place-based knowledge as a counter to 'scientific' knowledge (Rice, Burke, and Heynen 2015). The intersections between environmental controversies and contamination in particular remain areas in which to examine the intersections of science, epistemic authority, uncertainty and embodied knowledge (Bosworth, 2019; Judge, Brown, Brody, \& Ryan, 2016).

Literature on environmental contamination and toxicity highlights how concerns about chemicals have provided insight into scientific knowledge production. Roberts and Langston (2008) characterize uncertainty about chemicals as not neutral and inherently political. The literature exploring the connection between toxicity and uncertainty frames the existence of knowledge gaps as intentional and political, revealing the ways that science interacts with government and political entities (Ofrias, 2017; Auyero \& Swistun, 2008). The politics of scientific uncertainty are demonstrated through the West Virginia Elk River chemical leak that occurred in 2014 in which 300,000 residents' drinking water was contaminated with the chemical MCHM (Whelton et al. 2015). Little was known about the coal-cleaning chemical that leaked, and none of the government officials were willing to admit to this lack of knowledge about the chemical, except for the public health director (Bray 2017; Savoia et al. 2015). The lack of knowledge around that particular chemical was produced by lack of regulation (Bray 2017). Based on recent research on epigenetic effects in which chemical exposure can change human gene expression, toxic exposure complicates common held understandings of human environment interactions and scientific knowledge (Guthman and Mansfield 2012). 
Using this conceptual framework, this thesis is grounded in conversations about embodiment as the emotional experience of uncertainty around water and pollution, but also how epistemic authority functions around individuals' experience of water. The focus of this research is on West Virginian's embodied emotional experiences of household groundwater contamination, as well as their perspectives on the oil and gas industry, companies, and environmental regulations. Disentangling embodiment and perspectives can be tricky, because although they are different concepts, they are also co-constitutive. In one sense, the notion of West Virginians' perspectives arises from the research methodology, because the semi-structured interviews are designed for exploring participant perspectives (Baxter and Eyles 1999). At the same time, the analysis of this research rests on elucidating how embodiment is -- or is not -- part of these perspectives. Accordingly, perspectives and embodiment are intertwined. In this thesis, there is also a consideration of how these experiences translate into perspectives on industry and water itself, while thinking about how certain ideas and perspectives also shape experiences and emotions. 


\section{Chapter Three: Unconventional oil and gas extraction in the United States and West Virginia}

\subsection{Unconventional development in the United States}

The US is currently the world's largest producer of natural gas (Neville et al., 2017). The increased price of natural gas in the mid-2000s led to the proliferation of shale gas extraction across the US, notably of the Bakken Shale in North Dakota, Barnett Shale in Northern Texas, and the Marcellus Shale in Appalachia (See Figure 2) (Ratner and Tiemann 2015). The Marcellus shale lies under 95,000 square miles from West Virginia to New York (OgnevaHimmelberger and Huang 2015). Marcellus depths range from 2,000 to 9,000 feet deep below the ground surface (Ogneva-Himmelberger and Huang 2015). In the last two decades, production of natural gas in Appalachia went from less than 2\% to 40\% because of unconventional natural gas extraction in the Marcellus Shale (Sangaramoorthy 2019).

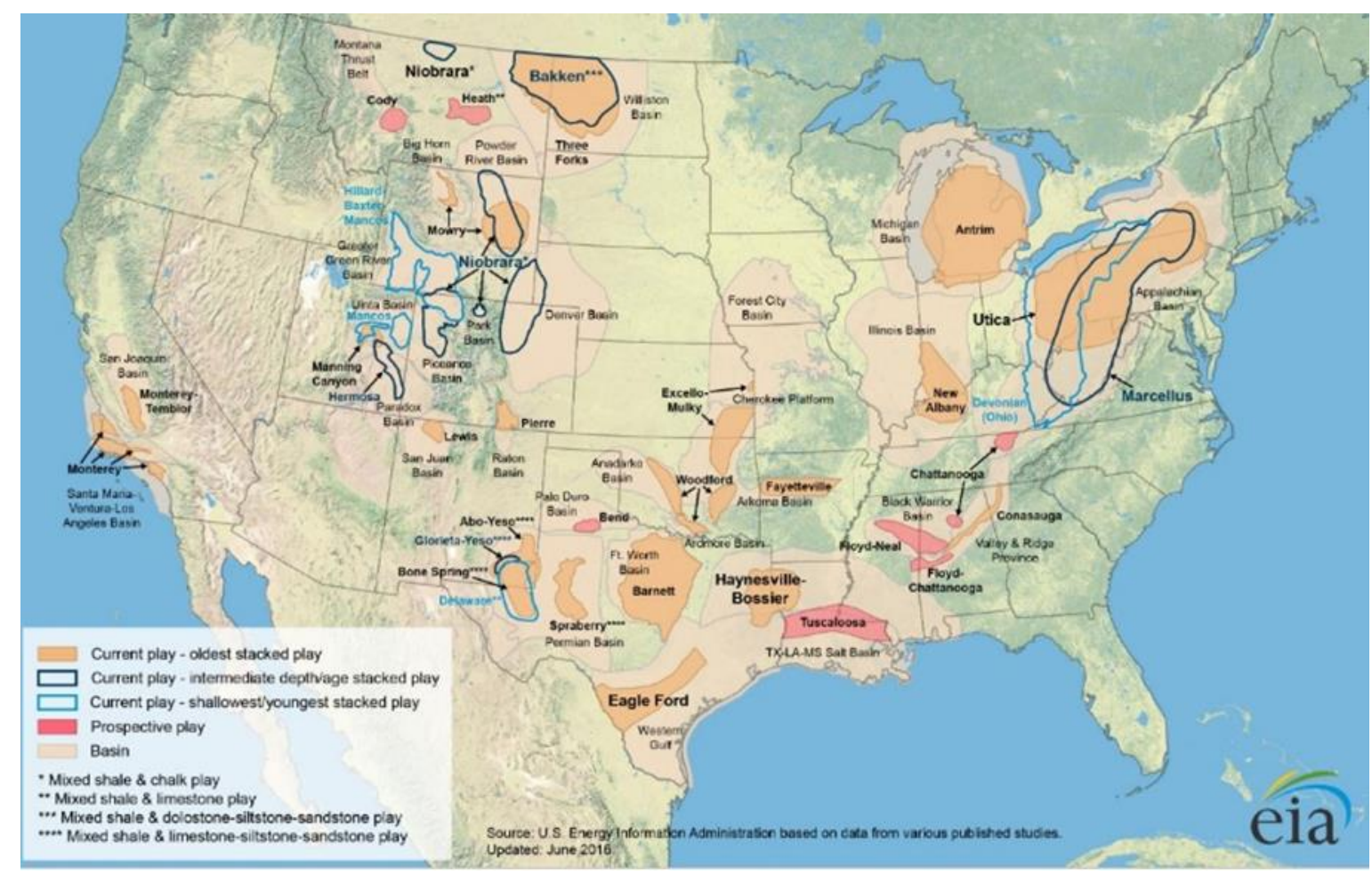

Figure 2. Shale development areas across the USA. (US EIA, 2016)

This chapter describes the processes of unconventional gas extraction and how they differ from conventional gas extraction. Additionally, this chapter considers the multiple pathways to groundwater contamination around UOG development and describes the ongoing debates about 
how hydraulic fracturing is or is not affecting water. Then, a short summary of the social science perspective on unconventional gas extraction in the US is provided, focusing most extensively on how social scientists have analyzed and politicized the issue of water.

Unconventional natural gas extraction entails using hydraulic fracturing to fracture deep, thin, non-permeable layers of shale to release tightly held oil and gas (Lave and Lutz 2016; Merrill 2013). Hydraulic fracturing itself is not new and has been used in the US since the 1940s (Scanlan 2017). What is new is the combination of high-pressure hydraulic fracturing combined with horizontal drilling, a process referred to as unconventional. Comparatively, conventional oil and gas drilling is characterized by extracting natural gas and oil trapped in hollow underground rock layers with a vertically drilled well (Merrill, 2013).

When an unconventional gas well is first fractured, it produces large quantities of natural gas, however production levels quickly decline after the first few months. Because of this, continuous drilling and fracturing of new wells is needed to maintain production levels (Lave and Lutz, 2016). Although unconventional extraction has become controversial due to environmental impacts, conventional well development had many of the same issues as UOG related to ground water contamination and disposal of wastewater (Lave and Lutz, 2016; Neville et al., 2017).

Although conventional wells also presented risks to water, the small size of the conventional wells and well pads makes them less disruptive than unconventional well pads (Figure 3). One of the main visible landscape differences between unconventional and conventional development is the size of the well pad development. Whereas conventional well pads often return to grass, and are built just near already existing roads, unconventional development typically entails a 5 to 10 acre well pad and the building of new roads (Litvak 2018). Although the size of well pads has increased dramatically since conventional development, with unconventional development multiple wells can be drilled on one well pad, hence requiring companies to develop fewer well pads and access roads per amount of mineral area developed (Lave and Lutz, 2016).

Water usage for unconventional natural gas extraction is high and intensifying. Hydraulic fracturing requires approximately 7 million gallons of water per well (Kondash, Lauer, and Vengosh 2018). There is much debate between scientists and the public about whether or how oil and gas extraction impacts water (King, Bryan and Clark, 2012; Vasi et al., 2015). Multiple 
scientific studies have suggested that hydraulic fracturing does not contaminate water (Harkness et al. 2017; U.S EPA 2016). This perspective is put into practice legally as oil and gas companies are exempt from the Safe Drinking Water Act (EPA 1974) and oil and gas wastewater is not classified as hazardous by the US Environmental Protection Agency (Lave and Lutz 2016; Willow and Wylie 2014).
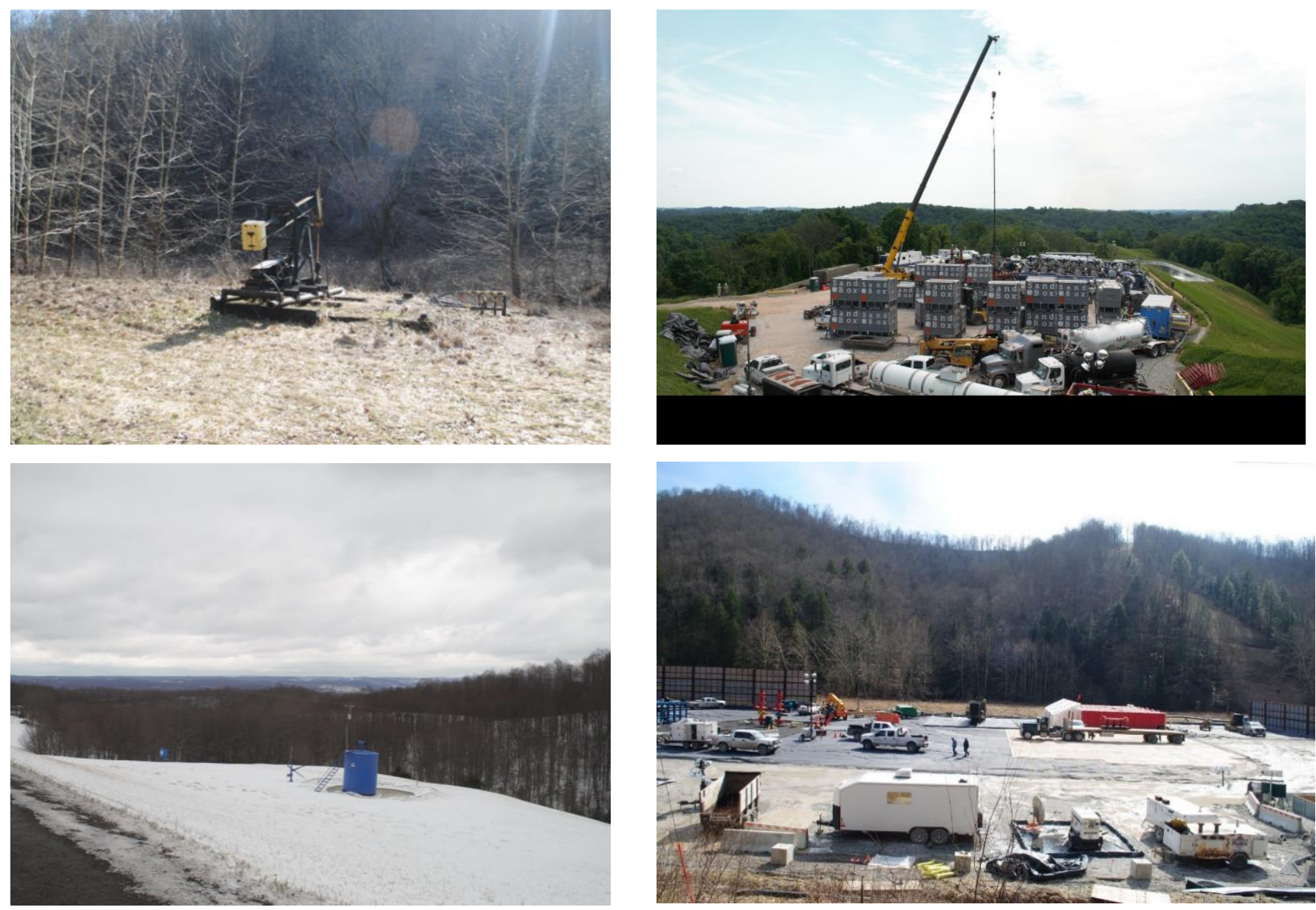

Figure 3. Comparison of conventional well pads (left) and unconventional well pads (right) in West Virginia. Photos taken in 2018 by Bethani Turley.

In particular, groundwater contamination due to UOG has been a question for scientists and regulators. The dominant scientific assertion is that hydraulic fracturing cannot contaminate water because of the depths of the fractured shale (See figure 4). However, other pathways to contamination exist. Faulty well casings are frequently cited as likely causes of contamination (Alawattegama et al. 2015; King et al. 2012). Additional causes are from waste pits where 
hydraulic fracturing fluids and/or waste waters are stored, and well communication (Vidic et al. 2013). Well communication is when fractured wells intersect, which can cause fluids to move through older wells that are not properly sealed (Danza 2012; Vidic et al. 2013). Some wells in West Virginia have been impacted long term, whereas other wells become contaminated but then after some time the wells "fix" themselves or returned to pre-fracking chemical levels.

Academic research on natural gas extraction's impacts on water tends to be about surface water impacts due to the high frequency of spills that occur from transporting produced water (Harkness et al. 2017). 10 to $30 \%$ of hydraulic fracturing fluid is returned from the well to surface after hydraulic fracturing; this is known as produced water (U.S EPA 2016; Ziemkiewicz n.d.). There is currently a debate about how to best manage wastewater - flowback and produced water - generated from hydraulic fracturing (Walton 2019). Injection wells have been used because they are the cheapest option, however injections wells have caused earthquakes in the Midwest and Western US and can also lead to groundwater contamination as well (Walton 2019).
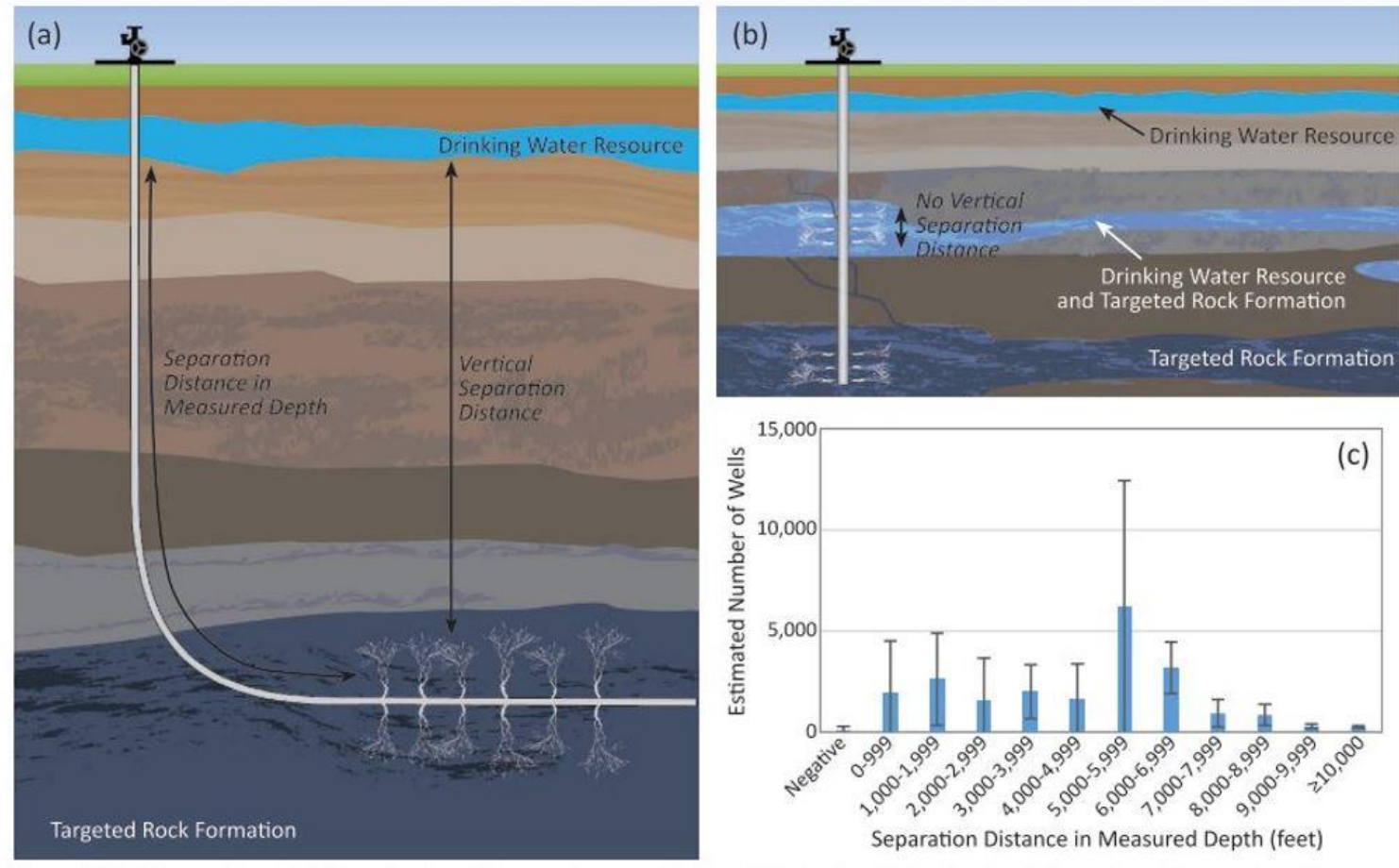

Figure 4. Subsurface depths of groundwater and horizontally drilled wells. (U.S Environmental Protection Agency, 2016) 
The chemicals themselves are a matter of controversy, because the chemicals used in hydraulic fracturing can be proprietary and not disclosed (Fink 2019; Kinchy and Schaffer 2018). It is beyond the scope of this thesis to focus on the specific chemicals, but it is important to note that in general these are contaminants that have perceived immediate and long-term health risks (Abatsis McHenry 2017). In general, when talking about water contamination, there is concern about methane contamination from the natural gas itself entering the water (Harkness et al. 2017), concern about the myriad of chemicals used in the hydraulic fracturing fluid that include known carcinogens such as toluene and benzine (Abatsis McHenry 2017), and/or concern about radioactivity and bacteria from deep flowback waters.

\subsection{The social dimensions of unconventional oil and gas development}

This section reviews social science literature about UOG development. Social scientists' interest in UOG development has boomed in recent years due to its widespread controversies (e.g. Gullion, 2015; Vasi et al., 2015; Neville et al., 2017). This section overviews the main branches of interest in the recent scholarship on UOG development. This section is divided into two subsections. The first section reviews the social science literatures on UOG development in Appalachia and the US. The second subsection reviews social science literature specifically about UOG and water.

\subsubsection{Social science literature on unconventional oil and gas}

The three foci in social science literature on the rise of UOG development in Appalachia are environmental community change, health impacts, and social mobilization. This section briefly reviews each of these foci to characterize the context of natural gas extraction.

Community change has been a salient feature of research on natural gas extraction due to the influx of male workers into rural towns for temporary work that accompanies drilling, hydraulic fracturing, and pipeline construction. Researchers have considered how this influx of male workers impacts rural community dynamics, including analyzing public health problems (Komarek and Cseh 2017) and a lack of skilled jobs being available to local women (MchenrySorber et al. 2016). There is emerging literature about the mobilities of these workers, who partake in a fly-in, fly-out pattern (Wilson 2017; A. Zwick 2018). Additionally, there has been 
attention to the boom and bust dynamics of oil and gas to characterize the long-term impacts to rural areas (Jacquet, Kay, and Ramsey 2014; Pothukuchi, Arrowsmith, and Lyon 2017).

Most prominent is the literature about the environmental and health risks from natural gas extraction. UOG development has raised individuals' concerns about human and environmental health impacts explicitly related to air pollution and water. There have been a few quantitative and spatial analysis studies conducted about water and environmental health impacts in the Marcellus Shale documenting chemical changes in well water and underground geology (Alawattegama et al. 2015; Darrah et al. 2014; Elliott et al. 2018; Vengosh et al. 2013). Studies indicate that there are increased health impacts from air pollution, and the residents report short term health impacts and concerns about long term health impacts (Abatsis McHenry 2017). Residents also report health impacts to their animals (Whitley 2019). Residents' experiences and knowledge around extractive industry have frequently been dismissed as lacking credibility or deemed anti-development and anti-science by scientists, legislators, and industry proponents particularly around women and children's health (Eisenberg, 2016; McHenry, 2017).

Following these emergent health concerns, social mobilization has also been a major focus of social science research. Across the US and the world, residents have mobilized against UOG development. Related specifically to water, the documentary Gasland has played a role in shaping the public's perceptions of UOG development's environmental impact and created space for mobilization and community formation especially through social media (Vasi et al., 2015). Unlike the focus of environmental justice literature, environmental controversies due to UOG are examined because they are occurring near populations that historically have not been affected by environmental disasters, providing a different entry point to explore impacts of uninvited environmental change in contexts where disempowerment is a new experience (Willow 2014). Privileged communities oppose natural gas extraction because they feel disempowered by the process but say that they could support fracking in rural areas if "landowners received full and accurate information to guide their decisions" (Willow, 2014, p. 247). This ambivalence, in which surface and mineral owners feel disempowered but willing to support extraction, have been themes in literature on natural gas extraction (Gullion, 2015). However, not all literature on UOG is about opposition. Jerolmack and Walker (2018) report on UOG support in Pennsylvania, 
analyzing the "quiet mobilization" of residents in close proximity to UOG development and arguing that close proximity does not necessarily produce opposition.

Geographic literature on UOG, which I have mentioned elsewhere and throughout this thesis, have focused on how gas extraction creates enclosures (Hesse et al. 2016), and distribution of environmental justice (Ogneva-Himmelberger and Huang 2015). While environmental justice has not been unequivocally determined around natural gas, scholars have analyzed how legal frameworks and spatial enclosure of minerals and property is producing space and enabling natural gas extraction (Hesse et al. 2016).

This subsection has briefly reviewed social science perspectives on UOG development to characterize the general conversations occurring around the social dimensions of natural gas extraction. This literature addresses the controversies around water by considering health impacts and social mobilizations. Now I turn toward literatures specifically about groundwater and household well water in the context of energy development.

\subsubsection{Water and unconventional extraction}

Water is a dynamic resource as both a source of life and sold as a commodity, as captured in the concept of waterscapes (Karpouzoglou and Vij 2017). Water has reproductive, spiritual and economic values. Accordingly, geographers and anthropologists have analyzed how knowledge around hydraulic fracturing and water is framed around exclusive conceptions of the value of water i.e. water as a resource for economic productivity versus the ecological value of clean water (Rijke 2018).

Finewood and Stroup (2012) suggest that UOG development causes residents to “internalize neoliberal strategies" (p. 74) pitting willing neighbors against neighbors unwilling to lease, and that water, land, and the home are rendered into exchangeable and interchangeable economic commodities. In this neoliberal socioeconomic context, the impacts of UOG development are normalized because individual landowners evaluate possible costs and benefits of participating in extraction, assuming the risks involved in selling and leasing their land and property (Malin and DeMaster 2016). In Pennsylvania and West Virginia, for example, water quality issues have been normalized due to the history of coal mining in which environmental qualities have been traded for economic gains (Poole and Hudgins 2014). UOG development presents a new context in which residents own the minerals that are leased for development and 
thus receive the benefits of mineral royalties, and must deal with environmental impacts to personal property (Malin and DeMaster 2016). Studies that focus on how residents must make neoliberal decisions do not consider split estates in which surface rights are separate from mineral rights. Mineral owners who lease their shale rights may not live near the extraction site and may never encounter the extraction processes.

Considering these different perspectives, social scientists have explored the ways in which industry representatives and residents frame the benefits, risks, and knowledge around UOG development (Hudgins 2014; Matz and Renfrew 2015). Industry representatives frame the benefits of UOG through future technoscientific promises and multi scalar impacts such as job creation, and the assertion that gas extraction is a safe, controlled risk (Andrews and McCarthy 2014; Cantoni et al. 2018). These promises are multi scalar because positive impacts are framed at every scale - local, regional, national - as well as across scales in multiple ways in which residents benefit from royalties in one place, and other residents experience better air quality from cleaner burning fuels in another place (Sica 2015). At the same time, ongoing scientific studies about how natural gas extraction impacts groundwater continues to assert that groundwater cannot be impacted because of the depth of the fractures, hence drinking water wells are safe (Harkness et al. 2017; U.S EPA 2016). Cantoni et al (2018) posit that these promises allow residents to become invested in the idea of economic prosperity through UOG development and believe that UOG extraction is progressively becoming safer through increasing extraction technologies.

Willow $(2014,2016 a)$ analyzes these conflictual claims about technological risks and safety to the environment as "competing subterranean waterscapes" (p. 174). Willow (2016a) describes the "truth" about risks to water and health as "less about 'objectivity' and more about the power to position one perspective as the accepted account", establishing what Foucault's (1980) would call "regimes of truth" in which some actors may position their perspective as legitimate and other perspectives as marginalized (p. 173). In her case study, water has new cultural importance under UOG development in Ohio, and she theorizes that water contamination replaces embodiment with alienation (Willow 2016a).

Despite the emergence of a field of social science about natural gas extraction, few articles address water governance around UOG development specifically. Moore et al. (2018) for instance focus on the role that water sampling data plays in water governance. Because of the 
uncertainty around environmental risk and outcome around UOG development, frequently researchers and residents alike call for more data. Moore et al. (2018) critique the call for more data as reifying objectivist positivist claims that given the "right" information, actors can make the right decisions. Often residents are represented as uninformed, with the "wrong" data, and that the correct information must be given to them (Hudgins 2014). Moore et al. (2018) critique privileging objectivist Western knowledge and solutions and suggest that instead scholars should be asking what data, what forms of governance, and who is responsible for and funding data collection. Whereas scientific data is typically framed as neutral, Moore et al. (2018) call for a politicization of scientific data collection to question who is funding the data collection and what are their goals.

Politicizing data collection also calls into question whether data collection is trusted by the public. Two articles about UOG development specifically mention the issue of trust. Moore et al. (2018) report that people's trust is shaped by who funds and controls data. Willow presents the concept of trust, saying that trust in a crucial component to Ohioans well-being (Willow 2016b). Her research shows that residents lose trust when they perceive being misled or misinformed by the UOG industry (Willow 2016b).

The first section of this chapter reviewed the dominant strands of social science inquiry into UOG development in which scholars have analyzed environmental and public heath, the neoliberal frameworks that UOG development thrives upon. The second section reviewed the literature about water to frame the contributes of this thesis. This literature analyzes how water is turned into a neoliberal commodity around natural gas extraction (Finewood and Stroup 2012), how water impacts wellbeing and one's "lifescape" (Willow 2016b) and how data collection about water should be seen as political and not neutral (Moore et al. 2018). Geographic perspectives on water and UOG development are needed to further elucidate how water, space, and social relations are produced around UOG development. This review demonstrates that discourses, experiences, power, and legal frameworks come together around water. This thesis contributes to these discussions by providing a case study through which to look at residents' experiences of water, social relations, legal frameworks and knowledge production around water. Additionally, this thesis will discuss groundwater which is different than surface water because of its relative inability to be seen and measured. A few of the articles reviewed argued that there is a contested domain of knowledge around groundwater (Melo Zurita and Munro 2019; 
Valencia and Carrillo Martinet 2017; Willow 2016a). Although this literature review has mentioned social mobilization, this topic is beyond the focus of this thesis. The following chapter will describe the methodology and research of this design, further explaining the focus of this research and thesis. 


\section{Chapter Four: Methodology}

This chapter describes how feminist epistemology and feminist theory have shaped this research's methodology by detailing how researcher positionality affects all aspects of the research project. Positionality has become a cornerstone of feminist research (England 1994) and is discussed in the second section of this chapter. The aim of this chapter to explore the notion of positionality within feminist geographic scholarship and to examine my own researcher positionality.

\section{1 Epistemology}

This research is positioned as a critique to the belief that more objective knowledge and better science communication will fix opposition to natural gas extraction (Choma, Hanoch, and Currie 2016; Moore et al. 2018). Feminist theorists have long questioned the assertions of scientific objectivity, instead insisting that all knowledge is partial and situated (Haraway 1988; Rose 1997). A feminist epistemology posits that no scientific research is purely objective, and has critiqued that only certain unmarked identities (i.e. white, male) have been given the status to claim objectivity (Haraway 1988; Longhurst 1995). It is the unmarked categories of whiteness that is normalized and given status of holding objectivity (Sundberg 2005). A key intervention of feminist theory and feminist geography is recognizing that all knowledge is partial and situated, particular and not disembodied, and informed by location, identity, and experience (Haraway, 1988; Mani, 1990). Feminist research considers how situated knowledges produce rigor by examining the social contexts that inform the research question. This practice of considering social contexts of research and social positioning of researchers is the process of reflexivity and examining positionality.

Lived experience has historically been important as feminist theorists and geographers centered "personal" and "private" life in their scholarship (Nelson and Seager 2005). In feminist theory, lived experience produces situated knowledges (Collins 2013). However, feminist theorists have also identified experiences as not purely objective. Scott (1992) urges us to think critically about the analytical usefulness of the concept of experience. She argues that experience is not a window into objectivity, absolute truth or "uncontestable evidence" (Scott 1992:24). Experiences are shaped and organized by politics and identity, and identities are historically produced (Scott, 1992). For feminist theorists, the risk of reifying the notion of fixed identities 
also emerges when scholars write about or represent others (Mani 1990; Mohanty 1984). Hence Scott (1992) argues for approaching identity and experience as being historically produced and in flux. Feminist geographers examine their own research through reflexively interrogating their own positionality (England 1994) as discussed in the following section.

\subsection{Positionality}

Within feminist epistemology, understanding the researcher's positionality is crucial for understanding power dynamics between researcher and participants, and to analyze what effect researcher positionality has on the research process and results (England 1994; Sharp and Dowler 2011). Positionality is a practice of identifying one's political and social position, often in terms of gender, race, age, socio-economic status, in order to understand how this social positioning impacts research methods and interpretation (England 1994; Moser 2008). Researchers, whether their approach is quantitative or qualitative, bring their own ideologies and experience to their research. Sharp and Dowler (2011) assert that the "field" itself is created by the researcher, and that research is always shaped by power dynamics particularly around knowledge production and participant representation. Stating one's positionality (such as race, gender, class, etc.) in a statement has become common in human geography, but this practice has been criticized for being uncritical and obligatory (Kohl and McCutcheon 2015). Instead, feminist theorists have sought models in which analysis of positionality is woven into the research presentation and analysis (Mani 1990).

Just as researchers do not produce a purely objective research product, research and research participants' perspectives do not reveal a purely objective reality. Research participants narrate their experiences in response to the research (Presser 2005). Hence, sometimes this process of participation and narration can be transformative to how participants view their situation, or a phenomenon. Arguably, feminist researchers value participants' knowledge and unequivocally accept research participant's knowledges (England 1994). However, at the same time, knowledges are co-created between researcher and participant (Presser, 2005).

Within this research, knowledge is co-created, as participants narrate their experiences to me and as I analyze and sort the research findings. Even though I continually return to interview transcripts, and have utilized practices intended to create analytical validity such as member checking and dissemination, this research has been informed by my interest in extractive industry 
and water following the 2014 chemical leak that occurred in West Virginia (e.g. Whelton et al., 2015). Although I want to acknowledge my investment in research on water in West Virginia, co-creation does not imply unreliable research. The 2014 chemical leak has shaped my interest and perspective on water because the leak was characterized by uncertainty, and residents' claims to embodied experiences and health concerns were dismissed (Bray 2017). Since the 2014 chemical leak, I have been interested in exploring other case studies in which industrial inputs and by-products impact upon water. To do so I have centered the notion of West Virginians' lived experience of water contamination.

Some analysts argue that perspectives on natural gas relate to individuals' political affiliation and their knowledge of objective science about extraction (Choma et al. 2016). However, I contend that how we view natural gas extraction is not merely predicted through these distanced notions of left and right politics and knowledge of science, but is also shaped by interactions and encounters with the process of natural gas extraction and encounters with other people (Vasi et al., 2015). Accordingly, through this research I have examined research participants' experiences with natural gas extraction, and I must also examine the social position I inhabit along with the perspectives and experiences I bring to this research.

When researchers examine positionality it is often by interrogating a predetermined set of identity categories that researchers embody, including race, gender, class, and nationality. These are categories that are important within this research. Additionally, I suggest that other categories of identity and difference emerge as salient categories that shape researcher-participant relations and reception of the research product. In the context of my research in which my race and nationality was similar or the same as the research participants, additional categories become salient. I think the strongest category that emerged had to do with pro- or anti-gas stance which I will elaborate on below.

In West Virginia I am both insider and outsider - a position that is fluid and shifting based on context (Smith, 2016). Insider/outsider positionality is not predictable and may change based on various factors like location (Elwood and Martin 2000), participants (Huisman 2008), and personality (Moser 2008). In a lot of ethnographic research being an outsider is typically seen as ideal because it implies that one can be more objective to the research subject if they are not "close" to it (Creswell 2014). This is problematic because it reifies a static insider/outsider dichotomy, as well as implying that research can be objective, and that only "outsiders" can be 
objective. The problem is that geographic research has often included white scholars traveling to "other" cultures to produce knowledge about them which reifies the idea that outsider research is better and more valid (Mohanty, 1984; Cook-Lynn, 2000; Khan, 2005). The insider category is seen ambivalently, because while insiders have access to research participants, insider research can be looked down up on 'backyard' research or biased research. Khan (2005) describes the burden of the "native informant" to speak "authentically" of their own culture.

This binary thinking does not represent the fluidity of insider/outsider relationships that play out in research. No one is strictly an insider or outsider as this category is always shifting in different contexts, with different research participants, and even within interactions with one individual. Interactions with individuals are not static, they can change from moment to moment (Moser, 2008). Additionally, insider/outsider categories cannot predict moments of connection or disconnection with individuals because interactions can depend on unknown commonalities or personalities (Moser 2008).

While being an insider can help leverage access to participants (e.g. Hall, 2014; Huisman, 2008), being an insider can also normalize parts of the research that would not be normalized to outsiders (Pratt 2012). My insider position, as someone living in West Virginia, risks normalizing how the state is reliant on extractive industries. Being from Charleston West Virginia, colloquially known as Chemical Valley, the density of chemical manufacturing plants and industrial sites in northwestern West Virginia is less surprising to me. On another level, being from an extractive mineral state, the idea of split estates in which surface rights are separated from mineral rights has been a legal framework I have been familiar with my whole life. This is not a disclaimer, but an exploration to unpack what the analytical consequences are of being an "insider". Part of the work of this research is to de-naturalize contexts like split estates that seem normal to me. At the same time, I am not an insider to rural West Virginia. Because natural gas infrastructure is relatively hidden from public view in West Virginia, first by existing in rural spaces and second by existing in hollers and on tops of hills, it has been surprising to me to see the industrialization of the rural landscape.

I have also defined my positionality as insider because I am from West Virginia, and because I often look like the research participants, meaning I am white in a predominately-white state. With the popularity of the memoir Hillbilly Elegy, and the 2016 US election of Donald Trump, stereotypes of West Virginia have coalesced around notions of a white, angry, working 
class population (Smith and Winders 2017; Vance 2016). Recent work has sought to broaden this image of Appalachia by exploring the cultural and political diversity of its inhabitants (Catte 2018). This research may not obviously answer the call to present a diverse Appalachia, but I have strived to at least present individuals who are more complicated than common depictions of Trump Country (Hoel 2016). Critical geographers have argued that race always matters, and that whiteness must be acknowledged in homogenously white spaces (Mollett and Faria 2013).

I was often frequently also an outsider because of my status as a graduate student at West Virginia University (WVU) and because I am not directly facing the issues with natural gas extraction like the research participants. Being an outsider can be advantageous, as many research participants wanted to tell me their story. My experience indicates that WVU is generally well liked by West Virginians, but in relation to UOG development, WVU can be perceived as being pro-industry and unsupportive to environmentalist and/or marginalized communities because of energy related research the university funds and produces (e.g. Carter et al., 2017). As Cramer's (2016) work suggests, rural residents may harbor resentment towards urban residents. In the context of West Virginia, Morgantown is urban as it has the fourth largest population although the temporary student population doubles the usual population size. During research, my affiliation with WVU positioned me as potentially both anti- and pro-development, depending on the context, participant, and audience. As this topic - natural gas extraction and specifically groundwater impacts - is particularly contentious and polarized, I often had to explain my position as a WVU researcher. My aim throughout the research process was to communicate that I am neither strictly anti or pro development. My positioning had to be discussed with participants frequently, by discussing both critical human geography research methodology, and discussing the abstract and funding sources.

While researching a polarizing topic, the goal of this project was to engage with people across the range of perspectives and hence engage with individuals that are proponents for, activists against, and individuals ambivalent to natural gas extraction in West Virginia. Although many West Virginians were willing to participate in this research, engaging with "all sides" required negotiating and explaining my position as researcher. On the one hand it could be difficult to engage with some natural gas extraction proponents because it was assumed that a university researcher asking about the social dimensions of extraction would have a critical and/or activist stance. 
On the other hand, because the West Virginia Energy Institute funded the study, it could be difficult to engage with activists and concerned citizens who did not see the project nor me as activist enough. The point of the project was to engage multiple perspectives and hence the project was not defined as either pro nor against, and it was not defined as an activist project. The contentious nature of the project required negotiation and building rapport, because for some participants this was a personal and sensitive subject to talk about. Kirsch (2005) writes about the politics of closeness and argues that although rapport is seen as positive in qualitative research, closeness with participants does not protect them from feelings of disappointment or exploitation.

Some residents who were activists against the natural gas industry saw me as potentially representing the gas companies and hence would not talk with me or would cancel their appointments with me. Others were a bit skeptical of the project but were willing to be interviewed and were willing to engage in a discussion about the aims of the project more deeply. In all, I feel that this work of negotiation allowed me to create rapport with the research participants. I some cases, residents who were more ambivalent appeared more comfortable with this work and were willing and enthusiastic about participating and were interested in the results.

The politics of trying to conduct research that engages participants across perspectives and experiences, and also create a non-polarizing research report, has meant trying to ensure access to multiple perspectives (while certainly closing off some) and presenting the research to multiple audiences. Although I find this approach productive and interesting, I also have felt critical of myself for striving for some notion of 'balance'. Researchers seek to understand and represent activist communities because those are often communities that are marginalized. My interest in water and the burdens of contaminated water are undeniable. Still I attempted to emphasize that I was not representing a pro-gas stance or group, nor was I only interested in the activist perspectives. With this researched I wanted to understand the less certain and more ambivalent perspectives of residents who may not identify as activist but who are faced with environmental issues. The creation of non-polarizing report is not making a claim for my own objectivity, but it has been a way to navigate myself around potential suspicions about my work. 


\section{$\underline{4.3 \text { Methods }}$}

Qualitative methods are appropriate for exploring the contextual, in-depth and personal aspects of the research questions. Qualitative methods are better suited for interpretive analysis, as opposed to quantitative methods which are better suited for broad theoretical generalization, deductive analysis, and spatial analysis (Flick 2011). To answer the research questions, it is essential to create rapport and establish relationships with research participants because understanding stakeholders' perspectives require storytelling and engagement that could not be elicited through more distanced method such as surveys.

\subsubsection{Case Study: West Virginia}

A case study approach is used in qualitative research to focus in-depth on a particular phenomenon, as compared to qualitative or quantitative research designed at broad theoretical generalization (Mabry 2008). A case study approach is hence appropriate for studying UOG development's impact on water quality in West Virginia. This section describes how scholars have theorized West Virginia's extractive history and its social and environmental consequences, highlight a few aspects specifically about water quality in West Virginia, and give background on UOG development in West Virginia.

West Virginia is the only state fully located within Appalachia. Historians have argued that the Appalachia is not a distinct regional, social or cultural region, and as such is a creation by outsiders (Batteau 1990). Appalachia has repeatedly garnered national attention, notably in the 1960's when the nation discovered Appalachia's poverty (Portelli 1984), and in 2016 when the media fixated on avid supporters of the coal industry and presidential candidate Donald Trump in West Virginia (McGreal, 2017).

Scholars have commonly referred to Appalachia as an internal colony or periphery to the US, singling out absentee ownership and the extraction of capital for outside interests as the reasons for the regions' environmental, economic, and social problems (Fox 1999; Lewis et al. 1978). The history of West Virginia and its water is shaped by extraction of coal, timber, gas, and salt (Fox 1999; Hufford 2007). The internal colony or internal periphery theorization of Appalachia seeks to explain how east coast companies invested in Appalachian land in the $19^{\text {th }}$ century, how the land has stayed primarily absentee ownership, and how the land was then leased to coal companies for mineral extraction (Fox 1999; Scott 2009). Understanding 
Appalachia in this way posits that outside capital investment, absentee ownership and natural resource extraction have generated environmental and economic problems in Appalachia (Lewis, Johnson, \& Askin, 1978). The internal colony critique illuminates the role of capital in the exploitation of the region, politically aligning the plight of Appalachia with more established critiques of the core/periphery or critiques of neocolonialism.

\section{Unconventional development in West Virginia}

Most recently, the economic decline of coal mining in Appalachia combined with the need for a cleaner burning fuel and the creation of technology to extract shale gas has led to investment in natural gas extraction of the Marcellus Shale in Appalachia. Appalachia has three shale gas "fields": Marcellus, Utica, and Rogersville. Marcellus leasing and drilling started in 2008. The Marcellus shale is desirable because it is predictable; the various products -- wet gas, dry gas, and natural gas liquid solids -- are distributed predictably with wet gas concentrated near large river bodies like the Ohio River (McKeen et al. 2018). The Utica has less predictable distribution of gas products, and it is deeper than the Marcellus, making it less attractive to natural gas companies -- for now (McKeen et al., 2018). However, test Utica wells drilled in West Virginia have shown gas production much larger than Marcellus wells (personal communications). Marcellus shale produces nearly $40 \%$ of US shale gas (Sangaramoorthy et al., 2016) and EIA estimates that Appalachia produces 31,602 million cubic feet of gas per day as of March 2019 (US EIA 2019).

West Virginia's northwestern counties have the biggest UOG development footprint (Figure 5). The approximate number of active wells per county in the counties where this research took place is: Marshall, 110; Doddridge, 613; Harrison, 355; Kanawha, 30; Marion, 105; Monongalia, 69; Ritchie, 255; Tyler, 292; Upshur, 130; and Wetzel, 622 (WVDEP 2019). Like much of West Virginia, these northwestern counties have low population density and are classified as rural (US Census 2010). In particular, this region is characterized by its economic connection to the chemical industry along the Ohio River Valley, as well as a landscape of mixed hardwood and pasture farming (Roberts 2013).

The scope of UOG development of the Marcellus Shale extends beyond Appalachia. The hydraulic fracturing supply chain extends beyond Appalachia and the immediate drilling areas, requiring massive inputs of frac-sand mined in Wisconsin, and chemical inputs and water 
(Pothukuchi et al., 2017; Willow and Wylie, 2014). Typically, drilling, fracturing, and well pad development relies on a migrating labor force, not from outside of the US, but short term, skilled labor is typically sourced from outside of the actual county being developed (Mchenry-Sorber et al. 2016). These migrant workers set up temporary RV housing called "man camps", often moving from place to place following the work (Komarek and Cseh 2017; Mchenry-Sorber et al. 2016).

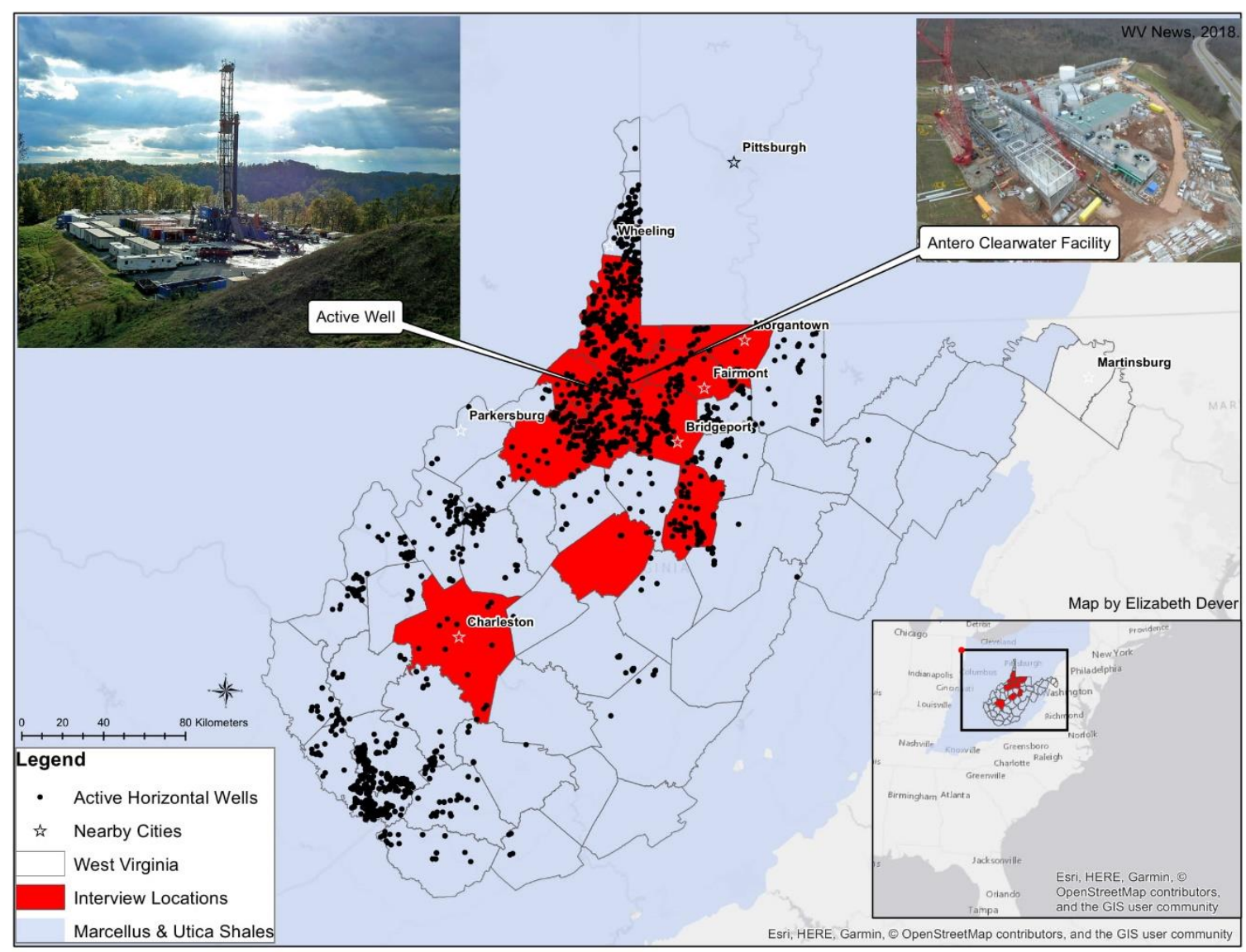

Figure 5. Map of West Virginia by Elizabeth Dever depicting locations of active horizontal wells, nearby cities, and interview locations within the Marcellus and Utica shale.

Abundant labor supply paired with neoliberal policies, and a general trend in the mechanization of jobs, has allowed for companies to transition their workforce to "secondary sector firms" in which the jobs are unskilled, low paid, and less "desirable" (Schwartzman 2013:154). The jobs that are available to locals in counties with hydraulic fracturing are typically 
jobs that fall into the "secondary sector" category. These jobs include road traffic workers and brine truck drivers. But locals do take up these jobs (Mchenry-Sorber et al. 2016). The narrative that UOG development creates jobs is not untrue, but it does not describe what kinds of jobs are available, where and for whom. Oil and gas development create a supply chain/hierarchy of jobs that includes low wage jobs, migrant and skilled labor, and executive and legal positions in urban centers such as Pittsburgh, PA.

UOG development is seen not only as a public good on the national scale but in West Virginia, a state that is historically poor because of the decline of the coal industry (Partridge, Betz, \& Lobao, 2013). News outlets also represents the possibility for poverty alleviation because of natural gas royalties, the creation of new jobs, and an increased number of workers and residents in areas with historically declining populations (Banks 2018; Boettner 2018).

Natural gas extraction is possible because of the legal separation of mineral and surface rights (Ryder and Hall 2016). In West Virginia surface and mineral rights are severed because of the state's long history with coal and other extractive industries, and hence are leased separately (Ryder \& Hall, 2016; Sangaramoorthy et al., 2016). Mineral owners lease their mineral rights to receive a royalty on the gas produced or landowners lease their land for well pad development. Residents must frequently negotiate with contracted land men, oil and gas companies, and lawyers over leases and agreements for use of their private property.

The northwestern counties have a long history of conventional oil and gas extraction, dating back to the $19^{\text {th }}$ century (West Virginia Geological and Economic Survey 2004). Individuals who signed leases at the beginning of the Marcellus development around 2008, were not necessarily aware of the new style of unconventional development, thinking they were signing a lease for conventional oil and gas extraction. Unconventional development includes a larger well pad development and increased extraction of gas because of deeper vertical wells (56k feet deep) and horizontal drilling up to two miles (Kondash, Lauer, \& Vengosh, 2018; Lave \& Lutz, 2016).

Well pad development has been controversial in West Virginia because well pads have been built in close proximity to homes (figure 6) (Shaw and Mishkin 2019). Living near a well pad entails increased light, noise, and traffic disturbances during the construction of the well pads, during drilling and fracturing. Less disturbance occurs after drilling and fracturing are complete, but individuals must still visit the well pad daily for upkeep and monitoring. 


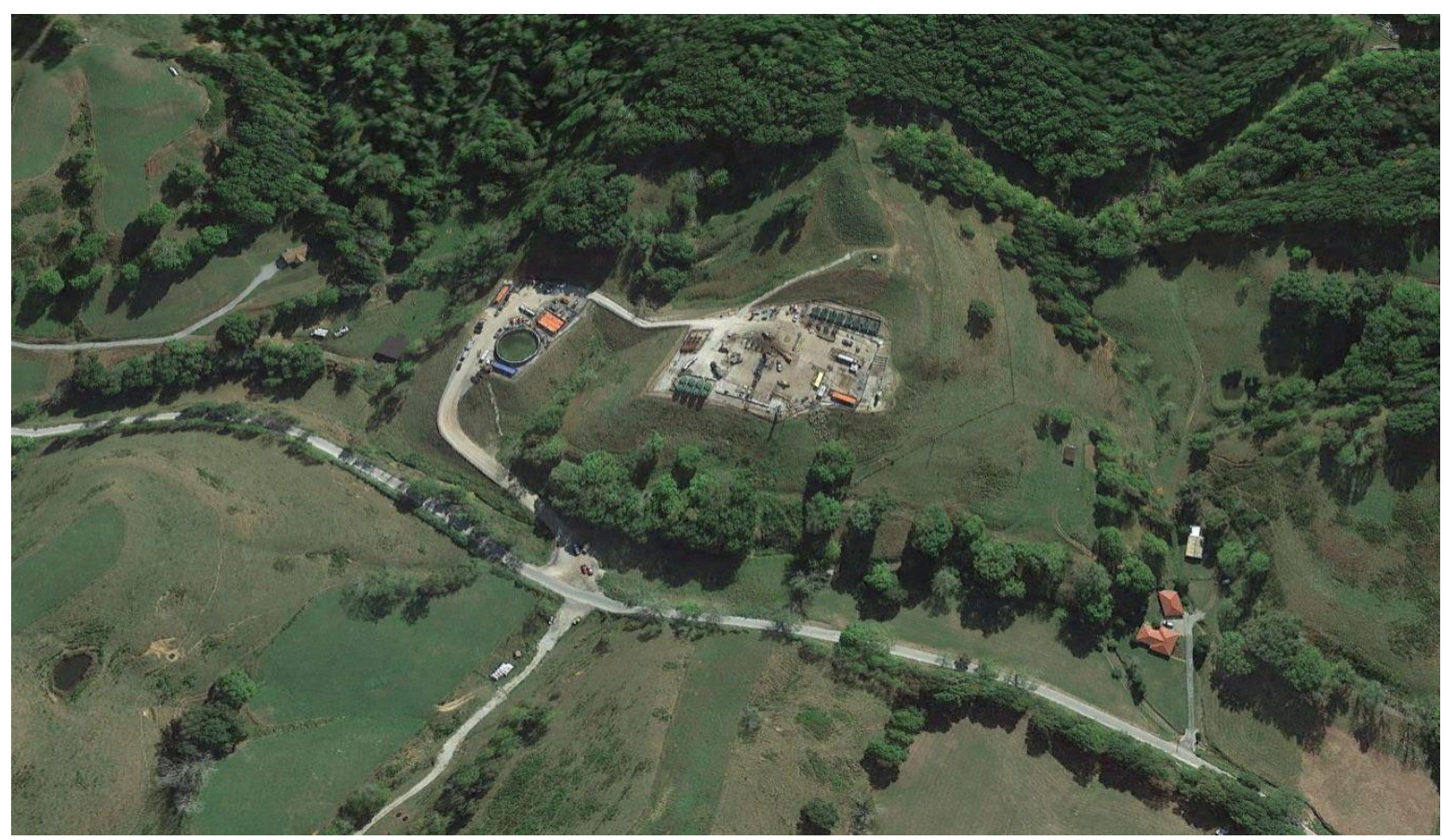

Figure 6. Well pad proximity to houses in northwestern West Virginia. In this photo, the well pad is approximately 650 feet from the house on the left, and 750 feet from the house on the right. Google Earth. June 2, 2019.

\section{$\underline{\text { WV Extraction and Water quality }}$}

The extraction of coal, timber, and natural gas has shaped the social and environmental history of West Virginia and its water resources. Deforestation for timber harvest in the early 1900s resulted in massive topsoil runoff into rivers and streams, and later, the transition from underground coal mining to surface and mountaintop mining has resulted in abandoned underground mines which have filled with water, seeping acid mine drainage into waterways (Fox, 1999).

Water usage related to UOG development is often considered an issue of water scarcity in arid environments, however in wet environments like West Virginia, water quality is a concern around UOG. No studies confirm that groundwater in West Virginia has been systematically contaminated by hydraulic fracturing, but storage and transportation of produced water (brine, chemicals, and water resulting from fracking) has impacted surface and groundwaters because of 
spills and truck accidents (Harkness et al. 2017). As previously mentioned, groundwater is immediately salient in West Virginia as estimates by the Water Use Section of the West Virginia Department of Environmental Protection (WVDEP), there is about 150 thousand residents relying on groundwater in the eight northwestern counties this research was based in (WVDEP 2013). Adding to this context, across the US, groundwater is historically unregulated (Ternes 2018). Although the question of whether drilling and hydraulic fracturing is systemically impacting groundwater is still being debated, it is known that the storage and disposal of wastewater presents risks to groundwater. In a recent report by the Natural Resources Defense Council, it was found that the WVDEP has failed to adhere to the Safe Drinking Water Act's Underground Injection Control program requirements for injecting wastewater into storage wells in West Virginia by injecting wastewater under expired permits and into abandoned unplugged wells (Treiger and Monk 2019). Other forms of wastewater such as runoff and leachate from landfills holding toxic drill cuttings, have been managed by municipal water treatment facilities, or discharged into streams (Hopey and Templeton 2019).

UOG development in West Virginia should be understood as part of the state's history of and resistance to extractive industry. Since the 1970's women have led resistance to coal mining because of health and environmental concerns (Maggard 1999). Environmental groups continue to work in West Virginia for post-mining environmental remediation (O’Brien 2017), protecting drinking water from chemical dumping (Ward 2017; Whelton et al. 2015), and against pipeline construction impacts on water quality (Sainato 2018). The 2014 Elk River chemical leak galvanized public efforts to protect streams and drinking water (WV Free 2014). After the 2014 chemical leak, the WV legislature passed SB 373 known as the Tank Bill, which require the monitoring of above ground chemical storage tanks. However, the bill was only in place for one year before being dismantled, and oil and gas development was not subject to regulations (Hoback 2017). The legislative and regulatory environment of UOG in West Virginia mirrors US policies that exempt UOG development from clean water and chemical disclosure regulations (Abatsis McHenry 2017; Willow and Wylie 2014) and the US 2005 Energy Policy Act allows for the chemicals used for hydraulic fracturing to be proprietary (Willow and Keefer 2015). 


\subsubsection{Interviews}

The data for this thesis was collected through 30 semi-structured in-depth interviews conducted between April and July of 2018 with stakeholders in eight WV counties: Marshall, Wetzel, Ritchie, Doddridge, Tyler, Harrison, Monongalia and Marion (Figure 7). In geography, semi-structured interviews have been championed for their effectiveness of exploring environmental risk (Baxter and Eyles 1999; Sultana 2009). In-depth interviewing, versus other modes of assessing risk via econometric and psychometric studies, focuses on individuals and communities, not just the nature of particular hazards (Baxter and Eyles 1999).

I interviewed individuals from different stakeholder groups including concerned citizens, and surface and mineral owners who have had direct experience with oil and gas companies (Figure 8). Concerned citizens are individuals affiliated with a local interest or watershed group, however some are not affiliated with a group and do their advocacy work individually. Concerned citizens do not necessarily have development on their property but are impacted by development close to where they live. Many watershed groups work specifically on water issues around UOG development, but not all watershed groups identify as anti-oil and gas development.

Surface and mineral owners have different concerns associated with UOG development. Mineral owners receive royalties from the produced gas but may not have surface development, while surface owners may have well pads or other infrastructure development on their property hence experiencing environmental disturbances due to development. These are not distinct groups, and occasionally individuals are both surface and mineral owners, and/or are part of concerned citizens groups. The first goal of the sampling used for this research was to interview different stakeholders. The second goal of sampling was to interview residents with groundwater to understand perspectives on household groundwater contamination risks in areas close to UOG infrastructure development.

Because of the overlapping categories, I will primarily refer to research participants as residents, and specify when they are surface and mineral owners, concern citizens, or part of an organization when necessary to do so. Research participants represented a range of support and opposition to UOG development. Often support and opposition were more complicated that a simple dichotomy and frequently participants voiced both concern and support for aspects of UOG development. "Mobile interviews" (Evans and Jones 2011) were an important method in this research and have contributed to creating rapport and connections with participants by 
spending time traveling around participants' communities with them. Driving and walking created time for participants to show me their surroundings and allowed me to ask more incisive questions than if I had not seen the development landscape.

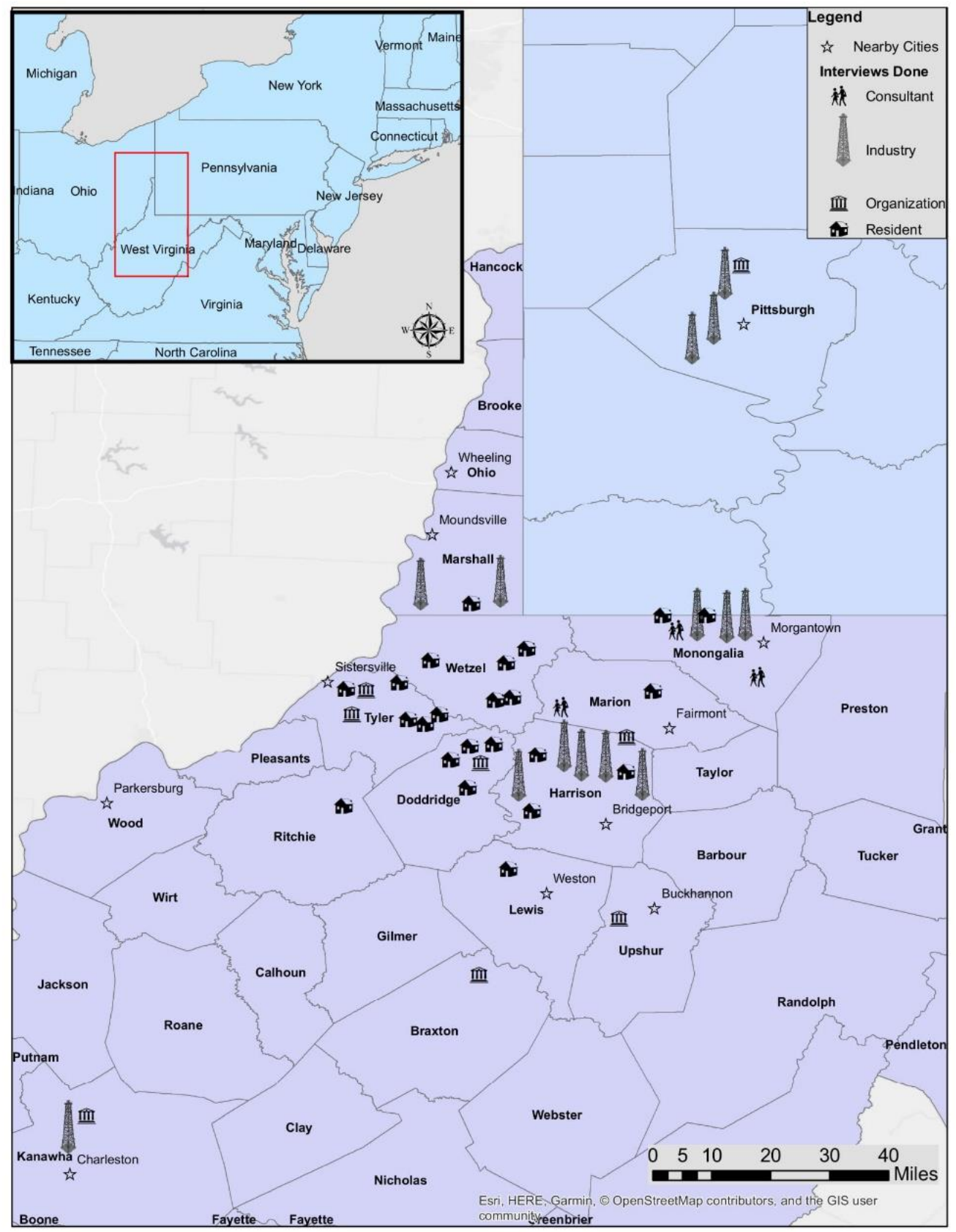

Figure 7. Map depicting distribution and categories of stakeholders interviewed. Map by Elizabeth Dever 


\begin{tabular}{|c|c|c|}
\hline Per County: & Wetzel Co & 7 \\
\hline & Tyler Co & 8 \\
\hline & Harrison Co & 3 \\
\hline & Doddridge Co & 5 \\
\hline & Monongalia Co & 4 \\
\hline & Upshur, Ritchie, Marshall, Braxton, Kanawha, Marion, Lewis & 1 each \\
\hline Per Stakeholder & Residents & 24 \\
\hline Category: & & \\
\hline & Organizations $^{1}$ & 9 \\
\hline & Consultants & 1 \\
\hline 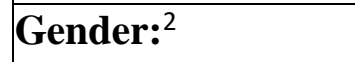 & Women & 12 \\
\hline & Men & 26 \\
\hline Rights ownership: & Surface owner & 14 \\
\hline & Mineral and surface owner & 10 \\
\hline $\begin{array}{l}\text { Household water } \\
\text { source: }\end{array}$ & Ground water wells & 22 \\
\hline & Municipal water & 12 \\
\hline
\end{tabular}

Figure 8. Breakdown of stakeholders interviewed by county, organization and gender.

\footnotetext{
${ }^{1}$ Examples: WV Surface Owners Rights Org, WV Royalty Owners Association, Farm Bureau, County Commissioners

${ }^{2}$ Sum of women and men interviewed exceeds total interviews because for some households both partners were interviewed.
} 
The most important facet of this research has been creating rapport. I have met with individuals prior to interviewing them, I have been given driving tours of their counties, and met participants for lunch. I have participated in public meetings and returned to disseminate preliminary results and ask for feedback. Within the constraints of living in Morgantown and commuting to disparate research locations, I have aimed to create trusting and transparent relationships with participants. I will also discuss rapport in the section about member checking and dissemination.

\subsubsection{Member-checking and dissemination}

I carried out two member-checking sessions with the help of Dr. Martina Angela Caretta (Figure 9). Member checking data analysis and dissemination of research results is part of feminist epistemology (Caretta, 2015; England, 1994). It has been argued that these methods increase participation in the study, and they begin to invert extractive research practices in which the researcher asks for data and then does not return to the community to share results (Caretta, 2015).
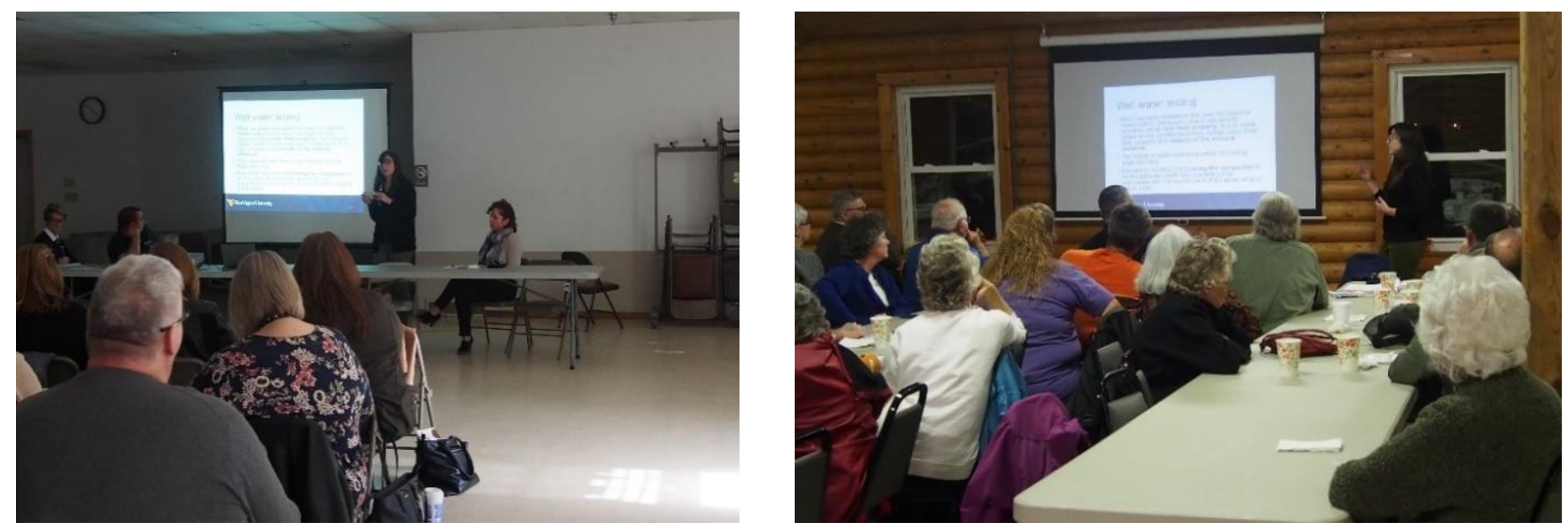

Figure 9. Public dissemination and member checking of preliminary results. Photo (Left) by Elizabeth Dever taken on Oct 19, 2018, and (Right) by Martina Angela Caretta on Oct 23, 2018

Typically, member checking is carried out as a method of transactional validity to validate the data and preliminary analysis with input from participants (Caretta, 2015). The advantages of this method include the opportunity to collect more data from participants as they 
respond to the preliminary analysis, and to both validate or conversely complicate the preliminary analysis of the data. Disagreement does not automatically invalidate the analysis but can further elucidate the social context (Caretta 2015).

In addition to the shifting connections with participants discussed in the section on positionality, the research report can also be interpreted different in different contexts (e.g. Mani, 1990). Mani's (1990) work is a reminder that positionality, and the politics of location, remain at work beyond fieldwork and remain into research dissemination. Put another way, the "field" in fieldwork is not just where researchers interact with research participant, but there is a "second site ... where my research will be read" (Khan 2005: 2023).

I wrote two preliminary analyses, one that looked at participants' perspectives on UOG, environmental regulation and policy, and another about participants' experiences of water contamination. Then we used this preliminary analysis to carry out two member-checking and dissemination sessions. The preliminary analysis was comprised of short summary of the research on the topics that included environmental regulation, road repairs, and water contamination. Additional to the research analysis, the dissemination materials included historical background information on West Virginia's environmental and roads related policy that was researched by colleagues at the WVU Law school. The first member checking session was conducted at a public meeting that was mostly comprised of industry representatives and emergency management officials. The second session was carried out with a group comprised of surface and mineral owners. This thesis will also be distributed to research participants upon completion.

Dissemination is not an event, it is a process intended to promote participation in the research (Caretta and Cheptum 2019). Accordingly, we combined dissemination and member checking by presenting a preliminary analysis and asking research participants and the other audience members to comment on the analysis. Member checking is more successful when there is rapport between the researcher and participants (Caretta 2018). The member checking and dissemination that I carried out for this research had mixed levels of engagement because of different levels of rapport and connection with the participating audiences. Industry representatives barely engaged at all with our attempts at member checking. The second session included a mixture of research participants and additional audience members who engaged with the member checking and expressed agreement about our analysis about water. 


\subsubsection{Data Analysis}

My colleague Elizabeth Dever and I transcribed all the interviews during summer 2018. Transcriptions were provided to the interviewees, so they could correct and/or redact information from the transcript. A few transcripts were returned to correct details and most corrections were to redact names. In fall 2018, the transcriptions were analyzed using computer based qualitative analysis software NVivo 12. Qualitative coding was conducted to sort and condense the data. For first cycle coding, I used provisional coding (Saldaña 2009) which entailed coding for particular themes I wanted to analyze in the data. For a preliminary analysis, I coded for themes: state and environmental regulation, West Virginia Department of Environmental Protection, road traffic and safety, and baseline water testing. Then I analyzed thematic commonalities across stakeholder groups (resident, organization, industry, and consultant). With this analysis, I prepared a written summary of the research that was then used for dissemination and member checking. Then, to further analyze the data about water, I returned to coding to pull out every instance where participants discussed water.

\subsubsection{Limitations}

One limitation that presented itself during research was the amount of research participants that had experienced household well water contamination themselves. I routinely tried to connect with more individuals that had experienced well water contamination in their homes but ran into a few road blocks. For one, rural West Virginia's population is aging (Christiadi, Deskins, and Lego 2014) and some residents were not up for an interview. Second, non-disclosure agreements are used by UOG companies after water contamination occurs, making it impossible to talk to people with first-hand experiences (Vasi et al., 2015). Additionally, because water contamination causes a house to lose its value, some households that experienced water contamination have moved away, so they would not be available for interview. Hence, this research analysis is shaped by the 'missing bodies' as much as it is shaped by the research participants. A silence is created by those individuals who have non-disclosure agreements, those who have moved away because of water contamination and individuals who chose not to participate because of my positionality. Lastly, UOG development is part of a larger "supply chain" that is geographically diffuse, hence it is difficult to address all aspects of this complex industry (Rijke 2018). Additionally, pipeline construction presents an emergent and 
timely issue related to UOG development that is currently occurring in West Virginia. Impacts of pipeline construction was beyond the scope of this project. More research will be needed to explore all the facets of UOG development in West Virginia. 


\section{Chapter Five: Household groundwater impacts due to natural gas extraction}

Residents, organizations, and consultants all discussed well water, surface water, and water infrastructure related to UOG development. Stakeholders debate and contest causes and even the existence of water contamination. All interviewees are aware of these contested narratives: they reference water contamination as a potential risk that is widely denied, or they mention that opponents to UOG development are apprehensive about water contamination. It is a ubiquitous concern and debate. This chapter presents research findings related to water. Section 5.1 covers findings about how residents are affected by well water contamination. Then, section 5.2 considers the interactions between company representatives and residents, the role of baseline water testing, and the context of water contamination in West Virginia.

\subsection{Impacts of water contamination}

Overall environmental and community impacts of natural gas extraction extend beyond water. The development of infrastructure for natural gas extraction (well pads, compressor stations, pipelines, etc.) changes landscapes and neighborhoods by increasing truck traffic, which produces environmental impacts such as increased dust on non-paved roads, and damaging road infrastructure. The need for outside workers drilling, hydraulic fracturing, and pipeline construction has the effect of increasing rural populations, leading to temporary housing of transient workers, and often increased housing costs (see Mchenry-Sorber et al., 2016; Hirsch et al., 2017), although sometimes rural residents can profit by renting out their homes. Additionally, residents discuss increased noise and light pollution, which cause psychological stress, due to well pad and compressor station implementation (See Hirsch et al., 2017; Jerolmack and Berman, 2019; Sangaramoorthy, 2019). All these environmental and community impacts were reflected in the research findings; however, it is beyond the scope of this thesis to address all of them. Issues related to water were ubiquitous in this research and amongst these broader impacts, water contamination emerged as a contested and controversial subject around natural gas extraction.

\section{Health concerns}

Many residents expressed worry about potential well water contamination. A fraction of residents interviewed were experiencing documented water contamination from drilling and hydraulic fracturing. However, water contamination is hard to define. Water contamination can 
include e. coli, hydraulic fracturing fluids, or sedimentary brines. Some residents suspect water contamination, based on perceived water changes, without explicit confirmation of chemicals entering their water. Sometimes water is contaminated for a period of time, and then it returns to being safe. The term water contamination can be a bit vague, but in general water is contaminated when residents find elevated levels of chemicals or unsafe contaminants in their well water when they are testing pre and post drilling.

Residents' concerns about their water centered on the long-term effects from use and contact with contaminated water. Even when potable water is available for drinking and cooking, bottled water does not easily accommodate other household usages such as bathing, that present equal or increased risks for the household.

Showering in it is probably worse than drinking it because the steam and stuff gets into your pores, the fact that we drank that water and all for 6 months, our chances of getting cancer or something increased... [Resident \#5, June 6, 2018]

I've been in WV all my life, so this is where my support system is, as I'm aging, I think I want to go south. But I just absolutely love it in my hollow. I'm afraid to stay here long term, I'm sure you hear that from other people. Those of us who knows what's happening, this is not where you want to live out your days. That was always my plan, was to live out my days here. Probably won't happen. I worry about my water, I worry about my air. [Resident \#23, July 27, 2018]

Worries about long-term health impacts extend beyond the immediate family, as interviewees also mention neighbors and workers that encountered water with fracturing chemicals and produced water at work via storage ponds, cleanup of fluids, transportation, etc.

I am afraid over time in 30,40,50 years when there are more health problems as a result of this... they had drained the water out of the frack pond and were in the process of cleaning up the sludge... which you know was radioactive, before they could take the liner out. And these kids... 20-year-old kids probably... They took off their respirators and 
pulled their hazmat suits down and tied them around their waist took their gloves off and they are there with their hands scooping this stuff up. [Resident \#1, May 18, 2018]

In the instance highlighted above, the UOG company was storing produced water (water that comes back up from the well that contains chemicals, sand, and brine) in a lined pit beside the well pad. Currently, it is unlikely that the West Virginia DEP would approve a permit for a pit or impoundments for hydraulic fracturing flowback fluids, due to instances such as the one above, as well as studies showing that in West Virginia impoundments are likely to be improperly constructed and that impoundments are the cause of nearly half of the documented cases of water contamination in Pennsylvania (Troutman 2019). This particular pond liner had ripped and produced water soaked into the ground, affecting the household's well water. In this example, the interviewee sees contaminated water as a risk for workers whose work is to clean up contaminated waters, and how these encounters may lead to health problems that do not present themselves until later in life.

Remediation: water buffalos and obtaining water

This research started out focused on water contamination and water quality around hydraulic fracturing, but interviewees also discussed losing water quantity, saying that their water wells went dry.

When this first started, people would come home from work and their well would just be disconnected from their house. Nothing would be said, no sign, no discussion, just disconnected. That's just somebody doing the right thing, not the company doing it. Somebody working there knew, and just unplugged them from their well. So you come home from work and you just don't have any water. Then a water buffalo shows up in your yard temporarily. I know people whose wells are dry. If when they frack it cracked the bottom of their well, the water came out of it and there's just no water in your well anymore. You just don't have any water. Well you can't live on a piece of land that don't have any water.

[Resident \#23, July 27, 2018] 
I lost a well in this house and I lost a well in that house. I'm not going to say it was fracking. And my neighbor. He's not willing to say yet. He contacted channel 9 about his. I didn't go that far with mine. Hopefully here in a couple months I'll know something more about that one... I'm always testing wells. Most of the time, the water in this house I use for back up. I am on city water here too. We wash vehicles, you got to keep using them, so they keep working. One day I was washing vehicles and it never come back on. [Resident \#20, July 13, 2018]

Whether a well is dry, or contaminated, another issue expressed was the burden of collecting clean water for oneself and one's household when clean water is no longer available from the well. To remediate the situation, an oil and gas company may offer a water delivery service, use a water pipeline to deliver water, or to install water treatment in the home. Individuals with water filtration systems report that the systems are expensive to maintain, and it is too costly to purchase themselves.

Potable water can be stored near homes using water buffalos. While the water buffalo provides a mechanism to supply water to the home, the company to continue to fill the water buffalo indefinitely. Otherwise, individuals must take the water buffalo to a municipal source themselves. Filtrations systems are also used to filter, vent or purify contaminated water.

Supposed to put a filtration system in but then we have to maintenance and keep it up, and if it goes bad it's all on us to do that, which we didn't have that problem before. Then, they want to give you a small amount of money, hush money basically, because they don't want it leaked out anywhere that they've had to do this because the news and everybody has had the impression that this oil and gas does nothing to the environment, there's nothing bad that ever happens... That's our problem, they're wanting to test it [the filtration system] one time to show that it works, but would you actually feel safe drinking water that has arsenic and stuff in it, 6 months from now not wondering if the systems actually working, because after they put it in and test it, they want to walk away, they're done.

[Resident \#5, June 6, 2018] 
West Virginia counties with urban centers have homes with municipal water, however well water is common in rural West Virginia. Some interviewees frame well water as "free" water, unlike municipal water that comes with a monthly bill. At the same time, municipal water represents freedom from some of the hazards of oil and gas development. A few interviewees with contaminated well water reported a desire to be on municipal water, because municipal water would "fix" their problem, allowing them to have drinkable and usable water at their homes. However, many rural West Virginians are not on municipal water and it would take infrastructure development to extend water to their remote homes. Residents reported that cities and counties do not want to take on this financial investment to build out water pipes to rural homes. Interviewees argue that reluctance to invest in water infrastructure is unacceptable considering county income increases because of natural gas revenue.

We would love to have city water. But it's been going on for, since before they started drilling in here. There's a discrepancy of who's, should have this area... Clarksburg says that it's not their responsibility over here. Wallace district ... they've came the other way and we're one road in between two roads, and neither one of them want to have the expense. [Resident \#5, June 6, 2018]

Connecting to municipal water is a potential solution for remediating groundwater impacts, however, rural homes in the northwestern counties are located miles away from municipal water sources and local governments would have to finance building out water pipes to remote rural homes.

\section{Property value}

Many residents stated that they invested their retirement savings into their home and that they planned to spend their retirement in a rural setting. Interviewees, specifically surface owners, discussed how impacted well water diminishes the value of one's home and makes it unsellable.

The appraiser said a house without water is not worth anything. So for example if the house is appraised at 350,000 dollars, it's only value is the ground it's sitting on...we lost 350,000 dollars... There is no bank that will loan money on a house with a tainted well, 
we've already checked it out. If you say, I love this house I love this view, yes, I'll buy it. I'll tell you can have it for \$1.98. The bank will not loan you that \$1.98. Now if you really loved it and came in with cash, then yay. But I would have to under West Virginia law I would have to give you notice that well the ground water is contaminated. [Resident \#1, May 18, 2018]

The greatest concern I have is we spent the last 10 years of our life building this property and our retirement home here and to have, my greatest concern was that there be a pump station going 24/7 and being next to the railroad tracks with the train there sitting on constant... Or the fact that if our water goes bad, there goes the value of our house. We put money into this with the idea that it would increase in value so that when we went to sell it, it would make a profit, we could enjoy the house. Yeah but if the water goes who wants to buy it? If there's a well site over there who wants to buy it? Coming in, we want to say its rural, its quiet, its peaceful, you know, people drive in from Pittsburgh or that, they're going to go passed all that oil and gas stuff and they're going to say we made a wrong decision. Like Al said, if there's a station right here - so to me its going to affect, it probably has, small local businesses, its wiping them out. Wild wonderful WV? No way. Its toxic and terrible... As far as impacts of the industry, the main concern is everything's so secretive, so you don't know what's going to happen. And having poured our - we 've done a lot of the work on this place ourselves, finishing it and looking that this would be our retirement place. Poured a lot into and the concern over what's going to happen and how its going to affect us and what's going to happen to the water. Those worries.

[Resident \#15, July 11, 2018]

They worry about losing their investment and wonder who would want to buy their homes if they decided to sell and move. The stakes are high for homeowner's investment, and so even potential well water contamination causes worry for homeowners near UOG development. This section reflects surface owners' perspectives on well water contamination that they experienced, and perceived risks of well water contamination. 


\section{Debates about impacts to water and environmentalism}

As previously mentioned, most interviewees have not had direct experience with documented household well water contamination in their homes, however narratives and debates around water quality in West Virginia due to UOG development were ubiquitous in interviews. Interviewees discussed the context shaping how residents interpret UOG development's impact on groundwater.

Farmers that were interviewed, who are both surface and mineral owners, were interested in promoting oil and gas development, if the development was not harming the environment. Their stance was most often that their farms were there to make money and oil and gas development is an important part of their financial livelihood although it is not the only nor the primary livelihood.

We went in with the idea that we were going to lease with because the money was there. The farm is a farm and it's there to make money for all of us. I haven't seen... I mean there's been a lot of talk about fracking and how it effects the surface and the water and what not and I have not seen that. And what I have tried to dig into it, and I haven't seen any of it around here. [Resident \#2, May 31, 2018]

Mineral rights owners choose to lease their minerals for royalty payments and may not have development directly on their land. The interviews show that perceptions of water contamination and concern for water is often framed around the subject of environmentalists and environmentalism in West Virginia. Frequently the interviewees used the term environmentalist pejoratively, called environmentalists "tree-huggers" and characterized these environmentalists as extreme, with ulterior motive, and originating from outside of West Virginia. Interviewees discussed how this negative view of environmentalists frames how individuals can communicate within their neighborhoods and communities. Both residents and industry representatives mentioned that controversial individuals (those with reputations as environmentalists) could not even communicate uncontroversial ideas and information because of their reputation.

No, said our neighbor's waters was bad, they had a water buffalo over there. I said well are you drinking your water? You don't think I should be drinking my water? No! Don't 
drink your water! They don't know. They don't know, who's going to tell them? Who are they going to believe? If _ knocked on their door and said don't drink your water, they're not going to believe her. [Resident \#23, July 27, 2018]

This__ is one of these people that moved here from the big city to live in isolation, out in the country, so he's a tree hugger. If he wasn't so far to the left people might listen to him. [Organization \#10, July 13, 2018]

Despite this reputation and perception amongst residents and organizations, environmentalists themselves reported successful communications with companies and regulators because of their thorough documentation and persistence. Environmentalists who work around water quality issues in West Virginia are constructed as outsiders to West Virginia, linked to the increased popularity of the documentary Gasland and the images it contains of oil and gas impacts on water i.e. the image of lighting one's water from the faucet on fire.

Yeah and I think that in the very beginning it was hard because people didn't understand what we were doing, and they were obviously influenced by you know actors in Hollywood putting out movies that were not really necessarily true and scaring people into believing that things were going to happen to their water. And so we as an industry and organization have been trying to set the record straight with a number of studies. [Industry \#1, March 27, 2018]

Interviewees used Gasland as a reference point to say either that the film has perpetuated misconceptions and exaggerations, or to say that even though the film Gasland seems extreme, the same issues are occurring here in West Virginia. Residents and industry representatives report a debate about water impacts, often citing scientific research to support their claims.

\section{Tradeoffs}

Overall, residents find them in an ambivalent situation in which they emphasize the uncertainty of industry's scientific and technological knowledge claims, while also recognizing that in West Virginia, economic prosperity is wanted and needed, and there are many other legacy contaminant issues in the state, from coal mining to straight septic systems. 
Well you know, we know we have wells that have been impacted here by the oil and gas industry, water wells. But then when they say... so we know that's going on. So then the industry says that there isn't any proof that fracking hits your water well. Well there's some truth to that too. But the truth is they really don't know where that crap is going to go when they put it down there. And__ is all upset about what they're doing but she's not at all upset about the straight septic systems we have flowing into Middle Island Creek. Which is a much bigger impact than what the oil and gas industry is doing. [Organization \#3, May 18, 2018]

In most cases, interviewees are concerned about whether water is an acceptable tradeoff for oil and gas development. Other nuisances are more acceptable such as, for example, truck traffic and noise. However, water contamination is framed as an accident of UOG development. Residents weigh water contamination against personal gains as mineral owners who receive royalties.

The problem with that is that most people don't want to pay a water bill. Right? Most people like having the water well. I know he makes money off of royalties off of it, but he will never forgive them [the company]. [Organization \#4, May 25, 2018]

However, in general tradeoffs to water quality and quantity are not seen as acceptable tradeoffs for energy development.

The water was the straw that broke the camel's back. We knew the drilling, we knew it was going to be active we were trying to tolerate it the best that we could knowing one of these days they're going to be done. But by them destroying the ground water and it's just that it's basically gone... there are pockets down there of this fracking stuff that is going to come up in the water and raise those concentrations. Even the concentrations now, the pre-test of our water system show all of these fracking fluids in there at levels that you don't want to drink or bathe in and that's been the straw. We can't live the rest of our 
lives with that on our backs. We're putting our whole livelihood into this. [Resident \#1, May 18, 2018]

I don't know if my neighbor across the road has let a water line go through her property. I do know that she said to me once that she didn't think she liked the idea of having our nice rural countryside ruined. [Resident \#4, June 5, 2018]

Individuals who have not directly experienced documented water contamination in their homes say that having a few cases of water contamination is the "price of progress", meaning that there will be incidences and mistakes made as the oil and gas industry develops the region and that development is progress that is beneficial the community.

There's a lady out here in this county who has two wells on her property and was an instant millionaire, but they screwed up her water, so she has a water buffalo now you know a tank outside of her house to get water. And there's people getting nothing but because of the oil and gas we finally have two stop lights in this county, we have a subway sandwich shop that we didn't have the local restaurant expanded, so it's... it's kind of trickling down in ways that it hasn't in the past. [Organization \#3, May 18, 2018]

At times, residents who have had direct experience with documented water contamination also position their problem within the context of gains for local, state or national scales. The interviewees indicate their support for energy production, and that it is reasonable to expect that companies, which are reaping income from natural gas production, should readily be willing to accommodate those who experience water contamination.

I don't have a problem with drilling because America, we need to be independent, it's just that they need to take responsibility and make sure they do it safely. I mean there's going to be some effect on the landowners... but like the water situation... if you can afford to pay 6 million dollars to put a hole in the ground, I'm not saying pay me 6 million dollars, I'm just saying make sure my waters safe to drink for my family and my kids and whatever. Basically, that's my biggest complaint about the whole deal. I can live 
with other stuff that they've done that I've not really liked. But us as a family right now, everybody has to have water to be able to survive. and right now, they've basically cut our water supply off. They're taking not only our way of life, but how we can actually exist. I mean if it wouldn't be for us hauling our own water, we wouldn't have any water at the house. And now it's coming out of our pocket to pay for their expense. [Resident \#5, June 6, 2018]

The debates about the tradeoffs and benefits of UOG development are contested amongst stakeholders, including residents who tend to be supportive or ambivalent towards natural gas extraction. In the discussion, I will contextualize the findings about baseline testing that shapes residents' trust of companies within the context that has been presented here in which economic tradeoffs are presented against water contamination issues, and in which environmentalist concerns are constructed as antithetical to support of natural gas extraction.

\subsection{Baseline water testing and trust}

All residents interviewed discussed the need for baseline water testing to be done before any activity related to natural gas extraction occurred on or near their property, or when development is happening in their vicinity, even when drilling and fracturing was outside of the setback distance. Baseline water testing is fundamental for judging water's safety for consumption by tracking the chemicals (chemicals in the water used for hydraulic fracturing, or chemicals from the ground that were disturbed during drilling and/or fracking i.e. arsenic) in well water, but the baseline water test is also considered important for having any legal standing if well water quality changes are detected. Although interviewees indicated the need for a baseline water testing for legal standing, it is beyond the scope of this thesis to fully examine how often baseline water testing led to actual legal recourse.

After it is discovered that water is contaminated, there is a legal process of determining whether the contamination was caused by drilling or fracturing, and therefore, whether it is the fault of the oil and gas company or not. If water quality changes are considered the oil and gas company's fault, an oil and gas company may offer a water delivery service or to install water treatment in the home. However, if fault is not established, it will be the homeowners' responsibility to procure their own water. Individuals living near well pad development perceive 
that changes in their well water were in fact due to drilling and development and as such should be considered the fault of the company. However, they have no way to prove it even if they have the baseline water test. Baseline water tests provide proof and visibility about household well water quality, and interviews indicate that baseline water tests provide safety and security against unknown risks to their water. However, interviews also suggest that companies retain power over the water testing process and legal outcomes of water contamination.

One of the most commonly discussed aspects at the intersection of water and oil and gas development was the trust that residents have in the oil and gas companies and hired contractors. Data shows that residents trust starts with the baseline water testing. Many residents asserted not trusting the companies to do the baseline test, because they assumed that companies will not want to be truthful about what is in the water, in order to avoid blame. Interviews show that one factor in individuals' violated trust is delayed test results.

Contractors hired by UOG companies carry out baseline water testing. Interviewees reported that the water test results were not returned to them promptly and often the test results were delayed many months. Delayed test results produce anxieties about water quality and about the reasons why the results are delayed.

After I complained and complained in August... they came out and they did a test and I didn't know it because they never told me. I didn't know of this until through FOIA I got the information... what I found out was that about two months or a month and a half after I started complaining, they tested the water ... And it wasn't just that I had lost water, but now my water was contaminated with E. coli. I said you mean to tell me that government... had a report that said my water was contaminated with E. coli and should not be consumed by humans and they didn't tell me especially because I was emailing them every other day? [Resident \#22, July 27, 2018]

They tested every month, but we don't get the test results. The results are ready in two weeks, so there is no reason that I shouldn't already have the last of April. So my question is whose desk, where do these reports sit on while we are exposed? Because we are exposed to the water. [Resident \#1, May 18, 2018] 
We had pictures of them fracking, then the very following month when they got the water samples that's when we had elevated arsenic and sodium... But they didn't tell us this. They had the test in their office and they never told us. So, we drank this water for 6 months. Actually, my dad said to the guy that was out here testing, can we get a copy of these results, we never see them... He said well yeah call into our office and we'll mail you a copy. When they mailed the copy and we got looking through the, that's when we discovered the arsenic and all that and that's when we called the attorney and got the DEP and basically, they hid it from us. The fact that it was... we drank that for 6 months, arsenic and everything else. [Resident \#5, June 6, 2018]

Interviews show that sometimes the contractors do not follow the correct testing procedure, which violates the trust of homeowners who know the correct testing procedures. Consultants echo this problem, saying that contractors do not always carry out the water testing procedures correctly, and that then impacts residents' trust of the companies.

They don't trust the company, so they don't trust anyone that is associated with them. Sometimes the companies themselves... perpetrate that by making things difficult... A lot of times those folks won't communicate with the land owners... to collect a groundwater sample you should purge a well...you want the fresh groundwater coming in. So a lot of times consultants have come out and not worn gloves, they have not purged the well they fill up a jar at the sink and leave. [Consultant \#2, April 19, 2018]

Trust is violated when companies test their water but do not demonstrate commitment to doing the test in the correct manner. When residents do not trust companies to monitor their water or to provide safe and usable water, the burden falls on the individuals and families to be aware of any slight changes to their water (i.e. changes in taste or sensations on skin) to report problems with their water back to the companies. Trust between homeowner and company is compromised by a lack of clear communication from the companies about the results of their water testing, and because of improperly followed testing procedures. Individuals with well water may need the companies to do water testing to have any legal ground to defend their 
property if changes in water quality were to occur, but their trust is violated due to interactions with the companies.

\section{Environmental regulations}

Setback distance is a regulation that determines a safe and unsafe distance for a well site to be developed from an occupied building (Sangaramoorthy et al. 2016). Companies see this legislative requirement as satisfactory, but residents view it as arbitrary. Multiple residents reported that the setbacks created an unrealistic boundary between what is considered safe and unsafe distance from well heads and other oil and gas development. For residents, the vast and unseen underground network of horizontally drilled wells negates the simple calculation of a safe distance between a well head and a building. Although setbacks are necessary for keeping well heads a sufficient distance from a home, they also create a perceived arbitrary boundary between what water is at risk for contamination and what is safe. Additional to setbacks, WV Code 226A-18 states that companies must test water wells within 1500 feet of the center of well pad.

WV Code 22-6A-18 Natural Gas Horizontal Well Control Act states that water contamination is presumed the fault of drilling activity when a pre-test shows that water quality changed within 6 months of drilling. This code also states that companies are not presumed responsible if the landowner did not allow the company to take a pre-drilling test, if the water supply is beyond 1500 feet of the well, or if another cause (i.e. land use change) can be identified. There is a window in which companies are deemed responsible automatically, assuming the other conditions of the code are met.

Yeah, they said it was over 2000, or 1000, they said it was over. When I called them and said I think I'm having water problems they said that's impossible because you're outside of our zone. [Resident \#23, July 27, 2018]

Residents rely on baseline water testing for potential future legal recourse. Water testing that shows well water quality changes do not automatically result in the company's culpability because of time limits, and the potential that landowners do not let companies provide water testing. In the WV Code 22-6A-18, it is presented as though a landowner may not allow a 
company to test their water. From the industry perspective, companies comply with the setbacks and sometimes go above and beyond what is dictated by regulations.

\section{Legal recourse}

Reliable and correct baseline testing is important for residents' legal standing if water quality changes. Although water contamination is highly debated, there are examples in which companies have bought out properties because of water contamination. This resident described to me an instance in which water testing was done for academic research, and how proof that water quality change led to someone having their property purchased by the company.

But it was really a win-win situation for them and for people in this community because water well testing for some of the parameters involved in this is very expensive. Very expensive. And this was all free. They got results back. So, they had something to state what their water was at that particular point in time. A water well test is just that point in time. I know people that have left the area that it actually helped because they had the baseline that Duke did and there was additional water well testing and their water had changed. After drilling occurred around their homes, surrounding their homes, there was acetylene in their well water. That's not a good thing. Iforget what else was there, but it was good. They had proof everything was fine before...Yeah, they got bought out by the company, they got bought out. They wanted out of here. [Resident \#21, July 2, 2018]

It was difficult to connect directly with individuals who had their property bought out because they are physically not living in West Virginia any more. Additionally, some interviewees indicated that their neighbors signed non-disclosure agreements after having their homes purchased or having remediation systems put in place by companies. (see also the section on limitations).

Legal recourse is not always attained when water quality changes occur. Residents must prove that UOG development caused water quality changes. One interviewee discussed a time when their baseline and subsequent tests showed water quality changes after drilling, but the company and experts did not see the causal link between UOG development and increased arsenic in the drinking water. 
Their argument is that arsenic... is naturally occurring in the ground. Which, I agree it is naturally occurring in the ground, they didn't pour it in there, it came out of the ground. But, they also had a specialist, when our well was contaminated, the first days that they came out, they had a company out of Pittsburgh ... one of their geologists or whatever, and one of the first things he asked me when we were standing by the well was if anybody had did any excavating or disturbing of anything right around the house there, he said because arsenic is in the ground and any construction or anything you do can make the arsenic show up in your water. At that point, I told him, I said no nobody has done anything, other than you all in the neighborhood drilling, you're on the work that's going on. Well so all that, they kind of changed their theory on that. We still have no water, so. You would think a company the size of that, a multi-million, multi-billion-dollar company could... I'm not saying they did anything wrong, it's just something that happened.

The way I look at it is, Antero took samples for 8 months previous to fracking, the month after they fracked my well was contaminated, so I feel that I've got fairly good evidence or proof that they were the ones that disturbed something that caused it and the DEP's on the other side, said really that doesn't mean anything. What would mean anything is basically, what could you do to hold them liable for it if you got pictures, you got previous water samples, you got samples after they did their fracking, and that doesn't stand up or have any proof to it, what else could you do? They pretty much do whatever they want to do. [Resident \#5, June 6, 2018]

Narratives about legal recourse, as shown above, are contextualized in the larger debate happening around UOG development tradeoffs, and the contested debate about UOG development's impacts to water. 


\section{Chapter Six: Discussion}

This thesis investigated the perspectives of West Virginia residents on household well water contamination due to UOG development in the northwestern counties, and how household well water contamination (in terms of both documented contamination and perceived risks) impacts residents. The previous chapter presented findings from interview data. This chapter provides a discussion of the various ways that residents are impacted by household well water contamination due to natural gas extraction. The findings are discussed by first considering the embodied impacts of household water contamination and how embodiment furthers our understanding of the issue. Residents with well water do not necessarily trust companies to monitor and manage water quality, and companies are perceived as having epistemic authority on water by managing and controlling baseline water testing, hence controlling the way that water quality is known. To examine the notion of epistemic authority on water, the uneven power relations that exist between residents and companies and the politics of scientific uncertainty that residents face are discussed. In an attempt to elucidate the multiple factors contributing to epistemic authority on water, this discussion covers how scale functions in West Virginians' lived experience, the legal and regulatory frameworks the shape safe and unsafe space in West Virginia, and the social implications of residents' concern about contaminated water. Conceptually, this research contributes to the literature on waterscapes by exploring a case study about subterranean water, bolstering political ecology scholarship with concepts from feminist geography. Additionally, this case study adds to the literature on UOG extraction with findings about water testing practices and test results, and environmentalism in West Virginia.

\subsection{Embodiment, emotion and uncertainty}

Embodiment is emerging as concept in social science research on energy production in order to bring attention to the "full spectrum of trans-boundary socio-environmental injustices linked to energy policy decision-making" (Healy et al. 2019:220). Embodied energy injustices in this case study are defined as impacts to the home and body due to energy production. Whereas previous studies have focused on embodiment as a physical toll, focusing specifically on health and health perceptions (Abatsis McHenry 2017; Adgate, Goldstein, and McKenzie 2014; Sangaramoorthy et al. 2016), this study focuses on embodiment as emotions, drawing from emotional geographies. Water quality issues have previously been analyzed by political 
ecologists as producing suffering (Perreault 2017; Sultana 2011), in addition to studies examining how water shortages and risk produce fear, anger, worry, and bother (Stevenson et al. 2012; Wutich and Ragsdale 2008). Emotions such as worry and concern, which are present around water risks and natural gas extraction, exist as a constant mental and emotional stress (Wutich and Ragsdale 2008). Uncertainty about water access and water quality, especially around industrial pollution, produces emotional responses (Davies 2018).

The concept of uncertainty manifests in multiple ways throughout this research. Firstly, reflecting political ecology literature, uncertainty about subterranean waterscapes is a recurring theme. Resource geographers in particular have sought to characterize the uncooperativeness of water (Bakker 2004) and limitedness of subterranean scientific knowledge (Melo Zurita and Munro 2019). This literature does not suggest that scientific work on water and natural gas is not valuable for understanding environmental impacts, but suggests that specialized scientific perspectives on water are also political, interested and partial knowledges. Governmental and academic scientists working on assessing UOG developments' impacts to water specifically point out uncertainties and data gaps (Sangaramoorthy 2019; U.S EPA 2016) and note that seeking to fill data gaps does not rectify this partiality if it is not considered who and how the data is being produced (Moore et al. 2018). Adding to these gaps and uncertainties, the concept of "undone science" has been used to describe the "systematic absence of research" around health and environmental risk (Bray 2017).

Second, in this research, surface and mineral owners articulate uncertainty about the outcomes of natural gas because the prevailing discourse says that natural gas is environmentally safe and yet many residents have mobilized around hydraulic fracturing's risks (Cantoni et al. 2018). Yet, beyond this polarized narrative, uncertainty about the outcomes of extraction produces emotional reactions because of how the potential harms are deferred to the future (Davies, 2018). Temporality is crucial for understanding toxicity, as one instance of exposure may produce no embodied effects, but exposure over a longer period of time can produced accumulated embodied effects. Additionally, because of the expectation that natural gas extraction is safe, and the cultural expectation of clean and accessible water in the US, there is emotional reaction to the violation of this cultural expectation (Jepson, 2014).

Third, Davies (2018) provides another reason for emotional reactions from industrial and toxic uncertainties. He describes residents' worries from seeing increasing industrial 
development in their neighborhoods. A similar scenario is present within this research. In this study, residents feel a sense of worry not just from having verified water contamination, but from seeing the emergent infrastructure development on or near their properties which they had no prior knowledge of nor control over.

Fourth, water well testing has uncertainties in that it represents partial knowledge because there are too many parameters to test for all the chemicals used in hydraulic fracturing fluid. Additionally, the flow of ground water influences accurate water testing. Hence, water testing is always partial, and many parameters and factors influencing water quality remain imperceptible and unknowable. Hydraulic fracturing chemicals are proprietary, often unknown to residents and homeowners. This is consequential because one must know what chemicals to look for in order to test for them comprehensively (Kinchy and Schaffer 2018). The chemicals are often imperceptible to the senses, although some sources say that discoloration, base taste, odor, or fizzing can be indicators of contamination from gas wells (Monk and McMahon 2013). While emphasizing how many chemicals are unknown because they are proprietary, it is also important not to over-determine their imperceptibility and to not downplay the "many mechanisms, embodiments and formations of informal knowledge that allow communities to recognize and live with pollution" (Davies 2019:11).

Water contamination presents as a myriad of contaminants -- e. coli, arsenic, chemicals from hydraulic fracturing fluids, salts, and sedimentary chemicals. Additionally, groundwater and contaminants are constantly flowing, making chemical concentrations vary. According to the WV Surface Owners' Rights Organization's web page, the West Virginia Department of Environmental Protection (WVDEP) mandates testing of chemicals and parameters such as $\mathrm{pH}$, iron, total dissolved solids, chloride, detergents methane and coliform bacteria (Monk and McMahon 2013). Companies may elect to test for more parameters if they desire. The WVDEP parameters do not include testing for heavy metals or other chemicals which the EPA has implemented standards for allowable concentrations; such as arsenic, lead, benzene, and toluene, among others (Monk and McMahon 2013).

Adding to this context is a lack of historical water testing data in West Virginia, the possibility of legacy contamination from mining and manufacturing, and the industry representatives' assertion that drilling and fracturing are safe. Surface owners' perspectives on the other hand see drilling as the obvious cause for water contamination, which mirrors the 
"precautionary principle" that Gullion (2015) uses to illuminate epistemic controversies around shale extraction in Texas. The precautionary principle is at work in situations in which science is uncertain, and in which the risk may present itself before scientific evidence about the risk is available (Gullion 2015). Hence, the precautionary principle describes how certain logics about the environment lean towards the possibility of environmental risks, versus an industry or legal perspective that is focused on proving environmental risks (King et al. 2012; Lave and Lutz 2016). There is disagreement between scientific and industry communities and the public and residents around the possibility of water contamination due to UOG development. Mobilized residents frequently put embodied harms and perceived risk over scientific 'proof' (Abatsis McHenry 2017; Gullion 2015). Residents question how a process characterized by uncertainty can be able to operate.

Embodiment is explored in this thesis as both the physical toll on the body and the emotional geography of water contamination and water contamination risks. Worries and concerns produce a mental and physical stress and emotional experience. These emotions are not exactly the same as "sufferings" from water (Sultana 2011), but represent a "slower" or constant, extended emotional experience from a myriad of uncertainties. Much like political ecologists have focused on how water distribution produces embodied effects and emotional experience (Sultana 2011; Wutich and Ragsdale 2008), this thesis explores how water testing, and regulation and uneven power relations produce uncertainties and hence emotional experiences (See Shriver, Adams and Messer, 2014 for similar analysis of industrial pollution and power).

This analysis draws on traditional conceptualization about embodiment, seen in residents and concerned citizens relying on their embodied physical experience of extraction versus techno-scientific knowledges. However, scientific testing is also a major part of the embodiment of industrial pollution especially when water testing can reveal contaminants that cannot be seen, smelled, or sensed. Additionally, water testing may be problematic because of the proprietary natural of chemicals used in hydraulic fracturing. Accordingly, this analysis does not stop at arguing that embodied knowledge may oppose scientific and industry knowledge. Science is interwoven into both embodiment and industry knowledge; hence this analysis aims to contribute to the conceptualization of embodiment by adding an analysis of epistemic authority. This study in particular then explores how science is interwoven into embodiment, and how power manifests through water testing and environmental regulation. 


\section{$\underline{\text { 6.2 Epistemic authority }}$}

Scholars have focused on how competing claims in the natural gas industry, often between industry, scientists and residents, to examine how knowledges are partial and not neutral, but that some knowledges are conferred legitimacy and epistemic authority, while some are marginalization (Hudgins 2014; Matz and Renfrew 2015; Willow 2016a). This section covers how uneven power relations exist around split estates, water testing, and legal frameworks of natural gas extraction in West Virginia. Uneven power relations create or enforce epistemic authority and hence produce effects about the creation, dissemination and legitimacy of knowledge.

\section{Surface and mineral ownership}

Natural gas extraction requires residents to lease their privately owned minerals and land, hence leasing ostensibly requires owners to weigh the benefits of selling their mineral rights for royalty payments against the potential costs of degradation to their land (Finewood and Stroup 2012). Split mineral and surface estates complicates this scenario in which benefits from mineral royalties and impacts to surface are accrued to the same individual. In West Virginia, mineral rights were severed from surface rights in service of coal mining (Ryder and Hall 2016). Additionally, mineral owners are deemed the senior estate, meaning that mineral owners have the right to develop minerals without surface owners' consent. The mineral senior estate is attributed to a case dating back to 1854 in which a Pennsylvania court rule that a mineral owner could mine for coal against the surface owners wishes (Ryder and Hall 2016). In West Virginia, mineral leasing and surface use agreements are often negotiated with separate owners. It is uncommon that a surface owner to own all of the minerals under their land in West Virginia. This separation has allowed for development to occur as well as producing conflict between mineral owners, who benefit economically, and surface owners, who bear the brunt of well pad development and infrastructure on their property (Collins and Nkansah 2015; Ryder and Hall 2016).

Surface owners without mineral rights tend to have more negative perspectives on development and its impacts (Collins and Nkansah 2015). Additionally, there is the uneven power between individual landowners, mineral owners, and oil and gas companies. Oil and gas companies have been depicted as "invading" rural areas, and presenting leasing decisions to 
landowners in which there is "no choice" but to comply with development (Malin 2014). In particular, this thesis shows that uneven power relations are present in the practice of water testing. Companies have greater access to monetary, legal and scientific resources.

The rest of this section will continue to elaborate on uneven power relations by addressing West Virginia residents' trust of companies to conduct baseline water testing of groundwater wells. To contextualize residents trust in oil and gas companies, the discussion will include factors that shape trust: such as scientific uncertainty, legal frameworks, expertise, production of scale and social marginalization.

\section{Baseline testing and trust}

Researchers are grappling with lack of public trust in both corporations (Emmett et al. 2011; Macnaghten 2017), government and science, especially science on climate change (Savoia et al. 2015) (Wachholz, Artz, and Chene 2014), and the rise of populist counter-expertise (Bosworth 2018). Sociologists in particular are interested in social trust around risk (Cvetkovich and Siegrist 2000; Slovic 1999). Within West Virginia, political trust has been eroded by controversies related to the coal industry (Bell 2009), but trust is dynamic and can be reified when the public senses the government or corporations are telling the truth (Savoia et al. 2015). In addition to the importance of trust as highlighted in the literature, trust emerged as a theme with interviewees.

Interviewees discussed lack of trust in the companies and hired contractors (who are seen as the company, instead of separate from it) because companies withhold information, bend the information to their need, and do not conduct testing in a way that will provide truthful results. Hence, their lack of trust in the companies has to do with uneven power relations - as companies have more capital and legislative power - but also because they see companies as harnessing power over knowledge production about water. Water well owners lose trust in the companies when they experience the companies demonstrating incorrect water testing procedures, and when the companies fail to return water tests in a timely manner. Companies and residents must complete water testing both pre-drilling and post-drilling, or they cannot track changes postdrilling. If companies carry out the tests incorrectly, the results may be incorrect. Incorrect water testing, or worries about incorrect testing procedures, produces suspicion about water quality and worries about future livability, cost and worth of their homes. 
Statewide organizations such as the WV Surface Owners' Rights Organization (WVSORO) also do work to inform homeowners about water testing. Because residents have learned that there are correct ways to test well water, such as running water prior to testing it, if a company is caught carrying out incorrect testing procedures they are seen to be violating the resident's trust. Residents often mentioned that they were drawn to living in rural West Virginia because they want to be on well water and have some control over their water source. West Virginia water is constructed as pure and safe, echoing research on hydraulic fracturing and mining in which communities express an idyllic past of pure water that has been corrupted by extractive industries, constructing contaminants in water as "matter out of place" (Rijke 2018).

Temporality is also an important concept around baseline water testing. Water testing is only a snapshot of a moment in time as water is constantly flowing underground. Hence there are these uncertain temporal qualities when claiming that water testing reveals contaminated and uncontaminated waters because test results reflect a moment in time and could be affected by precipitation and water flows. Legalistic frameworks that industry and regulatory bodies adhere to and operate under utilize water testing and see water as something static and testable, not something flowing.

Some water contaminants can be sense by smell, taste, or sight (Abatsis McHenry 2017; Monk and McMahon 2013), hence there is an embodied dimension to water contamination. There are more detailed descriptions of the embodied health impacts from water and air contamination in the Marcellus Shale (Griswold 2018). The health aspect is perhaps less represented in this research, due to the missing bodies and stories in West Virginia, discussed in the limitations section.

Other dimensions of embodiment must be explored in this case study because not all chemicals can be sensed, and hence well water users do need their water tested. Although some contaminants can be determined through smell, taste or sight, only scientific claims via testing of contamination can be used for legal recourse, hence baseline water tests become the only way to create knowledge about well water quality changes. This is evident in that sensory claims have not been permissible in legal cases (King et al. 2012). Residents rely on oil and gas companies (via third-party consultants) to create this knowledge. Industrial pollution exposure is characterized as an embodied experience that precedes scientific knowledge (Judge et al. 2016). However, in the case of contaminants that cannot be sensed, it is the baseline testing that allows 
the experience to be discovered. Because of this legalistic framework, it is only baseline water testing that can produce legally credible knowledge about water quality. Hence, it is only experts exclusively carry out water testing. Well water users can hire their own consultants for testing, but they must adhere to the framework set out by WV code in order to ensure legal recourse. General exclusion from water testing and the experience of delayed results and regulatory boundaries all contribute to residents' sense of risks to their household well water and a lack of trust in the companies to carry out monitoring their water responsibly.

Residents' sense of risk is analyzed as emotional embodiment earlier in this thesis. As argued earlier, political ecologists have analyzed aspects of emotional suffering around water access and contamination. This section of the thesis focuses on sense of risk and trust, arguing that political ecology perspectives have not equally considered how suffering and access contribute to sociological and ideological stances of trust in governments, corporations and experts (except for Gauchat, 2012; Scott, Westgate and Mcspirit, 2016). Sociologists are interested in social capital and distrust as a rural perspectives (Bell 2009). This thesis contributes to those discussions of trust and perspectives within rural settings. While this study was not designed to research rural identity or trust specifically, this analysis does suggest a link between experience and perspectives of trust.

Experiences and perspectives are shaped by context and identity (Scott 1992). The experiences of delayed test results and incorrect testing procedures clearly violate assumptions of care and social trust between individuals and companies and/or governments. Literature on surface owners shows a predisposition to see natural gas extraction unfavorably, specifically because of the uneven power between mineral owners and surface owners (Collins and Nkansah 2015). Additionally, residents with water wells demonstrate involvement, interest and investment in knowledge about their water, and the future of their well water (Kern 2015; Ternes 2018). Hence marginalization from the process and results of water testing leads to feelings of violation and distrust. However, if an individual is already disposed to not trusting a company, then viewing incorrect testing procedures and receiving late results can exacerbate pre-existing distrust. Considering that testing practices and testing results are not the only reasons for water well owners' lack of trust in oil and gas companies, the following sections discuss other contextual factor influencing the creation of companies' epistemic authority on water. 


\section{Legal frameworks}

Residents' conduct baseline water testing with the goal of obtaining legal recourse if water quality changes are found. The legal frameworks governing this recourse, WV Code 22$6 \mathrm{~A}-18$, construct water testing as the only way of knowing water quality changes. Residents note that incorrect testing procedures, delayed test results corrode their trust of companies carrying out water testing, and that legal frameworks are systematically against finding causality between UOG development and water contamination. It is the perspective of industry representatives and legal precedent that it is the individual landowner's responsibly to prove UOG development causation when they find well water quality changes (King et al. 2012).

Andrews and McCarthy (2014) suggested that critical geographies have paid more attention to informal arrangements and tacit relations than to considering how legal frameworks shape places and environments. The 2013 West Virginia Horizontal Drilling Well Control Act and the West Virginia setback regulations determine where a gas well can be drilled, and which water wells need to be tested based on proximity to the gas well. Because of WV Code 22-6A-18 that mandates a company's presumed liability for water quality to water wells within 1500 feet of the well head, companies are eager to sponsor testing of those wells (Boyer et al., 2011). Setback distances, which regulate where a gas well can be drilled, are not necessarily determined by scientific opinion but more likely derived out of compromise (Fry 2013). Reviewing multiple studies, Zwick (2018) reviews research that suggests setbacks should be at least 2000 feet, with many studies suggesting much higher distances. West Virginia setback distances currently mandate that wells are not drilled within 250 feet of an existing water well or spring used for human or animal consumption and that the center of the well pad cannot be within 625 feet of an occupied building. These differences show that industry, regulations and scientific studies are not always in agreement with each other. Environmental and regulatory frameworks demonstrate when and where industry's influence and power is articulated over scientific studies and public concerns. Although in other examples throughout this fieldwork industry and science work in conjunction, that is not always the case.

Willow (2014) refers to public perspectives on groundwater and setback distance, noting that residents in Ohio emphasize the fluidity and interconnectedness of groundwater versus the landscape of confinement and boundaries that setbacks, and presumed liability, suggest. Similarly, research participants suggest that setback and presumed liabilities are arbitrary 
distances and have opted to pay for their own water testing when their wells are beyond 1500 feet of the well head. There is worry and concern about water outside of spatial and temporal constraints of presumed liability and a suspicion about legislative setback distances. Interviewees suggest companies' power and epistemic authority operate through legal frameworks when companies contest their presumed liability. By pleading that water quality changes are from legacy contaminants or pre-existing pollution, companies can contest this liability. The overlapping histories of natural resource extraction within the state can work against legal recourse and water remediation for residents as natural gas companies cannot be held liable for legacy contamination from other industries. Another area of contestation is if a landowner refuses the company access to the land to do a pre-drilling test. Considering the possible lack of trust of companies even before water testing occurs, this is a potential loophole that enacts the ability of the oil and gas company to contest fault.

When water is documented as contaminated, companies may install water filtration systems to clean the water and/or vent off chemicals (Associated Press 2014) or install water buffalos to provide water. Companies may provide these remediation services even when they are not admitting blame or assuming responsibility for water contamination. Although baseline water testing can be used by residents against companies, non-disclosure agreements allow for companies to exercise epistemic authority over residents by disallowing them from sharing their stories and preventing the production of knowledge. Due to the nature of a non-disclosure agreement, there is not much literature written about NDAs and UOG development (cf. Vasi et al., 2015). Additionally, when companies buy out residents' homes, they are removed from their community and their experience is silenced in another form. Non-disclosure agreements as a legal practice shapes place and space by removing the ability for stories and information about water contamination to be shared.

These missing bodies and missing stories have also impacted this research, as those perspectives were not available throughout the fieldwork. The 'missing bodies' created from NDAs, and from residents leaving because of contaminated water, links epistemic authority of the companies back to embodiment, or rather to the non-embodiment, in the rural West Virginia waterscape. Embodiment and epistemic authority around natural gas extraction and water continue to be intertwined, and co-constitutive. Hence in this analysis it is necessary to consider how embodiment and epistemic authority intersect within this research. 


\subsection{Intersections of embodiment and epistemic authority}

Uncertainty has been present throughout the research and has embodied manifestations (such as worry, concern, stress) but also has epistemic authority ramification (who is allowed to be uncertain and still credible). To examine further intersections of embodiment and epistemic authority, this analysis next focuses on how scale is produced in industry perspectives and by the residents themselves. Second, this section discusses how the contested knowledges around natural gas construct environmentalists and activists as outsiders, and hence concerned citizens are marginalized and come to embody the contested knowledges and uneven social relations.

\section{Scale: epistemic authority, embodiment}

Residents' embodied knowledge informs their trust in the companies. Their interactions with companies, from water testing to receiving results to requesting remediation, shape their views about companies' trustworthiness. The embodied and emotional aspects of natural gas extraction presents a counter-narrative about natural gas's economic benefits for individuals, counties, states and the federal government (Sica 2015).

The arguments around natural gas and the environment are forms of a scale-based discourse. The way that actors define water contamination at particular scales reflects the way in which scale is used to confer legitimacy (Harrison 2006). In these findings, scale emerges in two ways. One is the question of whether systematic groundwater contamination is occurring because of hydraulic fracturing. The issue is focusing on hydraulic fracturing as the main concern, while labelling the other pathways to contamination as accidents, human error, or externalities. Harrison (2006) argues that the construction of "accidents" serves to "scale down" environmental issues to avoid regulations. Other pathways to water contamination around natural gas extraction are often from accidents: well casing failures, spills, or well intersections. Characterizing water contamination as accidents produces the problem as outside of scientific study of the systematic impacts of hydraulic fracturing on water. In this sense, water impacts are an anomaly rather than an expected outcome.

The second is that scale emerges as a frame for natural gas extraction's benefits. Despite having no gains from mineral royalties, surface owners in this study who had documented water contamination, or those who feared it would happen to them, still weighed their environmental and water issues and losses against gains for the local community, the state, and the nation. 
Across stakeholders, it was debated whether having a few cases of water contamination is an acceptable "price of progress" for the overall public good of UOG development. Surface owners argue that UOG development has been occurring for a decade now in West Virginia, and that companies should be able to, by now, develop natural gas in a way that does not affect people's water, in line with the technoscientific promises made by companies of safe technology and best practices. Additionally, surface owners felt that with all of the income generated from natural gas, the companies should compensate them for water losses. As mentioned before, the benefits of natural gas extraction have been framed as accruing at every scale, constructing the industry as widely beneficial (Sica 2015). Research findings indicate that participants do consider the local, state, and national benefits in relation to their experiences with water contamination. A majority of the research participants acknowledged the economic benefits of extraction. They debated whether it is an appropriate trade-off, but nearly all interviewees considered how gas revenues have led to new local facilities and buildings, state revenues, and bolstered notions of national energy independence.

These benefits to the local community, county, and nation are how oil and gas companies and federal, state, and municipal governments often frame knowledge about UOG (Sica, 2015). These benefits are often technoscientific promises for the future such as that of job creation, and the assertion that gas extraction is a safe, controlled risk (Cantoni et al. 2018). These promises allow residents to become invested in the idea of economic prosperity tied to this development and believe that UOG extraction is progressively becoming safer through increasing extractive technologies. It is against this backdrop of the promise of improvements, however, that residents frame their experiences. In this sense, they relinquish embodiment to the epistemic authority of gas companies, scientists and pro-gas rhetoric. However, as demonstrated in a few of the quotes, residents also frame well water contamination as an unacceptable tradeoff to residents for oil and gas development, depending on how companies respond water quality changes. Multiple benefits are acknowledged, but the occurrences of water contamination do not cohere with the promises and expectations of safety, technological improvements, and legal frameworks to protect well water.

However, interviewees frequently refer to their experience and their knowledge about water and water testing to contest the oil and gas company's techno-scientific knowledge on water. Recalling the participants who discussed arsenic in their water, and the ones who were 
outside of the water testing distance, they both asserted their knowledge of how subterranean water contamination occurs and hence refuted what companies, scientists, and regulators were telling them. Residents who are socially marginalized because of their concern for water also come to embody the polarized debate and become polarizing figures themselves. Gullion (2015) posits that scientific facts, lived experience, and ethics can all be part of the conversation around environmental regulation and natural gas extraction. Perceived risks from embodied experiences should be considered not as irrational, anti-science, anti-development, nor devoid of factual information, but as produced from a position in which science is uncertain and in which the stakes are high for residents who encounter water contamination.

\section{Counter expertise and environmentalism}

In feminist geography, epistemic privilege is a term that describes the ability of marginalized groups to know both their own oppression and also know the dominant oppressive culture (Janack 1997). Residents' experiences and knowledge around extractive industry has frequently been dismissed as lacking credibility or deemed anti-development and anti-science by scientists, legislators, and industry proponents particularly around women and children's health (Abatsis McHenry 2017; Eisenberg 2016). Gullion (2015) refers to the marginalization of nonindustry perspectives as "epistemic privilege". She uses this term to discuss how "facts" are leveraged by residents and industry representatives to support their claims, and how the residents must prove industry harms, versus industry having to prove that industry does not harm. While Gullion (2015) uses the term "epistemic privilege" borrowed from sociology scholarship, her usage of the term is congruent with the concept of "epistemic authority" from feminist theory and geography scholarship. Further, Davies (2019) characterizes the dismissal of "local claims of toxic harm" as a form of epistemic violence, based on a politics of indifference towards people's suffering (p. 13).

Counter-expertise is scientific knowledge that is at the same time forms of scientific contestation (Bosworth 2018). Counter-expertise around water in West Virginia is an interesting question. Environmental and watershed groups have operated in West Virginia for a long time in response to acid mine drainage, and groups have bolstered their work around pipeline stream crossings. However, around groundwater management, counter-expertise and social mobilization is still nascent. Most likely, this is because of aforementioned reasons, considering that 
groundwater testing for hydraulic fracturing chemicals requires identifying proprietary chemicals and the use of expensive testing technologies.

Residents working with researchers is one example of counter-expertise formed around groundwater testing. Public counter-expertise is being formed particularly around pipeline controversies in the US (Bosworth 2018). Bosworth (2018) posits that social mobilization around environmental controversies such as pipelines is possible because of the development of counterexpertise, not vice versa. This study is not about social mobilization; however, residents share knowledge with their neighbors and have come together to form collective law suits (Harvey 2019).

Some forms of counter-expertise do emerge in West Virginia. WV Surface Owners' Rights Organization attempts to inform the public about water testing via their website (Monk and McMahon 2013). Additionally, residents saw academic researchers who conducted baseline water testing in West Virginia as trustworthy and conferred epistemic authority on water favorably. When one interviewee described Duke University researchers providing baseline water tests for well water, they described the tests as legitimate and reliable sources of testing that residents could use. By not being affiliated with companies, the researchers were more trustworthy. This reflects Moore et al.'s (2018) suggestion to politicize who funds the creation of water data.

When residents are concerned about environmental impacts due to UOG development, they are cast by UOG proponents as environmentalists, or as being overly influenced by the popular documentary Gasland, which showed Pennsylvania residents lighting methane in their water on fire (Vasi, Edward T. Walker, et al. 2015). Despite the proliferation of concerned citizens working around the impacts of UOG development, technoscientific research is granted the epistemic authority to speak about the reality of UOG development's impact to people and environments.

Developing counter-expertise could lead to new forms of resistance in West Virginia. However, because of Gasland and the strongly produced dichotomy between jobs and environmental regulation (Cruger and Finewood 2014), the term activist has taken on pejorative meanings in some contexts in West Virginia (Luke et al. 2018). Luke et al (2018) have synthesized case studies internationally in which activists are framed as "outsiders" or "professional activists" and the same marginalization of activism is occurring in West Virginia. 
Because of this, residents who are concerned about water need to frame their opposition not as a form of activism but as coming from a "regular" person (Luke et al. 2018). As previously mentioned that interviewees often situated their personal losses within the context of benefits to local, regional and national scales. This occurrence reflects the dynamics of antienvironmentalism and anti-activism (see Griswold, 2018). In these contexts, economic growth is considered good for future of rural locations and hence potential of economic growth butts up against environmental concerns for the future (Luke et al. 2018). Contrary to this dichotomy of development versus the environment, it is the economic gains of mineral leasing that may help some residents continue to live in rural West Virginia and to steward their property (Roberts 2013).

Anti-environmentalism or pro-gas leasing may appear to be indicative of quiescence. Questions about resistance and lack of resistance (quiescence) to power and economic and environmental degradation from legacy pollution, especially in Appalachia, are long-standing (Gaventa 1980; Shriver et al. 2014). Shriver et al. (2014) argue that companies and elites use proactive measures for promoting quiescence around environmental issues. They posit that control of information, control of assessments, and diversionary tactics are used. Most relevant to the findings of this thesis is control of assessments (in their case soil testing) and diversionary tactics, in which other sources of contamination are blamed for soil contamination. These modes of gaining quiescence mirror the arguments put forth in this thesis about how authority over water is maintained by oil and gas companies. Additionally, Shriver et al. (2014) consider how activists are treated in their case study. They argue that activists are stigmatized and ostracized as a method for maintaining general quiescence. These modes of stigmatization are present in my analysis about how activists and people concerned about water are marginalized in West Virginia. Shriver et al. (2014) discuss how a company marginalizes activists, but this study, multiple stakeholders participate in the marginalization activists and activism. Again, although this thesis is arguing that the oil and gas industry maintains epistemic authority and the ability to produce quiescence, it does not intend to present West Virginians as powerless or without agency. Instead, it would seem that the combination of industry power, and the long standing ingenuity of West Virginians ability to steward land and stay in rural and remote areas (through, sometimes, mineral leasing) (Roberts 2013) creates residents' complicated and sometimes ambivalent feelings toward oil and gas development. 


\section{Rural and Subterranean waterscapes}

Returning to the overarching conceptual framework, this thesis seeks to contribute to the literature on waterscapes by presenting a case study about subterranean or groundwater waterscapes. Political ecology literature on groundwater has more prominently explored the distribution of drinking water in the Global South, revealing how technology has been used to modernize drinking water distribution, resulting in water technologies embodying political and social relations and creating the distribution of good and bad water (Sultana 2013). This study departs from this particular strand of research by focusing on energy modernizing and development projects' impact on water quality and water access in the Global North.

Waterscapes framework and the concept of the hydro-social cycle brings attention to the fact that changes in the waterscape and changes to the hydro-social cycle are shaped by and shape changes in social relations (Swyngedouw 1999). West Virginia is the water state and "the birthplace of rivers" (USDA and NRCS 1998) and accordingly, residents often referred to having the best or purest water. Perreault (2017) has analyzed a similar occurrence, in which pure water exists in memory, and residents narrate how industry has moved in and corrupted it. Similarly, the water in rural West Virginia is often constructed as pure and part of a rural idyll. Whether rural waters were ever pure in a historical landscape of manufacturing, coal mining, and oil and gas extraction, is not the point of this thesis. What this thesis does demonstrate, is that residents construct water as mostly pure before oil and gas development, similar to Perreault's (2017) analysis of water and mining in South America. More important is that the rural West Virginia landscape, in the northwestern counties, appealed to many for being an idyllic, clean, and quiet place, and industrial infrastructure development is replacing those qualities and residents' connectedness to the rural (for similar analysis see Willow, 2016a). For others who do not agree that water is threated by industry, their rural waters are still in fact changing, as streams and rivers have become the source of water for hydraulic fracturing, as water is being trucked and moved around rural West Virginia at an increasing rate, and as groundwater has become a divisive subject between neighbors.

Changes in household groundwater due to natural gas extraction produces social relations in which some residents gain from gas royalties while costing others their water and subsequently their homes. Changes in water quality have produced new forms of power relations around the creation of knowledge about water. Additionally, the risks of water contamination has 
produced new spatial configurations of safe and unsafe space, adding to previous legal spatial configurations shaping rural space, such as split mineral estate. Lastly, social marginalization of environmentalism (Luke et al., 2018) and anti-environmentalism (Williams 2002) in Appalachia is not new. Risks of water contamination have reified the jobs verses environmental rhetoric in Appalachia which then reifies who does or does not belong in West Virginia based on perceived industry support for the region. 


\section{Chapter Seven: Conclusion}

This research has explored how West Virginia's water is shaped by energy development, and how residents who lease their mineral and surface rights for UOG development experience the issue of and debate around water contamination. Risk of groundwater contamination characterizes extractive industry waterscapes, and ongoing natural gas extraction continues to produce transformations within the hydro-social cycle. In this research waterscapes is used as a framework to illustrate the social production of water in the context of UOG development in West Virginia. This framework illuminates how water and social relations are mutually produced, especially around "transformations of and in the hydrological process" (Swyngedouw 1999:444). Hence, waterscapes is a salient framework for addressing how UOG development both transforms and produces water.

This thesis is also grounded in feminist geography which has historically focused on issues of the body and home (Longhurst 1995). In particular, this thesis draws on feminist geography's stance on the epistemic authority of researchers, and on the concept of embodiment, to explore the changing waterscapes of UOG development through the lens of the home and lived experience. Lived experience of waterscapes provides insights into everyday experiences of social power around the infrastructures of natural gas extraction and the transformations of water. This research has contributed to the literature on waterscapes by centering residents lived experience and exploring how knowledge production about water contamination is a contested process. Considering embodiment provides an entry point for examining how West Virginians experience the processes of determining and discovering well water contamination.

Legal geographies and sociology of science have also been utilized in this thesis to elaborate how epistemic authority is produced in an extractive energy context. While this study is about the scientific, legal, and corporate structures that shape how natural gas extraction manages groundwater, it is primarily about West Virginia residents with groundwater drinking wells. Many West Virginians rely on - and sometimes seek out - groundwater wells for household use. While residents see this source of water as having some benefits over municipal water, this thesis has also elucidated the specific risks tied to groundwater wells in areas with natural gas extraction.

In some ways, this thesis is based on questions that are classic questions in geography and cognate social sciences. Questions of long-term environmental issues, power, and quiescence 
remain salient and urgent in West Virginia. While watershed groups across the state are still remediating acid mine drainage long after the coal companies are gone, new forms of extraction happening across the state brings forth questions yet again about the future of West Virginia's water.

\section{Revisiting researcher perspectives}

I entered this research thinking about UOG in the context of West Virginia being an "energy state" and a state that is suffering economically from the decline of coal mining and chemical manufacture. I have countless times been relayed stories about how desperate poor rural West Virginians are leasing their mineral rights to gas companies for the royalties. Often West Virginians are stereotyped as being rural and poor and hence fatalistic (Welch 2011). While my research was not aimed at debunking this particular stereotype, I have been aware that this research could present a counter-narrative about the populations and politics in Appalachia that often go unmentioned (Catte 2018; Noyes 2014). I do not refute that many people, in different parts of the state and in different positions (landowners, politicians, etc.) support UOG development for West Virginia and that many residents appreciate the economic benefits to themselves and their counties because of gas royalties and revenue. However, areas with UOG development do not overlap with areas with coal mining (except for Monongalia County along the Pennsylvania border). Additionally, residents of the northwestern counties of West Virginia are not a homogenous economic class (Gosnell and Abrams 2011). Circling back to the issue of split estate, not all surface owners have mineral rights, and not everyone that owns mineral rights in West Virginia lives where their rights are located.

I have alluded that future work on this issue could address the persistent silences created by non-disclosure agreements around water. I additionally want to comment on future research possibilities by considering the focus on embodiment in this research. On the one hand I have argued for a focus on West Virginia's embodied experiences, while at the same time I have cited other works arguing that the costs of natural gas extraction rely too heavily on individual costs and not on coherent multi-scalar costs (Sica 2015). To address this I want to return to feminist geography which has developed a theoretical perspective that links scales and destabilizes scalar categories. The potential futures of this work lies in embodiment as an entry point while linking these case studies with others to create research that works across scales and also destabilizes our 
conceptions of the local case study. Nagar (2014) has defined research that aims for creating situated solidarities as part of feminist epistemology. Situated solidarities are the products of research in which researchers aim to connect disparate groups around similar causes or desires (Nagar, 2014; Caretta \& Cheptum, 2019). These solidarities arise from the "larger interconnections produced by the globalization of economies and labor forces while challenging the colonialist prioritizing of the West" (Nagar 2014:87). Emerging case studies are demonstrating how extractive industry is producing similar consequences on water in many locations (e.g. Perreault, 2013; Marston, 2016). Linking translocal and transnational communities via extractive water pollution can work to hold companies accountable on a "hemispheric" scale (Caretta et al., under review). Producing an analysis around a differently constructed scale - transnational and not local - has the potential to change the analysis and applications of this research. 


\section{$\underline{\text { References }}$}

Abatsis McHenry, Kristen. 2017. "Fracking Women: A Feminist Critical Analysis of Hydraulic Fracturing in Pennsylvania." IJFAB: International Journal of Feminist Approaches to Bioethics 10(2):79-104.

Adgate, John L., Bernard D. Goldstein, and Lisa M. McKenzie. 2014. "Potential Public Health Hazards, Exposures and Health Effects from Unconventional Natural Gas Development." Environmental Science and Technology 48(15):8307-20.

Ahmed, Sara. 2004. “Affective Economies.” Social Text 22(2 79):117-39.

Alaimo, Stacy. 2010. "Material Memoirs: Science, Autobiography, and the Substantial Self." in Bodily Natures: Science, Environment, and the Material Self. Bloomington: Indiana University Press.

Alawattegama, Shyama K., Tetiana Kondratyuk, Renee Krynock, Matthew Bricker, Jennifer K. Rutter, Daniel J. Bain, and John F. Stolz. 2015. "Well Water Contamination in a Rural Community in Southwestern Pennsylvania near Unconventional Shale Gas Extraction." Journal of Environmental Science and Health - Part A Toxic/Hazardous Substances and Environmental Engineering 50(5):516-28.

Albrecht, Glenn, Gina Maree Sartore, Linda Connor, Nick Higginbotham, Sonia Freeman, Brian Kelly, Helen Stain, Anne Tonna, and Georgia Pollard. 2007. "Solastalgia: The Distress Caused by Environmental Change." Australasian Psychiatry 15(SUPPL. 1).

Andrews, Eleanor and James McCarthy. 2014. "Scale, Shale, and the State: Political Ecologies and Legal Geographies of Shale Gas Development in Pennsylvania." Journal of Environmental Studies and Sciences 4(1):7-16.

Associated Press. 2014. "Drilling Accident May Impact Wells." The Parkersburg News and Sentinel, October 1.

Auyero, Javier and Debora Swistun. 2008. "The Social Production of Toxic Uncertainty." American Sociological Review 73:357-79.

Baka, Jennifer, Arielle Hesse, Erika Weinthal, and Karen Bakker. 2019. "Environmental Knowledge Cartographies : Evaluating Competing Discourses in U. S. Hydraulic Fracturing Rule-Making." Annals of the American Association of Geographers.

Bakker, Karen. 2003. "Archipelagos and Networks: Urbanization and Water Privatization in the South.” Geographical Journal 169(4):328-41.

Bakker, Karen. 2004. An Uncooperative Commodity: Privatizing Water in England and Wales. Oxford: Oxford University Press.

Bakker, Karen and Gavin Bridge. 2006. "Material Worlds? Resource Geographies and the 'matter of Nature'." Progress in Human Geography 30(1):5-27.

Banks, Beverly. 2018. "In West Virginia: More Jobs, Fewer People.” US News, November. Batteau, Allen. 1990. The Invention of Appalachia. University of Arizona Press.

Baxter, Jamie and John Eyles. 1999. "The Utility of In-Depth Interviews for Studying the Meaning of Environmental Risk.” Professional Geographer 51(2):307-20.

Bell, Shannon Elizabeth. 2009. "'there Ain't No Bond in Town like There Used to Be': The Destruction of Social Capital in the West Virginia Coalfields." Sociological Forum 24(3):631-57.

Blaikie, Piers and Harold Brookfield. 1987. Land Degredation and Society. Routledge. Boettner, Ted. 2018. “Is West Virginia's Economic 'Comeback' Real?” West Virginia Center On Budget and Policy, August.

Bosworth, Kai. 2018. "The People Know Best: Situating the Counterexpertise of Populist 
Pipeline Opposition Movements." Annals of the American Association of Geographers $0(0): 1-12$.

Bray, Laura A. 2017. 'Media and 'Undone Science' in West Virginia's Elk River Chemical Spill.” Environmental Sociology 3(4).

Brenner, Neil. 2001. "The Limits to Scale? Methodological Reflections on Scalar Structuration." Progress in Human Geography 25(4):591-614.

Brickell, Katherine and Dana Cuomo. 2019. "Feminist Geolegality." Progress in Human Geography 43(1):104-22.

Budds, Jessica and Leonith Hinojosa. 2012. "Restructuring and Rescaling Water Governance in Mining Contexts: The Co-Production of Waterscapes in Peru (Manchester EScholar Services - The University of Manchester)." Water Alternatives 5(1):119-39.

Butler, Judith. 2013. "Performative Acts and Gender Constitution: An Essay in Phenomenology and Feminist Theory." in Feminist Theory Reader: Local and Global Perspectives, edited by C. R. McCann and S. Kim. Routledge.

Cantoni, Roberto, Matthias S. Klaes, Simone I. Lackerbauer, Claudia Foltyn, and Reiner Keller. 2018. "Shale Tales: Politics of Knowledge and Promises in Europe's Shale Gas Discourses." Extractive Industries and Society 5(4):535-46.

Caretta, Martina Angela. 2015. "Member Checking: A Feminist Participatory Analysis of the Use of Preliminary Results Pamphlets in Cross-Cultural, Cross-Language Research." Qualitative Research 1-14.

Caretta, Martina Angela. 2018. "Striving beyond Epistemic Authority: Results Dissemination in Smallholder Irrigation Farming Research." Annals of the American Association of Geographers 108(3):884-98.

Caretta, Martina Angela and Florence Jemutai Cheptum. 2019. "Enacting Feminist Countertopographies: Border Crossing through Participant Led Results Dissemination ." ACME: An International Journal for Critical Geographies 18(1):25-48.

Caretta, Martina Angela, Sofia Zaragocin, Bethani Turley, and K. Torres. n.d. "A Decolonial Multiscalar and Hemispheric Analysis of Women's Organizing against Extractivism." Human Geography.

Carter, K. M., Patchen, D. G., Moore, J. P., Fakhari, M., Daft Jr. G. W., Michael Solis, Brian J. Dunst, Robin V Anthony, Katherine Schmid, Kyle Metz, Philip Dinterman, Julie M. Bloxson, Erica N. Schubert, and John Saucer. 2017. A Geologic Study to Determine the Potential to Create an Appalachian Storage Hub for Natural Gas Liquids.

Catte, Elizabeth. 2018. What You Are Getting Wrong about Appalachia. Belt Publishing.

Chant, Sylvia and Matthew C. Gutmann. 2002. "'Men-Streaming' Gender? Questions for Gender and Development Policy in the Twenty-First Century." Progress in Development Studies 2(4):269-82.

Choma, Becky L., Yaniv Hanoch, and Shannon Currie. 2016. "Attitudes toward Hydraulic Fracturing: The Opposing Forces of Political Conservatism and Basic Knowledge about Fracking." Global Environmental Change 38:108-17.

Christiadi, John Deskins, and Brian Lego. 2014. "Population Trends in West Virginia through 2030." (March):18.

Clapp, Justin T., Jody A. Roberts, Britt Dahlberg, Lee Sullivan Berry, Lisa M. Jacobs, Edward A. Emmett, and Frances K. Barg. 2016. "Realities of Environmental Toxicity and Their Ramifications for Community Engagement." Social Science \& Medicine (1982) 170:14351 . 
Clement, Vincent. 2017. "Beyond the Sham of the Emancipatory Enlightenment: Rethinking the Relationship of Indigenous Epistemologies, Knowledges, and Geography through Decolonizing Paths." Progress in Human Geography.

Collins, A. R. and K. Nkansah. 2015. "Divided Rights, Expanded Conflict: Split Estate Impacts on Surface Owner Perceptions of Shale Gas Drilling." Land Economics 91(4):688-703.

Collins, Patricia Hill. 2013. "Defining Black Feminist Thought." in Feminist Theory Reader: Local and Global Perspectives, edited by C. R. McCann and S. Kim. Routledge.

Cook-Lynn, Elizabeth. 2000. "How Scholarship Defames the Native Voice... and Why." Wicazo Sa Review 15(2):79-92.

Cookson, Tara Patricia. 2018. Unjust Conditions. Oakland: University of California Press.

Cramer, Katherine. 2016. The Politics of Resentment: Rural Consciousness in Wisconsin and the Rise of Scott Walker. University of Chicago Press.

Creswell, John. 2014. Research Design: Qualitative, Quantitative, and Mixed Methods Approaches. 4th ed. SAGE Publications Inc.

Cruger, K. and M. Finewood. 2014. “'Blue Is the New Green': Representational Space and the Effective Co-Optation of Environmental Justice Discourses in Pennsylvania's Unconventional Natural Gas Drilling." Human Geography 7:26-43.

Cusick, Marie. 2014. "No Matter How You Spell It, Fracking Stirs Controversy." NPR Morning Edition, May 28.

Cvetkovich, George and Michael Siegrist. 2000. "Perception of Hazards: The Role of Social Trust and Knowledge." Risk Analysis 20(5):713-17.

Danza, Daniel J. 2012. "Ontogenic Landscapes: Hydro-Fracking, Potentiality, and the Assemblage of Identity over the Northeastern Marcellus Shale.” Rutgers.

Darrah, Thomas, Avner Vengosh, Robert B. Jackson, Nathaniel Warner, and Robert Poreda. 2014. "Noble Gases Identify the Mechanisms of Fugitive Gas Contamination in DrinkingWater Wells Overlying the Marcellus and Barnett Shales." PNAS 111(39).

Davies, Thom. 2018. "Toxic Space and Time: Slow Violence, Necropolitics, and Petrochemical Pollution." Annals of the American Association of Geographers 108(6):1537-53.

Davies, Thom. 2019. "Slow Violence and Toxic Geographies: 'Out of Sight' to Whom?" Environment and Planning C: Politics and Space 0(0):1-19.

Dyck, Isabel. 2005. "Feminist Geography, the 'Everyday', and Local-Global Relations: Hidden Spaces of Place-Making*." Canadian Geographer / Le Géographe Canadien 49(3):233-43.

Eisenberg, Ann M. 2016. Beyond Science and Hysteria: Reality and Perceptions of Environmental Justice Concerns Surrounding Marcellus and Utica Shale Gas Development. Vol. 77.

Elizabeth W. Boyer, PH.D., Bryan R. Swistock, M.S., James Clark, M.A., Mark Madden, B.S, and Dana E. Rizzo, M. S. 2011. "The Imapact of Marcellus Gas Drilling on Rural Drinking Water Supplies." The Center for Rural Pennsylvania 28.

Elliott, Elise G., Xiaomei Ma, Brian P. Leaderer, Lisa A. McKay, Courtney J. Pedersen, Chang Wang, Christopher J. Gerberr, Thomas J. Wright, Andrew J. Sumner, Mairead Brennan, Genevieve S. Silva, Joshua L. Warren, Desiree L. Plata, and Nicole C. Deziel. 2018. "A Community-Based Evaluation of Proximity to Unconventional Oil and Gas Wells, Drinking Water Contaminants, and Health Symptoms in Ohio." Environmental Research 167:28291.

Elmhirst, Rebecca. 2011. "Introducing New Feminist Political Ecologies.” Geoforum 42(2):12932. 
Elwood, Sarah A. and Deborah G. Martin. 2000. "'Placing' Interviews: Location and Scales of Power in Qualitative Research." Professional Geographer 52(4):649-57.

Emmett, Edward Anthony, Hong Zhang, Frances Susan Shofer, Nancy Rodway, Chintan Desai, David Freeman, and Mary Hufford. 2011. "Development and Successful Application of a 'Community-First' Communication Model for Community-Based Environmental Health Research.” J Occup Environ Med 51(2):146-56.

England, Kim. 1994. "Getting Personal: Refexivity, Positionality, And Feminist Research." Professional Geographer 46(1):80-89.

Evans, James and Phil Jones. 2011. "The Walking Interview: Methodology, Mobility and Place." Applied Geography 31:849-58.

Evensen, Darrick. 2016. "Word Choice Matters: Comment on Stoutenborough et Al. 2016, 'Is "Fracking" a New Dirty Word?"' Energy Research and Social Science 20:8-9.

Feltault, Kelly. 2006. "Development Folklife: Human Security and Cultural Conservation.” The Journal of American Folklore 119(471, Working for and with the Folk: Public Folklore in the Twenty-First Century):90-110.

Ferguson, James. 1994. "The Anti Politics Machine: 'Development' and Bureaucratic Power in Lesotho." The Ecologist 24(5):176-81.

Finewood, Michael H. and Laura J. Stroup. 2012. "Fracking and the Neoliberalization of the Hydro-Social Cycle in Pennsylvania's Marcellus Shale." Journal of Contemporary Water Research \& Education 147(1):72-79.

Fink, Elliot. 2019. "Dirty Little Secrets : Fracking Fluids, Dubious Trade Secrets , Confidential Contamination, and The Public Health Information Vacuum Dirty Little Secrets : Fracking Fluids , Dubious Trade Secrets , Confidential." 29(3).

Flick, Uwe. 2011. The SAGE Handbook of Qualitative Data Analysis.

Foucault, Michel. 1980. Power/Knowledge: Selected Interviews and Other Writings, 1972-1977. edited by C. Gordon. New York: Pantheon.

Fox, Julia. 1999. "Mountaintop Removal in West Virginia." Organization \& Environment 12(2):163-83.

Fry, Matthew. 2013. "Urban Gas Drilling and Distance Ordinances in the Texas Barnett Shale." Energy Policy 62:79-89.

Gal, Susan. 2016. "Scale-Making: Comparison and Perspective as Ideological Projects." Scale: Discourse and Dimensions of Social Life 91-111.

Gauchat, Gordon. 2012. "Politicization of Science in the Public Sphere: A Study of Public Trust in the United States, 1974 to 2010." American Sociological Review 77(2):167-87.

Gaventa, John. 1980. "8. Power and Powerlessness." Pp. 3-44 in Power and Powerlessness: Quiescence and Rebellion in an Appalachian Valley.

Gorman, Cynthia S. 2018. "Feminist Legal Archeology, Domestic Violence and the RacedGendered Juridical Boundaries of U.S. Asylum Law.” Environment and Planning A 282 91.

Gosnell, Hannah and Jesse Abrams. 2011. "Amenity Migration: Diverse Conceptualizations of Drivers, Socioeconomic Dimensions, and Emerging Challenges." GeoJournal 76(4):30322.

Gregson, Nicky and Mike Crang. 2010. "Materiality and Waste: Inorganic Vitality in a Networked World." Environment and Planning A 42(5):1026-32.

Griswold, Eliza. 2018. Amity and Prosperity: One Family and the Fracturing of America. Macmillan. 
Grosz, Elizabeth. 2005. "Refiguring Bodies." in The Body: A Reader.

Gullion, Jessica Smartt. 2015. Fracking the Neighborhood: Reluctant Activists and Natural Gas Drilling. Cambridge: MIT Press.

Guthman, Julie and Becky Mansfield. 2012. "The Implications of Environmental Epigenetics A New Direction for Geographic Inquiry on Health, Space, and Nature-Society Relations." Progress in Human Geography 37(4).

Hall, Sarah Marie. 2014. "Ethics of Ethnography with Families: A Geographical Perspective." Environment and Planning A 46(9):2175-94.

Haraway, Donna. 1988. "Situated Knowledges: The Science Question in Feminism and the Privilege of Partial Perspective." Feminist Studies 14(3):575-99.

Harding, Sandra. 1986. The Science Question in Feminism. Cornell University Press.

Harkness, Jennifer S., Thomas H. Darrah, Nathaniel R. Warner, Colin J. Whyte, Myles T. Moore, Romain Millot, Wolfram Kloppmann, Robert B. Jackson, and Avner Vengosh. 2017. "The Geochemistry of Naturally Occurring Methane and Saline Groundwater in an Area of Unconventional Shale Gas Development." Geochimica et Cosmochimica Acta 208:302-34.

Harris, Leila M. 2015. "Hegemonic Waters and Rethinking Natures Otherwise." Pp. 157-81 in Practising Feminist Political Ecologies: Moving Beyond "The Green Economy," edited by W. Harcourt and I. Nelson. London: Zed Books.

Harrison, Jill Lindsey. 2006. “'Accidents' and Invisibilities: Scaled Discourse and the Naturalization of Regulatory Neglect in California's Pesticide Drift Conflict." Political Geography 25(5):506-29.

Hartmann, Heidi I. 1979. "The Unhappy Marriage of Marxism and Feminism: Towards a More Progressive Union." Capital \& Class.

Harvey, Matt. 2019. "WV Supreme Court Mulls Marcellus Shale Mass Litigation Case from Harrison, WV." WV News: The Independent Voice of West Virginia, January 15.

Healy, Noel, Jennie C. Stephens, and Stephanie A. Malin. 2019. "Embodied Energy Injustices : Unveiling and Politicizing the Transboundary Harms of Fossil Fuel Extractivism and Fossil Fuel Supply Chains.” Energy Research \& Social Science 48(October 2018):219-34.

Hesse, Arielle, Jennifer Baka, and Kirby Calvert. 2016. "Enclosure and Exclusion Within Emerging Forms of Energy Resource Extraction: Shale Fuels and Biofuels." Pp. 641-60 in The Palgrave Handbook of the International Political Economy of Energy, edited by T. Van de Graaf, B. K. Sovacool, A. Ghosh, F. Kern, and M. T. Klare. Palgrave Macmillan.

Hirsch, Jameson K., K. Bryant Smalley, Emily M. Selby-Nelson, Jane M. Hamel-Lambert, Michael R. Rosmann, Tammy A. Barnes, Daniel Abrahamson, Scott S. Meit, Iva GreyWolf, Sarah Beckmann, and Teresa LaFromboise. 2017. "Psychosocial Impact of Fracking: A Review of the Literature on the Mental Health Consequences of Hydraulic Fracturing." International Journal of Mental Health and Addiction 1-15.

Hoback, Cullen. 2017. What Lies Upstream.

Hoel, Arne. 2016. "Trump Country: Why Democratic Strongholds Are Turning Red.” The Guardian, October 2.

Hopey, Don and David Templeton. 2019. "Belle Vernon Sewage Plant to Stop Accepting Contaminated Landfill Runoff." Pittsburgh Post-Gazette, May 16.

Huber, Matthew and Jody Emel. 2009. "Fixed Minerals, Scalar Politics: The Weight of Scale in Conflicts over the '1872 Mining Law' in the United States.” Environment and Planning A 41:371-88. 
Hudgins, Anastasia. 2014. "Framing Fracking : Private Property , Common Resources , and Regimes of Governance."

Hufford, Mary. 2007. Ethnographic Overview and Assessment: New River Gorge National River and Gauly River National Recreation Area. Boston: Northeast Region Ethnography Program, National Park Service.

Huisman, Kimberly. 2008. “'does This Mean You're Not Going to Come Visit Me Anymore?': An Inquiry into an Ethics of Reciprocity and Positionality in Feminist Ethnographic Research.” Sociological Inquiry 78(3):372-96.

Jacquet, B., Anne N. Junod, Dylan Bugden, Grace Wildermuth, Joshua T. Fergen, Kirk Jalbert, Brian Rahm, Paige Hagley, Kathryn J. Brasier, Kai Scha, Leland Glenna, Timothy Kelsey, Joshua Fershee, David L. Kay, Richard C. Stedman, and James Ladlee. 2018. "A Decade of Marcellus Shale: Impacts to People, Policy, and Culture from 2008 to 2018 in the Greater Mid-Atlantic Region of the United States." (March).

Jacquet, Jeffrey B., David L. Kay, and Doug Ramsey. 2014. "The Unconventional Boomtown : New Spatial and Temporal Scales." Journal of Rural and Community Development 9(1):123.

Janack, Marianne. 1997. "Standpoint Epistemology Without the 'Standpoint': An Examination of Epistemic Privilege and Epistemic Authority." Hypatia: A Journal of Feminist Philosophy 12(2):125-39.

Jepson, Wendy. 2014. “Measuring 'No-Win’ Waterscapes: Experience-Based Scales and Classification Approaches to Assess Household Water Security in Bcolonias b on the USMexico Border." Geoforum 51:107-20.

Jerolmack, Colin and Nina Berman. 2019. "Fracking Communities." 2(February):193-214.

Jerolmack, Colin and Edward T. Walker. 2018. "Please in My Backyard: Quiet Mobilization in Support of Fracking in an Appalachian Community." American Journal of Sociology 124(2):479-516.

Judge, J. Matthew, Phil Brown, Julia Green Brody, and Serena Ryan. 2016. "The Exposure Experience: Ohio River Valley Residents Respond to Local Perfluorooctanoic Acid (PFOA) Contamination." Journal of Health and Social Behavior 57(3):333-50.

Karpouzoglou, Timothy and Sumit Vij. 2017. "Waterscape: A Perspective for Understanding the Contested Geography of Water." Wiley Interdisciplinary Reviews: Water 4(3):e1210.

Kern, Eleanor. 2015. "West Virginia Community Awareness and Opinion of Water and Hydraulic Fracturing." Duke University.

Khan. 2005. "Reconfiguring the Native Informant: Positionality in the Global Age." Signs 30(4):2017-37.

Kinchy, Abby and Guy Schaffer. 2018. "Disclosure Conflicts: Crude Oil Trains, Fracking Chemicals, and the Politics of Transparency." Science Technology and Human Values 43(6):1011-38.

King, Jeffrey C., Jamie Lavergne Bryan, and Meredith Clark. 2012. "Factual Causation: The Missing Link in Hydraulic Fracture-Groundwater Contamination Litigation." Duke Environmental Law and Policy 1.

Kirsch, Gesa. 2005. "Friendship, Friendliness, and Feminist Fieldwork." Signs 30(4):2163-72.

Knoblauch, A. Abby. 2012. "Bodies of Knowledge: Definitions, Delineations, and Implications of Embodied Writing in the Academy." Composition Studies 402:50-65.

Kohl, Ellen and Priscilla McCutcheon. 2015. "Kitchen Table Reflexivity: Negotiating Positionality through Everyday Talk." Gender, Place and Culture 22(6):747-63. 
Komarek, Tim and Attila Cseh. 2017. "Fracking and Public Health: Evidence from Gonorrhea Incidence in the Marcellus Shale Region." Journal of Public Health Policy 38(4):464-81.

Kondash, Andrew J., Nancy E. Lauer, and Avner Vengosh. 2018. "The Intensification of the Water Footprint of Hydraulic Fracturing."

Kurtz, Hilda E. 2003. "Scale Frames and Counter-Scale Frames: Constructing the Problem of Environmental Injustice." Political Geography 22(8):887-916.

Latour, Bruno. 1993. We Have Never Been Modern. London: Harvester Wheatsheaf.

Lave, Rebecca and Brian Lutz. 2016. "Hydraulic Fracturing: A Critical Physical Geography Review." Geography Compass 17(1):739-54.

Lewis, Helen M., Linda Johnson, and Donalds Askin. 1978. Colonialism in Modern America: The Appalachian Case. Boone, NC: Appalachian Consortium Press.

Linton, Jamie. 2008. "Is the Hydrologic Cycle Sustainable? A Historical-Geographical Critique of a Modern Concept." Annals of the Association of American Geographers 98(3):630-49.

Linton, Jamie and Jessica Budds. 2014. "The Hydro-Social Cycle: Defining and Mobilizing a Relational-Dialectical Approach to Water." Geoforum 57:170-80.

Litvak, Anya. 2018. "These Days, Oil and Gas Companies Are Super-Sizing Their Well Pads." Pittsburgh Post-Gazette, January 15.

Loftus, Alex. 2009. "Rethinking Political Ecologies of Water.” Third World Quarterly 30(5):953-68.

Longhurst, Robyn. 1995. "The Body and Geography." Gender, Place \& Culture 2(1):97-106.

Luke, Hanabeth, Elisabet Dueholm, Darrick Evensen, and Michiel Köhne. 2018. "Is ' Activist' a Dirty Word? Place Identity, Activism and Unconventional Gas Development across Three Continents." The Extractive Industries and Society (June):0-1.

Lund, Ragnhild. 2012. "Researching Crisis -- Recognizing the Unsettling Experience of Emotions." Emotion, Space and Society 5:94-102.

Mabry, Linda. 2008. "Case Study in Social Research. The SAGE Handbook of Social Research Methods. SAGE Publications Ltd.” 214-28.

Macdonald, N., D. Chester, H. Sangster, B. Todd, and J. Hooke. 2012. "The Significance of Gilbert F. White's 1945 Paper 'Human Adjustment to Floods' in the Development of Risk and Hazard Management." Progress in Physical Geography 36(1):125-33.

Macnaghten, Philip. 2017. "Public Perception: Distrust for Fracking." Nature Energy 2(5):1-2. Maggard, Sally Ward. 1999. "Coalfield Women Making History." Pp. 228-50 in Confronting Appalachian Stereotypes: Back Talk from an American Region, edited by D. B. Billings, G. Norman, and K. Ledford. Lexington: The University Press of Kentucky.

Mah, Alice and Xinhong Wang. 2018. "Accumulated Injuries of Environmental Injustice: Living and Working with Petrochemical Pollution in Nanjing, China." Annals of the American Association of Geographers 0(0):1-17.

Malin, Stephanie. 2014. "There's No Real Choice but to Sign: Neoliberalization and Normalization of Hydraulic Fracturing on Pennsylvania Farmland.” Journal of Environmental Studies and Sciences 4(1):17-27.

Malin, Stephanie A. and Kathryn Teigen DeMaster. 2016. “A Devil's Bargain: Rural Environmental Injustices and Hydraulic Fracturing on Pennsylvania's Farms.” Journal of Rural Studies 47:278-90.

Mani, Lata. 1990. "Multiple Mediations: Feminist Scholarship in the Age of Multinational Reception." Feminist Review 35.

Marston, Andrea J. 2016. "Alloyed Waterscapes: Mining and Water at the Nexus of Corporate 
Social Responsibility, Resource Nationalism, and Small-Scale Mining." Wiley Interdisciplinary Reviews: Water 4(1):e1175.

Marston, Sallie A., J. P. Jones, Sallie A. Marston, John Paul, Jones Iii, and Keith Woodward. 2007. "Human Geography Without Scale Human Geography without Scale." Transactions of the Institue of British Geographers 32:264-76.

Massaro, Vanessa A. and Jill Williams. 2013. "Feminist Geopolitics." Geography Compass 7(8):567-77.

Matz, Jacob and Daniel Renfrew. 2015. "Selling 'Fracking': Energy in Depth and the Marcellus Shale." Environmental Communication 9(3):288-306.

Mcdowell, Linda. 1997. "Women / Gender / Feminisms : Doing Feminist Geography." Journal of Geography in Higher Education 21(3):381-400.

McGreal, Chris. 2017. "God and Coal: Trump Won on Both Issues in West Virginia but Inspires Doubt." The Guardian, March 30.

Mchenry-Sorber, Erin, Kai A. Schafft, Ian Burfoot-Rochford, and Daniella Hall. 2016. "The Masculinized Work of Energy Development: Unequal Opportunities and Risks for Women in Pennsylvania Shale Gas Boomtown Communities.” Journal of Rural Social Sciences 31(1):1-23.

McKeen, Timothy, Jamie Chapman, Andrew Graham, and Lauren Turner. 2018. "The Future of Oil and Gas in Appalachia." in West Virginia Law Review Appalachian Justice Symposium. Morgantown.

Melo Zurita, Maria de Lourdes and Paul George Munro. 2019. "Voluminous Territorialisation: Historical Contestations over the Yucatan Peninsula's Subterranean Waterscape." Geoforum 38-47.

Merrill, Thomas W. 2013. "Four Questions about Fracking." Case Western Reserve Law Review. 63(4):p971-993. 23p.

Mohanty, Chandra. 1984. "Under Western Eyes : Feminist Scholarship and Colonial Discourses." 12(3):333-58.

Mollett, Sharlene and Caroline Faria. 2013. "Messing with Gender in Feminist Political Ecology." Geoforum 45:116-25.

Monk, George and Dave McMahon. 2013. "Water Testing Before Drilling Starts: Why and How." West Virginia Surface Owners' Rights Organization. Retrieved (https://wvsoro.org/water-testing-before-drilling-starts/).

Moore, Michele-lee, Karena Shaw, and Heather Castleden. 2018. “" We Need More Data !' The Politics of Scientific Information for Water Governance in the Context of Hydraulic Fracturing." d(1):142-62.

Moser, Sarah. 2008. "Personality: A New Positionality?” Area 40(3):383-92.

Moss, Pamela. 2005. “A Bodily Notion of Research: Power, Difference, and Specificity in Feminist Methodology." in A Companion to Feminist Geography, edited by L. Nelson and J. Seager. Oxford: Blackwell Publishing ltd.

Nagar, Richa. 2014. Muddying the Waters: Coauthoring Feminisms across Scholarship and Activism. Champaign: University of Illinois Press.

Nelson, Lise and Joni Seager. 2005. A Companion to Feminist Geography. Blackwell.

Neville, Kate J., Jennifer Baka, Shanti Gamper-Rabindran, Karen Bakker, Stefan Andreasson, Avner Vengosh, Alvin Lin, Jewellord Nem Singh, and Erika Weinthal. 2017. "Debating Unconventional Energy: Social, Political, and Economic Implications.” Annual Review of Environment and Resources. 
Nixon, Rob. 2011. "Introduction." Pp. 1-44 in Slow Violence and the Environmentalism of the Poor. Cambridge: Harvard University Press.

Noyes, Dorothy. 2014. "Heritage, Legacy, Zombie: How to Bury the Undead Past." Pp. 58-86 in Cultural Heritage in Transit: Intangible Rights as Human Rights. Vol. 086.

O’Brien, Miles. 2017. "How Mountaintop Mining Affects Life and Landscape in West Virginia." Scientific American, May 5.

Oberhauser, Ann. 1995. "Towards a Gendered Regional Geography: Women and Work in Rural Appalachia." Growth and Change 26:217-44.

Ofrias, Linsay. 2017. "Invisible Harms, Invisible Profits: A Theory of the Incentive to Contaminate." Culture, Theory and Critique 58(4):435-56.

Ogneva-Himmelberger, Yelena and Liyao Huang. 2015. "Spatial Distribution of Unconventional Gas Wells and Human Populations in the Marcellus Shale in the United States: Vulnerability Analysis." Applied Geography 60:165-74.

Pain, Rachel. 2015. "Intimate War.” Political Geography 44:64-73.

Partridge, Mark D., Michael R. Betz, and Linda Lobao. 2013. "Natural Resource Curse and Poverty in Appalachian America." American Journal of Agricultural Economics 95(2):44956.

Perreault, Tom. 2013. "Dispossession by Accumulation? Mining, Water and the Nature of Enclosure on the Bolivian Altiplano." Antipode 45(5):1050-69.

Perreault, Tom. 2017. "Mining, Meaning and Memory in the Andes." The Geographical Journal.

Perreault, Tom, Gavin Bridge, and James McCarthy. 2015. The Routledge Handbook of Political Ecology.

Pile, S. 2010. "Emotions and Affect in Recent Human Geography." Transactions of the Institute of British Geographers 35(1):5-20.

Poole, Amanda and Anastasia Hudgins. 2014. "'I Care More about This Place, Because I Fought for It': Exploring the Political Ecology of Fracking in an Ethnographic Field School." Journal of Environmental Studies and Sciences 4(1):37-46.

Portelli, Alessandro. 1984. "Two " Peripheries " Look at Each Other : Italy and Appalachian America." Appalachian Journal 12(1):31-37.

Pothukuchi, Kameshwari, Melissa Arrowsmith, and Natalie Lyon. 2017. "Hydraulic Fracturing." Journal of Planning Literature 088541221773399.

Pratt, Geraldine. 2012. Families Apart: Migrant Mothers and the Conflicts of Labor and Love. Minneapolis: University of Minnesota Press.

Presser, Lois. 2005. "Negotiating Power and Narrative in Research: Implications for Feminist Methodology." Signs 30(4):2067-90.

Ratner, Michael and Mary Tiemann. 2015. An Overview of Unconventional Oil and Natural Gas: Resources and Federal Actions. Congressional Research Service: R43148.

Rice, Jennifer L., Brian J. Burke, and Nik Heynen. 2015. "Knowing Climate Change, Embodying Climate Praxis: Experiential Knowledge in Southern Appalachia." Annals of the Association of American Geographers 105(2):253-62.

Rijke, Kim de. 2018. "Produced Water, Money Water, Living Water: Anthropological Perspectives on Water and Fracking." Wiley Interdisciplinary Reviews: Water 5(2).

Roberts. 2013. "The Art of Staying Put: Managing Land and Minerals in Rural America." The Journal of American Folklore 126(502):407.

Roberts, Jody and Nancy Langston. 2008. "Toxic Bodies/Toxic Environments: An Intersdisciplinary Forum.” Environmental History 13(4):629-35. 
Robyn, Longhurst, Ho Elsie, and Johnston Lynda. 2008. "Using 'the Body' as an 'Instrument of Research': Kimch'i and Pavlova.” Area 40(2):208-17.

Rose, Gillian. 1993. "Feminism and Geography: An Introduction." Pp. 1-16 in Feminism and geography: The limits of geogragraphical knowledge. University of Minnesota Press.

Rose, Gillian. 1997. "Situating Knowledges: Positionality, Reflexivities and Other Tactics." Progress in Human Geography 21(3):305-21.

Ryder, Stacia S. and Peter M. Hall. 2016. "This Land Is Your Land, Maybe : A Historical Institutionalist Analysis for Contextualizing Split Estate Conflicts in U . S . Unconventional Oil and Gas Development." Land Use Policy.

Sainato, Michael. 2018. "Meet the Activists Arrested for Opposing the Mountain Valley Pipeline." Salon, July 25.

Saldaña, Johnny. 2009. The Coding Manual for Qualitative Researchers. SAGE Publications Inc.

Sangaramoorthy, Thurka. 2019. "Maryland Is Not for Shale : Scienti Fi c and Public Anxieties of Predicting Health Impacts of Fracking." The Extractive Industries and Society 6(2):463-70.

Sangaramoorthy, Thurka, Amelia M. Jamison, Meleah D. Boyle, Devon C. Payne-Sturges, Amir Sapkota, Donald K. Milton, and Sacoby M. Wilson. 2016. "Place-Based Perceptions of the Impacts of Fracking along the Marcellus Shale.” Social Science and Medicine 151:27-37.

Savoia, Elena, Michael A. Stoto, Rahul Gupta, Nasandra Wright, and Kasisomayajula Viswanath. 2015. "Public Response to the 2014 Chemical Spill in West Virginia: Knowledge, Opinions and Behaviours.” BMC Public Health 15(1):790.

Scanlan, Stephen J. 2017. "Framing Fracking : Scale-Shifting and Greenwashing Risk in the Oil and Gas Industry." Local Environment.

Schafft, Kai A., Yetkin Borlu, and Leland Glenna. 2013. "The Relationship between Marcellus Shale Gas Development in Pennsylvania and Local Perceptions of Risk and Opportunity." Rural Sociology 78(2):143-66.

Schmidt, Jeremy J. 2014. "Historicising the Hydrosocial Cycle." Water Alternatives 7(1):22034.

Schwartzman, Kathleen. 2013. The Chicken Trail: Following Workers, Migrants, and Corporations across the Americas. Ithaca: Cornell University Press.

Scott, Joan W. 1992. "Experience." in Feminist Theorize the Political, edited by J. Butler and J. W. Scott. New York: Routledge.

Scott, Rebecca R. 2009. "The Sociology of Coal Hollow: Safety, Othering, and Representations of Inequality." Journal of Appalachian Studies 15(1/2):7-25.

Scott, Shaunna L., Philip M. Westgate, and Stephanie Mcspirit. 2016. "The Long-Term Effects of a Coal Waste Disaster on Social Trust in Eastern Kentucky." Journal of Appalachian Studies 22(2):261-74.

Sharp, Joanne. 2009. "Geography and Gender: What Belongs to Feminist Geography? Emotion, Power and Change." Progress in Human Geography 33(1):74-80.

Sharp, Joanne and Lorraine Dowler. 2011. "Framing the Field." in Companion to Social Geography, edited by R. Panelli. Wiley.

Shaw, Al and Kate Mishkin. 2019. "A Guide to Every Permitted Natural Gas Well in West Virginia." ProPublica Local Reporting Network, March 6.

Shriver, Thomas E., Alison E. Adams, and Chris M. Messer. 2014. "Power, Quiescence, and Pollution: The Suppression of Environmental Grievances." Social Currents 1(3):275-92.

Sica, Carlo E. 2015. "Stacked Scale Frames: Building Hegemony for Fracking across Scales." 
Area 47(4):443-50.

Sinha, Mrinalini. 2013. "Gender and Nation." in Feminist Theory Reader: Local and Global Perspectives, edited by C. R. McCann and K.-S. Kim. Routledge.

Slovic, Paul. 1999. "Trust, Emotion, Sex, Politics, and Science: Surveying the Risk-Assessment Battlefield (Reprinted from Environment, Ethics, and Behavior, Pg 277-313, 1997).” Risk Analysis: An International Journal 19(4):689-701.

Smith, Barbara Ellen and Jamie Winders. 2017. "Intervention -- 'The Trump Effect? Whiteness, Masculinity, and Working-Class Lives."” Antipode Foundation: A Radical Geography Community. Retrieved (http://www.ashburtoninvestments.com/int/individualinvestor/news/insights/article/https://antipodefoundation.org/2017/08/08/the-trumpeffect//11/15/trump-effect-on-africa).

Smith, Neil. 1984. Uneven Development: Nature, Capital, and the Production of Space. Oxford: Blackwell.

Smith, Sara. 2012. "Intimate Geopolitics: Religion, Marriage, and Reproductive Bodies in Leh, Ladakh." Annals of the Association of American Geographers 102(6):1511-28.

Smith, Sara. 2016. "Intimacy and Angst in the Field." Gender, Place and Culture 23(1):134-46.

Stevenson, Edward G. J., Leslie E. Greene, Kenneth C. Maes, Argaw Ambelu, Yihenew Alemu Tesfaye, Richard Rheingans, and Craig Hadley. 2012. "Water Insecurity in 3 Dimensions: An Anthropological Perspective on Water and Women's Psychosocial Distress in Ethiopia." Social Science and Medicine 75(2):392-400.

Stoutenborough, James W., Scott E. Robinson, and Arnold Vedlitz. 2016a. "A Response to 'Word Choice Matters : Comment on Stoutenborough et Al ., 2016, " Is ' Fracking ' a New Dirty Word?"'" Energy Research and Social Science.

Stoutenborough, James W., Scott E. Robinson, and Arnold Vedlitz. 2016b. 'Is ' Fracking' a New Dirty Word? The Influence of Word Choice on Public Views toward Natural Gas Attitudes." Energy Research and Social Science 17:52-58.

Sultana, Farhana. 2009. "Fluid Lives: Subjectivities, Gender and Water in Rural Bangladesh." Gender, Place and Culture 16(4):427-44.

Sultana, Farhana. 2011. "Suffering for Water, Suffering from Water: Emotional Geographies of Resource Access, Control and Conflict." Geoforum 42(2):163-72.

Sultana, Farhana. 2013. "Water, Technology, and Development: Transformations of Development Technonatures in Changing Waterscapes." Environment and Planning D: Society and Space 31(2):337-53.

Sundberg, Juanita. 2005. "Looking for the Critical Geographer, or Why Bodies and Geographies Matter to the Emergence of Critical Geographies of Latin America." Geoforum 36(1 SPEC. ISS.):17-28.

Swyngedouw, Erik. 1999. "Modernity and Hybridity: Nature, Regeneracionismo, and the Production of the Spanish Waterscape, 1890-1930." Annals of the Association of American Geographers 89(3):443-65.

Ternes, Brock. 2018. "Groundwater Citizenship and Water Supply Awareness: Investigating Water-Related Infrastructure and Well Ownership." Rural Sociology 83(2):347-75.

Thien, Deborah. 2005. "After or beyond Feeling? A Consideration of Affect and Emotion in Geography." Area 37(4):450-54.

Tolia-Kelly, Divya P. 2006. "Affect - An Ethnocentric Encounter? Exploring the 'universalist' Imperative of Emotional/Affectual Geographies.” Area 38(2):213-17.

Treiger, Mordechai and George Monk. 2019. West Virginia's Groundwater Is Not Adequately 
Protected from Underground Injection Control Pollution.

Troutman, Melissa A. 2019. Still Wasting Away: The Failure to Safely Manage Oil and Gas Waste Continues.

U.S EPA. 2016. Hydraulic Fracturing for Oil and Gas: Impacts from the Hydraulic Fracturing

Water Cycle on Drinking Water Resources in the United States. Executive Summary.

US Census. 2010. West Virginia: 2010.

US EIA. 2019. "Drilling Productivity Report.” US Energy Information Administration

Independant Statistics \& Analysis, February 19.

USDA and NRCS. 1998. Soil Survey of Pocahontas County, West Virginia.

Valencia, C. and M. Carrillo Martinet. 2017. "Local Control: Authority, Resistance, and

Knowledge Production in Fracking." Wiley Interdisciplinary Reviews: Water 4(2).

Vance, J. D. 2016. Hillbilly Elegy: A Memoir of a Family and Culture in Crisis. Harper.

Vasi, Ion Bogdan, Edward T Walker, John S. Johnson, and Hui Fen. 2015. “" No Fracking

Way !' Documentary Film, Discursive Opportunity , and Local Opposition against

Hydraulic Fracturing in the United States , 2010 to 2013."

Vasi, Ion Bogdan, Edward T. Walker, John S. Johnson, and Hui Fen Tan. 2015. "'No Fracking

Way!' Documentary Film, Discursive Opportunity, and Local Opposition against Hydraulic Fracturing in the United States, 2010 to 2013." American Sociological Review 80(5):93459.

Vengosh, Avner, Nathaniel Warner, Rob Jackson, and Tom Darrah. 2013. "The Effects of Shale Gas Exploration and Hydraulic Fracturing on the Quality of Water Resources in the United States." Procedia Earth and Planetary Science 7:863-66.

Vidic, R. D., S. L. Brantley, J. M. Vandenbossche, D. Yoxtheimer, and J. D. Abad. 2013. "Impact of Shale Gas Development on Regional Water Quality." Science 340(6134).

Wachholz, Sandra, Nancy Artz, and Douglas Chene. 2014. "Warming to the Idea: University Students' Knowledge and Attitudes about Climate Change.” International Journal of Sustainability in Higher Education 15(2):128-41.

Walton, Brett. 2019. "EPA Considers Options for Reuse and Discharge of Oil and Gas Wastewater." Circle Of Blue, May 23.

Ward, Ken. 2017. "3 Years after MCHM Spill, Concern about WV Drinking Water Remains." Charleston Gazette-Mail, January 9.

Watts. 2015. "Now and Then: The Origins of Political Ecology and the Rebirth of Adaptation as a Form of Though.” Pp. 19-41 in The Routledge Handbook of Political Ecology, edited by T. Perreault, G. Bridge, and J. McCarthy. Routledge.

Watts, Michael. 1983. "On the Poverty of Theory: Natural Hazards Research in Context." Pp. 231-60 in Interpretation of Calamity: From the Viewpoint of Human Ecology. Boston: Allen \& Unwinn.

Welch, Wendy. 2011. "Self Control, Fatalism, and Health in Appalachia.” Journal of Appalachian Studies 17(1):108-22.

West Virginia Geological and Economic Survey. 2004. "History of WV Mineral Industries - Oil and Gas."

Whelton, Andrew J., LaKia McMillan, Matt Connell, Keven M. Kelley, Jeff P. Gill, Kevin D. White, Rahul Gupta, Rajarshi Dey, and Caroline Novy. 2015. "Residential Tap Water Contamination Following the Freedom Industries Chemical Spill: Perceptions, Water Quality, and Health Impacts." Environmental Science and Technology 49(2):813-23.

Whitley, Cameron. 2019. "Exploring the Place of Animals and Human-Animal Relationships in 
Hydraulic Fracturing Discourse.” Social Sciences 8(2):61.

Williams, Michael Ann. 2002. "When I Can Read My Title Clear': Anti-Environmentalism and Sense of Place in the Great Smoky Mountains." Culture, Environment, and Conservation in the Appalachian South 87-99.

Willow, Anna J. 2014. "The New Politics of Environmental Degradation: Un/Expected Landscapes of Disempowerment and Vulnerability." Journal of Political Ecology 21:23757.

Willow, Anna J. 2016a. "Troubling Water: Shale Energy and Waterscape Transformation in a North American Extraction Zone.” Anthropologica 58(2):166-78.

Willow, Anna J. 2016b. "Wells and Well-Being: Neoliberalism and Holistic Sustainability in the Shale Energy Debate.” Local Environment 21(6):768-88.

Willow, Anna J. and Samantha Keefer. 2015. "Gendering Extraction: Expectations and Identities in Women's Motives for Shale Energy Opposition." Journal of Research in Gender Studies 5(2):93-120.

Willow, Anna J. and Sara Wylie. 2014. "Politics, Ecology, and the New Anthropology of Energy: Exploring the Emerging Frontiers of Hydraulic Fracking." Journal of Political Ecology 21:222-36.

Wilson, Riley. 2017. "Moving to Jobs: The Role of Information in Migration Decisions." Ssrn.

Wutich, Amber and Kathleen Ragsdale. 2008. "Water Insecurity and Emotional Distress: Coping with Supply, Access, and Seasonal Variability of Water in a Bolivian Squatter Settlement." Social Science and Medicine 67(12):2116-25.

WV Free. 2014. Women and Water: Lessons from the Elk River Chemical Spill Listening Sessions.

WVDEP. 2013. West Virginia Water Resources Management Plan.

WVDEP. 2019. Oil and Gas Wells Geodatabase.

Ziemkiewicz, Paul. n.d. Characterization of Waste Streams from Shale Gas Development.

Zwick, Austin. 2018. "Comparison of the Coal and Fracking Industries in Northern Appalachia." Journal of Appalachian Studies 24(2):168-84.

Zwick, Austin Lewis. 2018. "Resource Boom to Revitalization: The Local Economic Planning and Governance Implications of Fracking in Northern Appalachia." University of Toronto. 


\section{Appendix A: Interview guide for local stakeholders}

\section{Personal}

1. How long have you lived here?

2. When did you first hear about hydraulic fracturing?

3. How have you been getting knowledge about it?

4. Where is the drilling/operation going on in relation to your home? How has the landscape changed around your home?

\section{Community}

5. How would you describe the level of knowledge around hydraulic fracturing or pipeline development in your community?

6. What would you say your community was about/what characterized your community before the development? How about now?

7. How has your relationship with your neighbors been affected?

8. Could you provide us with an example of a typical/representative family in your community?

9. Can you think of any apparent visual change in your community?

Regulations

10. How would you characterize the role of regulators/local government in the development of the current energy landscape in WV? Would you consider regulators/local government as reliable on this issue? Tell us why.

11. How would you describe the role of WVDEP and EPA in these phenomena? How often do they come out for inspections? How do they respond to any complaints? Give us an example.

12. How would you describe the relationship between you and the operators/industry?

13. How would you describe your community relationship with the operators/industry?

14. How would you describe the opinions around hydraulic fracturing in your community?

15. Have there been conflicts/misunderstandings/diverging opinions that you know of? If so, how have those conlicts been dealt with? Give us a practical example of how conflict around fracking operations have been resolved

16. How many people from your community do you know that are employed by the industry? In which positions? For how long?

17. Describe yours and your community quality of life before and after hydraulic fracturing.

18. Give us some examples of how your life has improved/worsened because of hydraulic fracturing.

19. Could you think of anything in your daily routine that has changed after gas development? 
20. Do you have concerns in relation to hydraulic fracturing? Which ones? How would you rank them in order of importance for you?

21. Before hydraulic fracturing began, had you ever had the same concerns? E.g. water? For contamination? For road safety?

22. Has this new energy development affected your relationships/affected your stress level? How? Provide us with examples.

23. Are you part of any concerned group of citizens/activists? What have you mobilized around? Which action has been most successful? Which are the challenges that your group is faced with? What is your current action? Have you linked up with any other organization at the national level?

24. Who do you think should be involved in public discussions around hydraulic fracturing?

25. Have you ever participated in a forum where all actors met? When? How did that go?

26. If you never had one, would you like to have one? How would you envision one? How do you think the divide between different stakeholders could be bridged?

27. How do you think benefits could be equally shared? Who's most impacted by this development? (local stakeholders vs i.e. kids? women?)

28. If you have fracturing or pipeline development on your property: did you make the decision to lease? If not, why? Based on what did you take the decision to lease? How were you approached by the industry?

29. Have you ever received royalties related to oil and gas extraction from hydraulic fracturing? Do you think royalties are fairly divided? How do you think royalties should be divided?

30. Do you co-own any property with oil and gas resources? What do you think should happen if some co-owners want to sell or lease property for hydraulic fracturing of oil and gas and other co-owners do not?

31. Do you think foreign companies should be encouraged to invest in oil and gas development from hydraulic fracturing?

32. How would you describe the relations between your community and national energy security?

33. Do you think that knowledge about the outcomes of hydraulic fracturing is accurate/reliable? Which data is needed? Where could a common repository of data be constituted?

34. How would you like this research to be disseminated?

35. Who do you think we should be talking with? 